Illinois State University

ISU ReD: Research and eData

Theses and Dissertations

$4-5-2018$

\title{
Communication In Live Sports Broadcasts: Attributions Of Task Performance Errors
}

Benjamin J. Lynn

Illinois State University, bjlynn2@ilstu.edu

Follow this and additional works at: https://ir.library.illinoisstate.edu/etd

Part of the Communication Commons

\section{Recommended Citation}

Lynn, Benjamin J., "Communication In Live Sports Broadcasts: Attributions Of Task Performance Errors" (2018). Theses and Dissertations. 869.

https://ir.library.illinoisstate.edu/etd/869

This Thesis is brought to you for free and open access by ISU ReD: Research and eData. It has been accepted for inclusion in Theses and Dissertations by an authorized administrator of ISU ReD: Research and eData. For more information, please contact ISUReD@ilstu.edu. 


\title{
COMMUNICATION IN LIVE SPORTS BROADCASTS: ATTRIBUTIONS OF TASK PERFORMANCE ERRORS
}

\author{
BENJAMIN J. LYNN
}

\section{Pages}

A single study was conducted exploring perceptions of causal attributions communicated through a task performance error during a live sports broadcast. Participants were recruited from within the live broadcast sports community and causal attributions of a camera operator's performance were measured using a Multidimensional Observer Attributions for Performance Scale (MOAPS) developed by Rutherford, Harari, and Rudolph (2013). Additional scales were created to measure perceptions of importance, frequency, and future hiring recommendations. Results found that following a camera mistake in a live sports broadcast, the camera operator's relationship with the director significantly influenced future hiring recommendations and attributions of ability in certain conditions. A camera operator in a close relationship with a director was more likely to be recommended for future work compared with a camera operator in a distant relationship with a director. As expected, fatigue had no significant impact on future hiring recommendations. However, fatigue influenced attributions of luck in certain conditions. This study extended attribution theory into the area of live sports broadcasts and sports communication generally. Practical and theoretical implications of the results are discussed. KEYWORDS: attribution, communication, sports, television, MOAPS, broadcast 
COMMUNICATION IN LIVE SPORTS BROADCASTS: ATTRIBUTIONS OF TASK

PERFORMANCE ERRORS

BENJAMIN J. LYNN

A Thesis Submitted in Partial Fulfillment of the Requirements for the Degree of

MASTER OF ARTS

School of Communication

ILLINOIS STATE UNIVERSITY

2018 
Copyright 2018 Benjamin J. Lynn 
COMMUNICATION IN LIVE SPORTS BROADCASTS: ATTRIBUTIONS OF TASK

PERFORMANCE ERRORS

BENJAMIN J. LYNN

COMMITTEE MEMBERS:

Kevin R. Meyer, Chair

Stephen K. Hunt

Brent K. Simonds 


\section{ACKNOWLEDGMENTS}

Thank you, Dr. Kevin Meyer. Your mentorship has meant the world to me. You have been a guide throughout my time in the graduate program at ISU, not just during the thesis process. You always allowed me to try, and fail, and I cannot say thank you enough for that. It was through the attempts and failures that you taught me valuable lessons I was able to apply while writing this thesis, and other research proposals. You have a great deal of patience, more than most will know. Every question I asked, you answered. Despite the many shortcomings of my writing, you were patient and waited for me to improve. I am grateful you took a chance on me and this sports-com based thesis. Your input and guidance throughout the research process has made this study better in every way. Thank you for sharing so much of your time and knowledge with me. You helped me reach my academic goals and I hope that, in return, it has been worth your time and effort. You taught me a great deal about writing, research, and myself. I will always treasure the time we spent over the summer sitting in your new office, tossing around ideas for the thesis, and talking about sports.

Thank you to Dr. Steve Hunt and Dr. Brent Simonds for your constant support and friendship. You are both men I look up to and your guidance has helped me greatly.

Thank you, Bob Carroll. None of this would have been possible without your support. Thank you for asking me to join the TV-10 program and learn from you. Your mentorship will always be valued. Thank you, Laura Trendle-Polus for your unwavering support.

Thank you, Dr. Ott, Dr. Lippert, and Dr. Davis. Without your insights and guidance, this study would not have been possible. Thank you Dr. Carr and Dr. Moore. Thank you Dr. Comadena for introducing me to communication research methods and supporting me in my research, as a mentor and a friend. 
Thank you to my office mates, Mary, Erik, and Leila. We shared many laughs together and you were the best. Cecelia, you reminded me to think positive and live every moment in a meaningful way. Corey, you were, and are, a guiding light in a dark world. Tina, you were always a step ahead, pulling me along. Thank you for not cutting the line and leaving me behind. Alex K., you had a knack for texting me while I was writing this document and I came to expect it and enjoy it. Victoria and Marcus, you two are awesome! Thank you for your encouragement and your friendship. Thank you, Nate, Lucy, Gilbert, Tunde, Jen, Katy, Jorgi, Jeanette, and Jenna. You have all become friends I look forward to seeing again in the future.

Thank you, B-Dubs gang: Dakota, Anna, Sam, and Brian. You provided me with academic guidance at times and, more importantly, you gave me a lot of laughs when I needed them. Your weekly companionship, and levity, will be missed.

Thank you, Steve, Craig, and the entire SEC crew on CBS. Thank you, Rich, J.D., and Jim for supporting me through my graduate school.

To all my former Com 163 students, and all the TV-10 students in general, you have been an inspiration and I thank you. Emily, your laughter always brightened the classroom and I will miss it when I am gone. Keep the light shining. Scott, Molly, Luke, Zack, Grace, Rosie, Ashley, Adam R., Adam B., Jacob, and so many more, you exceeded my expectations and I am proud of you. I am blessed to have been a part of your lives for a time and I look forward to seeing where you go in life. May you enjoy the journey as much as the destination.

To my wife Katsura and my children Koki, Jay, and Erika, you have been my foundation for the past 20 years and I would not be here today without your love and support. Thank you.

B. J. L. 


\section{CONTENTS}

Page

ACKNOWLEDGMENTS

$\begin{array}{ll}\text { CONTENTS } & \text { iii }\end{array}$

TABLES Viii

CHAPTER I: INTRODUCTION TO TELEVISION PRODUCTION TECHNIQUE 1

Communication Based Research $\quad 3$

The Importance of Researching Broadcast Television Sports $\quad 5$

$\begin{array}{ll}\text { Direct Connection of Industry and Academics } & 8\end{array}$

$\begin{array}{ll}\text { Social Benefits } & 9\end{array}$

$\begin{array}{ll}\text { The Director and Camera Operator Relationship } & 11\end{array}$

$\begin{array}{ll}\text { Production Technique } & 13\end{array}$

$\begin{array}{ll}\text { Director Technique } & 14\end{array}$

$\begin{array}{ll}\text { Directing style. } & 17\end{array}$

$\begin{array}{ll}\text { Communication skills. } & 19\end{array}$

Camera Operator Technique 23

$\begin{array}{ll}\text { Physical skills. } & 25\end{array}$

$\begin{array}{ll}\text { Cognitive skills of the camera operator. } & 28\end{array}$

Communication skills of the camera operator. 31

$\begin{array}{ll}\text { Composition. } & 35\end{array}$

$\begin{array}{ll}\text { Technical Director } & 36\end{array}$

Categorizing Live Sports Productions $\quad 37$

CHAPTER II: ATTRIBUTION THEORY 41 
Attribution Theory Conceptualized $\quad 41$

Variables in Attribution Theory 43

Correspondence Bias in Measurement $\quad 44$

$\begin{array}{ll}\text { Timing } & 48\end{array}$

$\begin{array}{ll}\text { Task Difficulty } & 49\end{array}$

$\begin{array}{ll}\text { Social Perceptions } & 51\end{array}$

Similarity to Target $\quad 53$

Measuring Attributions of Performance $\quad 53$

Applying Attribution Theory to Live Sports Broadcasting 57

$\begin{array}{ll}\text { Research Questions and Hypotheses } & 60\end{array}$

$\begin{array}{lc}\text { CHAPTER III: METHOD } & 64\end{array}$

$\begin{array}{ll}\text { Participants } & 64\end{array}$

$\begin{array}{ll}\text { Procedures } & 66\end{array}$

$\begin{array}{ll}\text { Scenarios } & 67\end{array}$

$\begin{array}{ll}\text { Video Selection } & 69\end{array}$

$\begin{array}{ll}\text { Survey Format } & 71\end{array}$

$\begin{array}{ll}\text { Measures } & 72\end{array}$

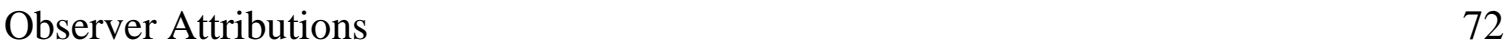

$\begin{array}{ll}\text { Importance Scales } & 72\end{array}$

$\begin{array}{ll}\text { Importance to crew } & 73\end{array}$

$\begin{array}{ll}\text { Importance to viewing audience } & 73\end{array}$

$\begin{array}{ll}\text { Importance to the camera operator } & 74\end{array}$

$\begin{array}{ll}\text { Importance to director } & 74\end{array}$ 
$\begin{array}{ll}\text { Future Hiring Recommendations } & 75\end{array}$

Frequency of Task Performance Error $\quad 76$

$\begin{array}{ll}\text { Manipulation Checks } & 77\end{array}$

$\begin{array}{ll}\text { Survey Type } & 79\end{array}$

$\begin{array}{ll}\text { Open-ended Questions } & 80\end{array}$

$\begin{array}{lr}\text { Descriptive Statistics } & 80\end{array}$

$\begin{array}{ll}\text { Data Analysis } & 80\end{array}$

CHAPTER IV: RESULTS $\quad 82$

$\begin{array}{ll}\text { Tests of Differences } & 82\end{array}$

$\begin{array}{ll}\text { MANOVA Results } & 82\end{array}$

ANCOVA Results $\quad 85$

Research Question Three $\quad 86$

Regression Models $\quad 86$

Research Question Four $\quad 86$

Research Questions Five and Six $\quad 88$

$\begin{array}{ll}\text { Hypothesis Two } & 90\end{array}$

Hypothesis Three $\quad 91$

$\begin{array}{ll}\text { Correlations among Variables } & 92\end{array}$

CHAPTER V: DISCUSSION 96

$\begin{array}{ll}\text { Summary of Findings } & 100\end{array}$

$\begin{array}{ll}\text { Research Question One } & 100\end{array}$

$\begin{array}{ll}\text { Hypothesis One } & 101\end{array}$

Research Question Two 104 
Research Question Three $\quad 106$

Research Question Four 107

$\begin{array}{ll}\text { Research Questions Five and Six } & 108\end{array}$

$\begin{array}{ll}\text { Research question five } & 108\end{array}$

$\begin{array}{ll}\text { Research question six } & 112\end{array}$

$\begin{array}{ll}\text { Research questions five and six } & 114\end{array}$

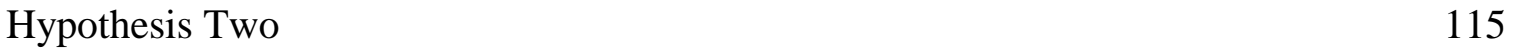

$\begin{array}{ll}\text { Hypothesis Three } & 117\end{array}$

$\begin{array}{ll}\text { Implications } & 118\end{array}$

$\begin{array}{ll}\text { Relational Implications } & 118\end{array}$

$\begin{array}{ll}\text { Task Difficulty } & 119\end{array}$

Group Attributions $\quad 121$

Training and Development for Current Professionals 122

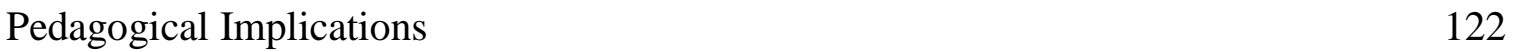

Theoretical Implications for Academics 123

$\begin{array}{ll}\text { Limitations } & 126\end{array}$

$\begin{array}{ll}\text { Survey Video } & 127\end{array}$

$\begin{array}{ll}\text { Number of Participants } & 128\end{array}$

$\begin{array}{ll}\text { Generalizability } & 129\end{array}$

$\begin{array}{ll}\text { Future Research } & 129\end{array}$

Independent Variables 130

$\begin{array}{ll}\text { Attribution Theory } & 130\end{array}$

$\begin{array}{ll}\text { Internal and external attributions } & 130\end{array}$ 


\section{TABLES}

Table

Page

1. Descriptive Statistics and Reliability Estimates for Ability, Effort, Task Difficulty, and Luck

2. Factor Loadings for Importance to Production Crew Scale

3. Factor Loadings for Importance to Viewing Audience Scale

4. Factor Loadings for Importance to the Camera Operator Scale

5. Factor Loadings for Importance to the Director Scale

6. Factor Loadings for Recommendation of Future Hirability Scale

7. Factor Loadings for Perceived Frequency of Mistake

8. Descriptive Statistics for the MANOVA

9. Fatigue Known and Unknown MANOVA Comparisons

10. Descriptive Statistics of Perceived Importance Scales

11. Descriptive Statistics for Hiring Recommendation and Effort and Ability

12. Descriptive Statistics for Hiring Recommendation and Task Difficulty and Luck

13. Beta Weights of Task Difficulty and Luck Predicting Future Hiring Recommendations

14. Beta Weights of Task Difficulty Predicting Ability

15. Beta Weights of Task Difficulty Predicting Effort

16. Pearson Correlations for MOAPS Scale

17. Pearson Correlations for Frequency, Hiring Recommendation, Importance, and Experience 


\section{CHAPTER I: INTRODUCTION TO TELEVISION PRODUCTION TECHNIQUE}

One summer I was working as a camera operator at Mid-Ohio Motorsports Park, for NBC Sports, covering a NASCAR Xfinity Series race. As a broadcast sports camera operator, I have covered motorsports racing during the summer for many years, including the Mid-Ohio track. Following an uneventful morning of setting up cameras, I grabbed lunch with three of my co-workers; we will call them Brad, Josh, and Isaiah. As we walked into a nearby sports bar, it became immediately clear that the sports bar was jam-packed and we were going to be waiting a while for our meals. Because our camera set-up had gone so smoothly, we had plenty of time to wait so we found a table and sat down to place our orders. We broke into our typical conversations about how preparation for the show was progressing.

During our conversation, I noticed the TV screens around the bar were showing various live sports broadcasts. Several screens were tuned to the 2017 World Track and Field Championships, live from London Stadium in Stratford, England. The World Championships were being watched and/or followed by millions of people around the world because it had been widely publicized prior to the event that this would be Usain Bolt's final races. Bolt was attempting to close out his esteemed career with one more display of sprinting perfection.

While I was looking away from the TV's, I suddenly heard, in unison, Brad and Josh exclaim, "whoa!” I asked them, “what happened?” Based on their enthusiastic reactions, I had apparently missed something important. They said one of the cameras on the World Championships broadcast had made a whip pan on-the-air. On-the-air means the whip pan had occurred live, with no opportunity for someone to change the shot or correct the mistake. A whip pan is when a camera operator moves their camera so quickly from side-to-side that the entire image becomes blurred (Jones, 1969b). I asked my co-workers to tell me what they had seen. 
They both described how the camera had been framed on one subject, a female runner, and then it suddenly whip panned from the runner to the crowd. Unprompted by me, Brad and Josh then launched into a full discussion about why they thought the mistake had happened. They went back and forth about it; with each detailing why their explanation was the most likely reason for the mistake. Josh attributed the mistake to the camera operator forgetting they had a tally light and so they just whipped off for a crowd shot; whereas Brad believed it might have been caused by a technical problem with the equipment. We never discovered the actual reason why the camera operator from the World Championships made the on-air mistake.

This lunch conversation regarding the whip pan is representative of a typical conversation between sports camera operators watching a live sports production and illustrates two points that form the basis of this thesis. First, when a camera operator makes a mistake on-the-air during a live sports broadcast it is perceived by those in the industry to be an important event. Second, industry professionals make attributions based on their own experience in broadcast sports.

Grounded in conversations similar to this one, and real-world examples from sports broadcasts, I propose that on-the-air camera mistakes in live sports broadcasts communicate meaning to those who work in the live broadcast sports industry. Furthermore, individuals from the broadcast sports industry are qualified to make attributions regarding why the mistakes occurred because they are uniquely suited to read and interpret the language of camera movement and the grammatical structure of the production narrative. Their insider position and professional expertise provide the ability to identify grammatical errors in the narrative caused by a camera mistake. Based on the perceived context of the mistake, they are able to form attributions regarding why the mistake occurred in the first place. To those in the live broadcast sports industry, camera mistakes represent important events that communicate a multitude of 
possible meanings. While the specific topic of camera mistakes in television sports broadcasting is new to the academic literature, the general study of movement, and the perceived meanings it communicates, has been of area of interest to the academic community for some time.

\section{Communication Based Research}

In 1944, psychologists Heider and Simmel conducted one of the earliest experiments empirically examining the meaning communicated through the movement of an object. The idea, that the way an object moved communicated meaning, dated back to Darwin's work in 1872. Darwin made detailed observations of how animals communicated with each other, concluding that part of the communication process was based on the animals' movements: the specific way the animals moved told other animals, and people, what they were feeling and thinking. A halfcentury after Darwin posited the idea, Heider and Simmel conducted an experiment investigating how movement communicated meaning to others. In their study, Heider and Simmel showed participants a film that featured a rectangle, with what was perceived as a door in one corner, and three simple geometric shapes moving across the screen in different directions, at varying rates of velocity, and coming into contact with each other at times. One of the shapes was a relatively large triangle, one of the shapes was a small triangle, and one of the shapes was a small circle. The shapes appeared to interact with each other through the specific movements they made on the screen. After watching the film, Heider and Simmel asked the participants to describe, in their own words, the emotions that the simple geometric shapes conveyed. The film was shown in forward motion to two groups of participants and shown in reverse motion to a third group of participants. The results were coded and they found that participants, within both the forward and reverse conditions, provided extremely consistent descriptions of the emotions the simple geometric shapes conveyed; all based on the objects movements, proximity, and context. Their 
study provided some of the first empirical evidence that causal attributions could be communicated through the movement and context of objects.

Several studies since the early research by Heider and Simmel (1944) expanded the literature of attributions through movement (Johansson, 1973; Runeson \& Frykholm, 1981; Tagiuri, 1960; Valenti \& Costall, 1997). However, none of those studies applied the attributions of movement to a visual communication medium from the perspective of those who produce the content. The current study extends the early empirical work of Heider and Simmel from 1944 into the field of communication by examining the attributions communicated through the movements of television sports cameras. Guided by attribution theory (Heider, 1958; Kelley, 1973; Weiner, 1995), we will examine the attributions communicated in a live television sports production when a camera operator makes an on-the-air camera mistake. While empirical research specific to camera movement in a live sports production environment is limited, camera movement has long been conceptualized as part of a visual communication language through which people express their ideas.

Camera movement was conceptualized as part of a visual language even before film had a theoretical base (O'Leary, 2003). Visual images, including camera movement, are expressions that shape how others perceive the world around them (Morgan, 2016). Movement is one part of the visual communication process that includes shapes, tones, and colors, all of which communicate to the viewer specific moods, emotions, and ideas, while providing structure to the content (Block, 2001). The various elements are combined to create a visual discourse for the viewer (O’Leary, 2003), a narrative in a visual language. When we watch a film, a television broadcast, or any visual based medium, every shot in a sequence is like a sentence, every scene change begins a new paragraph, and holistically these elements form a visual grammar 
(Thompson, 1998). The visual language demands the same rigor and attention to detail as other forms of communication. A live sports director who selects the wrong camera when making a cut, suddenly creates an incomplete sentence that is immediately noticeable to anyone fluent in reading the grammar of the visual narrative. It is believed that even lay audience members can immediately judge the quality of a production based on just the first few camera movements they see on the screen (Smith, 1991). Professionals spend years mastering the visual language until they are capable of adjusting the narrative on the fly (Zumoff \& Negin, 2015). This study will look at the perceptions communicated when a disruption in the visual narrative is seen by those who work in the television production industry.

In addition to an analysis of camera movement, this study will evaluate the communication relationships within the temporary, or semi-permanent, organizational setting that is the live television production; specifically, the communication interactions that occur between the shows director and the shows camera operators. Across multiple disciplines, communication interactions have been singled out as one of the biggest challenges facing directors today (Owens, 2016b; Wood, 2014). Directors are tasked with employing effective communication skills in chaotic, highly stressful production environments (Owens, 2016b; Owens \& Infante, 1988). Poor communication between the director and a camera operator can result in a miscommunication that disrupts the visual narrative through a camera mistake and/or discontinuity in the sequential order of the shots seen by the viewers.

\section{The Importance of Researching Broadcast Television Sports}

Today, there is little doubt sport plays an important role in the social lives of people around the world. However, live sport broadcasting has not always enjoyed such a prominent position in the cultural spotlight. When live sports broadcasting first started, with radio in the 
United States, it was seen as a threat to the event organizers. At the time, event organizers were reluctant to allow broadcasters to cover their events for fear that if their event was being broadcast, people would stay home and listen to the broadcast on the radio rather than come and attend the event in person (Evans, Iosifidis, \& Smith, 2013). Due to perceived concerns over lost revenue, broadcasters were required to pay a fee to the event organizers as compensation for the potential customers who stayed home to watch the event rather than attend in person. However, it became clear very quickly that when a sporting event was broadcast on the radio, the venue was still capable of filling up to capacity. Plus, the broadcast was reaching an additional, much larger audience. In addition, the broadcast created a growing interest in the sport being covered (Evans et al., 2013). This was the setting for television, the visual medium, as it joined radio in producing live coverage of sporting events.

The pivotal moment for television sports in the United States came in 1956 when the NFL negotiated a one-year, season long contract with CBS (Cressman \& Swenson, 2007). That marked the first time a league had negotiated on behalf of the teams, and it would set the standard for how future network television negotiations would proceed. The league-based negotiations ushered in a new era establishing a symbiotic relationship between the league, the network, and the advertisers (Evans et al., 2013). The relationship they formed was one in which the entities organized, presented, and sold sport to the mass public in ways that served all of their best interests. As the audience grew, so did the advertising revenue and so did the rights fees the networks were paying to the leagues to cover their sports. Over the decades, as the audience base grew, and sport began to permeate all aspects of society (Boyle \& Haynes, 2009), the three entities began making massive amounts of money by selling sport as a commodity (Evans et al., 2013) and today it is a highly valued product. The current NFL contract was signed in 2011, for 
\$28 billion over nine years, between three networks (Flint, 2011), with ESPN paying \$1.9 billion by themselves for the rights to the single Monday Night Football coverage (Sandomir, 2016). However, the revenue from the networks to the sport leagues, via the advertisers, had some strings attached.

With the broadcast model in America being based on revenue from advertisers, it has always been in the networks best interest to provide their advertisers with the largest possible audience in the demographic they are trying to reach. When networks can connect their advertisers with a coveted target audience, such as the 18 to 49 -year-old demographic, they can command higher rates for their commercial spots (Bettinger, 2009; Koeppel, 2012). Early in the development of broadcast sports productions, the networks began to pressure the sports leagues, like the NFL, to change the times their games were played to time slots that reached more viewers, such as prime time television in the evenings (Schultz, 2002). The networks continue to assert influence over sports leagues today by influencing when the events will occur (Clements, 2016; National Football League, 2017) and working closely with leagues to find ways of making the product, the sport, more television friendly for the viewer (Putterman, 2017). However, like any healthy relationship, it is a two-way interaction. The leagues are also concerned about the way their product is displayed and they have input on the "look" of how their sport is shown. The clearest example of this is the relationship between Augusta National Golf Club and CBS Sports. Unique among sports broadcasts, Augusta National does not sign a contract with CBS Sports for the broadcast rights, they simply allow CBS Sports to broadcast the event (KerrDineen, 2017). Without a contract in place, it allows the event organizer to maintain full control over how their product is presented by CBS to the public. If they decide they do not like a camera angle, they will have that camera re-positioned or removed altogether. Augusta National 
is the exception to the rule in broadcast sports, but they provide a clear reminder that every sports league is concerned with how their product is being portrayed and contract or not, they will not hesitate to voice concerns over what they might see as unprofessional production values.

While this study is not aimed at examining the attributions of those who operate the sports leagues, the background information about the symbiotic relationship between the leagues, the networks, and the advertisers is essential to understanding the pressure placed on production crews to deliver a broadcast product that meets the quality standards of both the leagues and the advertisers. While the images that come from the various sporting events are not visible money per se, they are a form of currency (Kerr-Dineen, 2017). Taking this one step further, if the images from the event are a form of currency, then we must ask the question: how much does a camera mistake cost a network when it makes it on-the-air and is seen by millions of viewers? It is through that lens that this study will seek to understand the attributions production crew members place on situations where a camera operator makes a mistake on-the-air.

\section{Direct Connection of Industry and Academics}

Unique to this study is the examination of attributions from the viewpoint of those who create the content, not those who view the content. There is a large body of research on mass communication and the effects on sports fans (Challenger, Gray, \& Christmas, 2014; Jensen et al., 2016; Wenner, 1990) and textual analysis can be found examining how broadcasters shape the narrative of the event for the viewer (Desmariais \& Bruce, 2010). However, there is a distinct lack of empirical research focused on the production crew responsible for creating the content used in sports productions. This study will address this gap in the literature and provide a basis for future research into the area of sports content production from the perspective of the crew who produce it. At first glance, this study may not appear to be of much significance to broadcast 
sports productions around the globe; after all, television sports production crew members number in the tens of thousands. However, the content these professionals create is seen by billions of viewers around the world and these professionals influence these viewers perceptions of sport through their presentation of it. Further, the results of this study could have an immediate impact within the production industry. Carless and Waterworth (2012) found that attributions in a task performance failure can directly impact a persons' chances of being hired for a job in the future. The attributions assigned to a poor performance by a camera operator can help shape the communication skills and technique used by directors and camera operators in future broadcasts and therefore increase their potential to stay actively employed. There is currently no research examining the possible consequences of camera operators who fail in their task performance in a live sports production environment. In addition to a direct connection to current broadcast sports professionals, this study can better prepare the next generation of production personnel for challenges they may face and strategies to overcome them. When the production values and techniques are improved, both in the industry and in the academy, the social benefits can be maximized to their full potential.

\section{Social Benefits}

While sports broadcasting may be seen purely as entertainment by some, it is seen by others as serving a much deeper role in society. Sports broadcasting is seen by some as a way of helping create a more inclusive and participatory society (Evans et al., 2013). Sport, and its distribution through mediated broadcasts, may help society develop a collective consciousness. Idealistically, sports broadcasts provide people with a common talking point that allows people of all backgrounds to transcend cultural barriers and enjoy a common interest. In addition, sport productions like the Olympics and World Cup promote national identification. Sport provides 
societies with a sense of lived history and members of societies want to be a part of that experience (Boyle \& Haynes, 2009).

Another social benefit of sports broadcasts is that they can serve as therapeutic devices following tragic events (Bodenheimer \& Phillips, 2015; Chidester, 2009). In the wake of the terrorist attacks on the World Trade Center buildings on September $11^{\text {th }}, 2001$, sport helped restore the nation to a degree of normalcy. Athletes are now framed as modern-day heroes and sporting competitions are viewed as battles between enemies (Hartman, 2009). A close sporting match can have the dramatic flair of a Hollywood blockbuster, without the predetermined outcome. It is for this reason sports broadcasts have such powerful effects on viewers and why sports are still the main television production format viewers prefer to watch live rather than recorded (Gaines, 2015).

In addition to facilitating social cohesion and serving as a therapeutic device, the distribution of sport has become a popular culture phenomenon that borders on a religion. When queried about their viewing habits regarding television genres, Gantz, Wang, Paul, and Potter (2006) found a drastic difference in the viewing habits of sports fans and fans of other types of television formats. Sports fans were found to do a lot of pre-game research about the event as well as a great deal of post-game analysis of what took place. They tend to replay the events of the game many times following the conclusion of the match. The sports fans' mood was correlated with the outcome of their teams' performance and when their team won, they were in a good mood. The conclusion was that sports fans appeared to be more emotionally involved in the content than fans of other genres.

In an interview focused on value in television, Corner and Roscoe (2016) called for future research in television to be conducted from within the production framework, not simply 
from the outside looking in as we see with so many textual analyzes. This study is an answer to their call for more research focused on the production framework, not the target audience.

\section{The Director and Camera Operator Relationship}

Relationships are characterized by interdependence between individuals (Kashy \& Levesque, 2000). During a broadcast, directors are dependent on camera operators to execute their camera movements without jarring the audience, and camera operators are dependent on directors to communicate clearly when their shots will be used. When performance errors occur, the responsibility ultimately rests with both the director and the camera operator for their inability to coordinate their efforts and avoid a camera mistake on-the-air (Jones, 1969b). The director and the camera operator rely on each other to keep jarring camera movements from being seen on-the-air during a broadcast. The interdependence needed to accomplish a common goal, a mistake free broadcast, provides incentive for the individuals to develop a close relationship.

Close relationships have been defined as having strong, frequent, and diverse interactions which have lasted for months or years (Kelley et al., 1983). This definition includes working relationships and does not imply the relationship have a positive effect. The term "close," as defined in this study, means two people share many strong causal connections. The interaction patterns between the individuals determines the quality of the relationship (Fehr, 2004). Close relationships have interaction patterns used for support; through the exchange of information, guidance, and advice (Gillespie, Lever, Frederick, \& Royce, 2015). Directors and camera operators who interact in supportive ways for long periods of time are conceptualized as having a close relationship. 
While directors and camera operators experience periodic separation due to geographic and work limitations, their relationships can still be conceptualized as "close" based on the nature of the interactions they have when they are in contact with each other. In live sports productions, directors and camera operators typically live in geographically different parts of the country and only see each other face-to-face during the time they are at the remote location for the broadcast. In addition to the geographical separation common between broadcasts, there might be long periods of time, possibly months between sports seasons or years between sporting events, when a director and camera operator may not work together. According to Kelley et al. (1983), the distance and lack of frequent contact between the individuals when they are not working on a broadcast would make it unlikely that their relationship could be defined as close. However, other literature indicates that a relationship can still be defined as close even when there is geographic separation. Johnson (2001) found that while individuals performed more relational maintenance in face-to-face friendships, there were no significant differences in the perceptions of closeness or satisfaction in long-distance relationships. In a similar study by Johnson, Haigh, Craig, and Becker (2009), no significant differences were found in the way individuals perceived their close friendships, whether long-distance or face-to-face. Regardless of the relationship type, "self-disclosure" and "help and support" were the most common definitions used to describe closeness in their friendships. The "frequency of interaction" was an important theme, but it was speculated that it might be referring to the individuals expected levels of interaction and there could still be an emphasis on interactions during shared activities. This would explain why camera operators and directors might perceive their relationships to be close, even if they only engage in a small number of broadcasts per year. Directors and camera operators who frequently provide each other with help and support while working together 
should feel close to each other. The close/distant nature of the relationship between the director and the camera operators may have a measurable impact on the quality of the broadcast.

The cohesion of the director and the camera operators, how well they complement each other during a broadcast, seems to have a direct effect on the quality of the production. While there has been no empirical research comparing the task performance of a cohesive television production crew with that of a non-cohesive television production crew, meta-analyses of military research on general group cohesion and task performance indicated group cohesion was positively associated with overall group performance (Evans \& Dion, 1991; Oliver, 1988; Oliver, Harman, Hoover, Hayes, \& Pandhi, 1999). The conclusion was that in military, team-focused task settings, group cohesion was critical for effective performance (Ahronson \& Cameron, 2007). With a strict hierarchical communication structure during a broadcast, television production crews and their group performance are similar to that of military units. The empirical findings are supported by the experiences of those who work in the television industry. Veteran live event director Phil Heyes believed the cohesion of the crew was important and it made a difference in the quality of the production (Wood, 2014). Ollie Bartlett, a live studio director, added further support to this when he said that he has found a consistent team to be the best way of achieving the results he was looking for when directing a show (Wood, 2014). Based on the research analyses and the experience of industry professionals, television directors and camera operators should expect close relationships to result in improved group task performance.

\section{Production Technique}

The director and the camera operator coordinate their efforts during the production, but as individuals, they have unique skill sets and techniques, which they develop over time as their 
experience grows. We will begin with a look at the technique of the director, followed by the technique of the camera operator.

\section{Director Technique}

The technique of directing a live television sports production is a difficult subject to broach from an academic standpoint. Owens and Infante (1988) found a lack of academic research dealing with live television directing in general and there is still not a unique body of research addressing the topic. This might be attributed to the fact that live television directors work in relative obscurity and their work is difficult to understand and profile (Rose, 1999). The complexity of their job actually adds to their obscurity because it is difficult to generalize what they do since they have to be adept in so many different areas (Rose, 1999). While there is no lack of general literature on the subject, there is a lack of empirical research. The technical literature details the skill set of the television director and what their role is on a remote sports production. To understand the sports director is to gain insight into the techniques employed by the men and women who construct the narrative of events seen by hundreds of millions of sports fans each week.

If one were to observe a veteran director, one would quickly realize that even before the show starts the director is manipulating multiple threads of incoming information with adept skill and poise. During the actual broadcast, they are like performing artists, in their element and verbally maneuvering the show as the chaos in the production truck, and in the venue, seek to overwhelm their senses. The atmosphere in the production truck can be rushed and they are under a tremendous amount of pressure to meet the demands of the show (Owens \& Infante, 1988; Rose, 1999). Live sports directors must simultaneously listen to, and coordinate with, their producers and announcers, while directing their camera, replay, and graphics operators, and 
selecting shots that will advance the visual narrative, all at the same time. They are responsible for interpreting the event for the viewing audience (Lewis \& Greer, 1990) while simultaneously performing all of those tasks. While an experienced director has the ability to make the job seem effortless, their talent and expertise belie the vast amount of skill and training required for them to execute their job proficiently at such a high level. Ultimately, directing a live sports production demands more skill sets from the director than any other area of television (Rose, 1999). Because their task performance is so multi-faceted, there are many ways in which a miscue by the director can lead to a mistake in the production making it on-the-air. The following section will outline the skill sets television sports directors utilize in their jobs and what could happen if they were to have a poor performance.

One of the reasons sports are such difficult productions to direct is because there are a great deal of external distractions that have the potential to affect the show in negative ways. Even in ideal conditions the director is managing multiple verbal and visual communication sources at the same time, while also attempting to plan ahead for how they will present the narrative of the sport. In addition to the already high cognitive workload, the director must also deal with any unforeseen changes that occur. Between the technical elements of the production and the constantly evolving content changes, a remote sports production will generally have some type of unforeseen change occur during a broadcast. This can range from minor changes such as the producer deciding not to show the announcers on-camera during a segment, which requires little adjustment by the director, to major changes like the power going out in the venue and the lights turning off, which requires massive adjustments by the director. A sports director is expected to control any negative effects influencing the production (Owens \& Infante, 1988) and one of the ways they do that is through their ability to adapt to the situation as it changes. 
Proficient directors are able to react quickly and adjust the narrative as it unfolds to accommodate the unforeseen changes, while being careful not to allow the side-narratives to cause them to miss a key moment of the main action (Rose, 1999). While this sounds simple enough, it has the potential to fluster even veteran directors. The relevance of outside influences on the director to this study is that if a director becomes distracted or flustered while attempting to manage these outside influences, this could lead to a mistake in the production; one of which could be cutting to a camera operator who is about to make a whip pan or snap zoom.

Another skill the production literature identifies as necessary for a sports director is their ability to coordinate their efforts with the rest of the production crew during the broadcast. The director is not simply dictating what will take place during the production; they are listening to other crew members input and instructions throughout the process and attempting to integrate those ideas with their own in a way that benefits the show as a whole. The goal of the production crew, and the director, is to form a highly integrated team (Rose, 1999) that can create a seamless visual narrative for the viewers at home. While the director plays an important role in orchestrating the efforts of the crew during the broadcast, they are still only one part of the whole that makes a broadcast what it is. Typically, a top-level sports production will have upwards of 40 people on the crew including the technical personnel and the production personnel. Those people form sub-groups, which all play a part in helping the broadcast make air and keep the show going for the duration of the event. CBS Sports director Bob Fishman said that when working on a remote production, he had to rely on the talents of many different people (Rose, 1999). Fishman's reliance on other crew members was both a testament to his personality, and a necessity of the role he had as the director of a live sports broadcast. Part of integrating with the crew, to form a highly cohesive team, is that the director has to provide clear communication 
throughout the course of the broadcast to ensure that the production continues to move in the direction they want it to go.

While the director may be constantly talking once they have put their headset on and the production has begun, it would be incorrect to assume sports directors are spending their time verbally talking the camera operators through every shot. The reality is that there is simply no time for the director to talk the camera operators through every shot. In sports, directors select shots based on what is available at the time and their selections guide the production where it needs to go (Owens, 2016b). Directors spend the vast majority of their time in the dialogue needed to put each camera on the air in the specific order they would like it. Directors rely on their camera operators to provide the shots they want, at the time they need them, and in the way they would want them to look. Accomplished ABC Sports director Doug Wilson said he was only as good as the camera operators who were with him (Rose, 1999). In that statement, Wilson was both acknowledging the limitations of his position, and emphasizing the importance of the relationship he shared with his camera operators. Wilson had to trust that his camera operators were capable of creating the vision he had shared with them for the show. Through his guidance during his camera meetings, and his communication with the operators, Wilson ensured his camera operators were ready for the show. Once a director becomes comfortable with managing multiple sources of information at once, and what their role is on the production, they can begin to focus on their directing style.

Directing style. Style, in regard to directing, is conceptualized as the unique order and pacing that a director arranges the images in a sports broadcast. A director of a top-level live sports production on network television will normally have a compliment of different camera angles from which to select from as they build the visual narrative. The order and timing in 
which they use the shots will establish their directing style. In addition to the cameras, sports directors also have a number of instant replays to select from at any given time. While the producer typically decides which replay to use and tells the director which one to put on the air, it is the director's responsibility to integrate the replays into the show. Over time, the choices the director makes when selecting shots and replays form distinct patterns that represent their directing style, also known as their cut.

Depending on the sport being covered, the directors' cut, the order in which they select the images, will typically utilize what is known as a game camera for most of the broadcast coverage. Game cameras are assigned to provide wide, steady shots of the action whenever they are used in the show live. Game cameras provide the view the audience members are accustomed to seeing as they watch the event unfold live. Game cameras tend to be safe cameras for the director because they can cut to at any time and know that they have a smooth and steady shot available for the broadcast. CBS Sports director Bob Fishman said he did not have to worry too much about the coverage from his game camera because he knew it was solid (Wood, 2014). At a break in the game action, such as a time-out or a stop in game play, the director will cut off of the game cameras and use their other cameras in ways that build the narrative, as they see it. There is an art in the way a director cuts their show and how they present the content. It is during the breaks in the action that the director can employ their craft to its full potential and weave their "visual tapestry" (R. Vincent, personal communication, July 18, 2017). A good director can sense the pacing and flow of the event and match that with the appropriate cuts, as if they were directing a ballet (Owens, 2016b). While normally invisible to the viewing audience of a sports broadcast (Owens, 2016b), to a competent camera operator the directors' style should become apparent very quickly. As the camera operators work with the director and learn the directors' 
style, they will anticipate when their camera might be used, what cuts the director is making, and what shots the director is looking for from every camera. Identifying the director's style will help the camera operator anticipate the directors' needs, as well as help maintain a consistent "look" for the show (Cury, 2017). While a director has the potential to create a narrative with their cuts, they also have the potential to disrupt the narrative with the timing and choices they make.

When the director cuts to the wrong camera, it has the potential to distract the viewing audience, interrupt the announcers, and/or put camera mistakes on the air. No matter how important the event, or how large the viewing audience, if the grammatical structure of the narrative is wrong because of the way the director is cutting the show, then their desired message will not get through to the viewers (Jarvis, 1998). Thus, errors during broadcasts risk miscommunication. Erratic cuts, those that deviate too far from a particular sports traditional style, will ultimately confuse the audience (Lewis \& Greer, 1990) and risk the director cutting to an unsuspecting camera operator who might be about to make a camera mistake on the air. These kind of disruptions, regardless of why they happen, are what every director attempts to avoid at all costs (Lewis \& Greer, 1990; Rose, 1999). While these disruptions are labeled as major mistakes in the professional literature, there is currently no empirical research evaluating the perceptions of how important an on-air-mistake is to the director, the camera operators, and the production crew.

Communication skills. The ability to communicate effectively with the production crew may be the most important skill a live television sports director can possess. Through verbal communication, the director must coordinate the efforts of several groups at the same time during a broadcast. With the camera crew, the director faces two communication challenges: prior to the broadcast they must communicate the production teams' vision of the show to the 
camera operators, and during the broadcast they must manage their communication channel in constructive ways. Many directors spend hours preparing for a broadcast by researching the event they are covering and planning the techniques and locations of the cameras used to cover the event. Some directors have studied the teams they are covering to the point they know them as well as the announcers (Rose, 1999). The directors' planning and experience are what allow them to form a production plan for the show. The production plan is an outline of how they will present the coverage and it is developed by the director, with input from the producer and other members of the production team. After the director has developed their production plan, they must determine how they will communicate their vision for the show to the camera crew prior to, or during, the event.

The traditional place for the director to communicate their coverage plan to the camera operators has been during the camera meeting that normally takes places a few hours before the event. The camera meeting has been an opportunity for the director to share their overall vision for the show, as well as explain the individual assignments to each camera operator. Doug Wilson, an ABS Sports director, explained that when he was covering ice-skating, he used the camera meeting to explain his basic philosophy for covering that sport, with his goal being to make the coverage appear seamless (Rose, 1999). Wilson shared with the camera operators how he saw each of their cameras integrating with the others to form the overall visual narrative. While he acknowledged that most of the camera operators had heard his speech before, because it did not change, he continued to give it to ensure it was fresh in the crews' mind right before the show. His speech also provided anyone who had not heard the information yet with the opportunity to learn his style and what he was looking for from the coverage. He spent time communicating the specific language he would use during the broadcasts so the camera operators 
could become familiar with some of the nuances of his directing style. Wilson's goal was to create subtle camera work; he believed that if the camera work became noticeable to the viewer at home in any way, positively or negatively, he had failed in his role as the director of the show. Wilson claimed that he was only as good as the camera operators with him; however, it should be noted that those same operators also relied on Wilson and his ability to articulate his vision for the show during his camera meetings. The camera meeting was the formal opportunity for the director to communicate with the camera operators and for the camera operators to seek clarification of any issues, or concerns, they had about the production. In addition to the using their communication skills during the camera meetings, the director must be an effective communicator during the actual broadcast.

Directors spend the entire length of the broadcast, plus time before the broadcast, verbally communicating to their production crew. Owens (2016b) described the directors' role in the following way:

A multi-camera remote production is like a symphony. It is not a solo effort. The director is the conductor, juggling the various components, relying on an incredibly talented crew, to create a production that allows the audience to feel as though they are at the event and as though they have participated. (p. xvii)

The visual orchestra Owen's describes takes place with the director's voice as the guiding influence. Zumoff and Negin (2015) described the director as the one who weaves together the various pieces to tell the story of the event. They go on to say the director needs to combine the equipment and the crew in aesthetically pleasing ways, all while making split second decisions as the event unfolds. The director is always mentally attending to multiple sources of information and their verbal communication is aimed at various production personnel; simultaneously, the 
technical director, camera operators, tape operators, graphics personnel, and any specialized technicians who are also part of the production crew. A lack of clarity and precision in their verbal communication can cause miscommunications between the director and the camera operators (Lynn, 2016). Liz Claire, a live studio director, said the tone of the directors' voice sets the mood for the production (Wood, 2014), and the empirical research supports her statement.

In one of the only empirical research studies specifically addressing live television directors, researchers examined the effects of a director's communication style on the perceptions of the production personnel. Owens and Infante (1988) created different tape recordings of a mock newscast using different types of communication styles by the director: agitated and calm. They played back the different versions of the recordings to randomly assigned production personnel, who then completed a survey about the director they had heard on the recording. Their study found that calm directors were perceived to have better communication skills, higher social and task attractiveness, and higher satisfaction with the crew compared with directors who used an agitated communication style. Crew members were more forgiving of an agitated director if they saw the situational factors as contributing to the reason for the director being agitated. Overall, a calm director was favorable to an agitated director, regardless of the situation. The takeaway from this research is that directors set the tone for the production crew and their communication has measurable effects.

To summarize the role of the television sports director, they utilize multiple skill sets throughout the production process. Prior to the broadcast they communicate their vision for the show with the camera operators. During the broadcast, they create a visually appealing narrative for the audience by cutting a show that will not disorient the viewer; while at the same time, taking the viewer into the action from the perspective of the players and fans. They have to 
divide their attention among multiple facets of the production as they attend to producers, announcers, cameras, and their own vision of how the narrative should look. Directors must be effective communicators who are able to articulate their vision for the show to the camera operators during the camera meeting. Finally, they must manage their communication during the broadcast in a calm tone that is clear and predictable. Television sports directors are tasked with a difficult job and they must rely on the professional camera operators they work with to build the visual narrative for the viewers at home.

\section{Camera Operator Technique}

"The television cameraman is a specialist in a specialized industry: the techniques of his craft are geared to the particular problems of television" (Jones, 1969a, p. 106). Jones was describing what it was like to be a live television camera operator in the 1960's, with an emphasis on live studio productions and while his observations were made almost 50 years ago, there is still a great deal of relevance for the live sports broadcast camera operators of today. The camera operator is still a specialist who employs a unique skill set required for working in a live television production environment. Live productions rely on a team of individuals, working together in unison, to accomplish a common goal (Wood, 2014). Each individual on a production crew has a specific task they must perform and together, as a unit, the individual efforts are combined to create a cohesive production. The challenge, not only for camera operators but for every member of the production crew, is that every task must be executed correctly the first time (Owens, 2016b). When working on a live television production, mistakes in job performance by individuals translate directly into mistakes in the production as a whole. There is no opportunity to go back and change or correct a mistake in live television. For the camera operator, flawless task performance demands an exceptionally high level of technique; the kind of technique that 
only a specialist can provide. Live sports camera operators begin and end their careers striving towards a single goal: provide the viewer with smooth, stable shots that are not distracting (Jones, 1969a; Jones, 1969b; Smith, 1991; Thompson, 1998). The following sections will detail the specific skills a camera operator must master if they are to provide the stable, nuanced shots called for in the literature. If the professional literature is correct, and others can determine the quality of a production almost immediately based on just a few panning movements (Jones, 1969b; Smith, 1991), then mastery of these techniques is crucial for camera operators. The techniques a camera operator must master involve three distinct skill sets: physical skills, cognitive skills, and communication skills (Lynn, 2013).

The greatest challenge for live television camera operators, whether covering sports or any other live production, is that every movement the operator makes with the camera must be perfect every time, without exception (Jones, 1969a). Unlike large productions in the film industry, which might allow for multiple takes of shots if the camera operator makes a mistake, in broadcast sports there are no second chances; every camera movement must be flawless each time it is used in the production. This puts pressure on the camera operator to deliver the best possible performance while they are on the air. Camera operators spend years developing their technique with the camera to ensure the movements they make are on-point throughout the broadcast (Zumoff \& Negin, 2015). Individuals who have not sufficiently developed their technique will find that their physio-motor skills break down very quickly once they must simultaneously listen to a directors' instructions, comprehend what the announcers are saying, think about the next shot they are supposed to have, and maintain their shot composition as the subject moves around in their frame. When operators become overloaded with information, they struggle to move their body and appendages in the subtle ways needed to not distract the viewer. 
Proper zoom control requires a light touch of the operator's hand (Owens, 2016a) and simultaneous coordination of their arms to adjust the cameras framing as the zoom is executed. If camera operators are nervous or distracted, they could easily apply too much pressure to the zoom rocker and the zoom may suddenly snap in or out. The technique of the camera operator lies in their ability to blend the various elements of operation together in a meaningful way that does not distract the viewer from the content.

Physical skills. The physical skills of the camera operator can be conceptualized as the physical movement of the camera, and the manipulation of the camera controls, by the camera operator. In other words, a camera operator's physical skill refers to how adept they are at manipulating the image created by their camera. While veteran camera operators spend many years developing their physical skills with the camera, the operation of a broadcast television camera is straightforward and simple enough for the average person to grasp within a few minutes time (Zumoff \& Negin, 2015). The cameras themselves are designed to be ergonomically practical, with all of the main camera controls accessible to the camera operator without the need for them to remove their hands from the control surfaces while they are using the camera for the broadcast. While the general operation of a broadcast camera is straightforward, true mastery of the controls takes considerable practice (Williams, 1988). Manipulating each control requires specific physical skills by the camera operator. The pan and tilt require exceptional core body strength to provide smooth, nuanced control of the camera that will generate camera movements invisible to the average viewer. It is recommended the camera operator shift their entire body as they make a movement, because if they use only their arms then the movement will not be as fluid (Williams, 1988). The panning and tilting of the camera is not the only physical aspect of the task requiring deft control of the camera. 
The zoom rocker, the device that controls the cameras zoom lens by "rocking" left or right, is a sensitive piece of equipment that requires fine muscle control of the operator's hand, fingers, and thumb. A simple slip of the operator's thumb could cause the zoom to "snap" in or out. In this study, a snap zoom is defined as a zooming movement so fast the image becomes blurred. Because it can draw attention to the camera work and jar the audience, a snap zoom during a live broadcast is considered a serious task performance error (Smith, 1991). Using the zoom function of the camera, while not considered a genuine camera movement by some literature (Jarvis, 1998; Thompson, 1998), has been conceptualized a camera movement in this study. Zooming the camera requires the same degree of precision and nuanced control as pans and tilts (Gross, Foust, \& Burrows, 2005). The literature is clear that all camera adjustments in live television, whether pans, tilts, or zooms, should be smooth and unnoticeable to the viewer at all times.

When a distracting camera movement makes it on the air, regardless of the reason, it is an important event for the production crew and is considered a mistake. The worst movements a camera operator can make are ones which distract the viewer from the content and makes them aware of the camera operator (Jones, 1969a, 1969b; Smith, 1991; Thompson, 1998). Smith (1991) called poor camera movement a sign of operator incompetence and erratic movements were seen as indications the operator was inexperienced. These physical movements of the camera are the communication medium from the camera operator to the rest of the production crew and the viewing audience. Causes of poor physical camera movement should be carefully considered in this study.

From a physical perspective, there are several explanations why a camera operator might make a mistake and allow their camera work to become noticeable on-the-air. First, the operator 
might have poor technique and they are not be capable of manipulating the camera controls simultaneously in a satisfactory way. Put another way, their physio-motor skills have not developed to the point where they can implicitly operate the camera under all conditions. As will be explained in the cognitive section, camera operating requires a high cognitive workload that can be overwhelming to inexperienced operators. An inexperienced operator might show acceptable movement during the warm-up time, but during the actual broadcast their physical skills might break down and others will see a noticeable drop-off in the quality of their work (Jones, 1969b). Another explanation for a physical camera mistake is that the operator became physically fatigued and was unable to maintain the fine physio-motor skills needed to operate the camera at the level required for live television. Sports camera operators must operate their cameras outdoors, in all kinds of inclement weather (Boston \& Hoover, 2013), and for extremely long periods of time. At some point the fatigue of the camera operator may affect their performance levels. A final possibility is that the camera operator's mistake was caused by some type of external physical interference at the location where they were operating the camera. For example, a camera operator using a hand-held camera is normally close to the action of the event and surrounded by a number of people. There is always the possibility the camera operator could be physically bumped or pushed by an unsuspecting fan, player, or worker and it could create a jarring movement of the camera which could affect the production if the interruption occurred while the camera was on-the-air. Because camera operators have to work under all types of conditions, the weather could become another physical limitation on the camera operator's ability to move their camera. All of these examples are possible explanations of why a camera operator might make a physical camera mistake on-the-air. While a physical mistake is the 
visible result communicated to others, the cause of the mistake might be attributed to one of the other skill sets utilized by the camera operator.

Cognitive skills of the camera operator. While the physical manipulation of the camera is the eventual visible manifestation of the operators' technique, their cognitive skills, while not overtly visible to others, influence the nature and quality of their physical movements. In a live sports production, one cannot operate a camera in isolation from the rest of the production crew. The production crew is a cohesive unit and the camera operator is tasked with integrating their work with that of every other camera operator on the show in the specific ways they have been, and are being, instructed by the director (Jones, 1969a; Owens, 2016a). Cognitively, camera operators must be capable of actively processing a range of information and synthesize it into specific shots that will help the production. Their timing, ability to read situations, and composition skills are all aspects of their cognitive abilities. Live sports broadcast camera operators cannot be simply "doers" of the job, they must be "thinkers." The literature identifies several cognitive tasks as either vital to the role of a camera operator, or worth consideration for the purposes of this study.

One of the first aspects of camera operation a novice camera operator thinks about, exerts cognitive resources on, while operating their camera is controlling their body's physical movements (Smith, 1991). The physical movement of the camera requires fine muscle movements to maintain an image that is not jarring to the viewer. For those who have not spent years operating a camera, they must spend cognitive resources on actively managing their body's movements. The expenditure of mental resources will be conceptualized as their "cognitive workload." As their cognitive workload increases, such as when they transition from practicing their movements to performing them during the actual broadcast, they may be forced to shift 
cognitive resources to other areas, such as attending to the director's commands. In many situations, this will result in the operators' physical movements becoming noticeably erratic (Jones, 1969b; Smith, 1991) as they can no longer cognitively attend to their physical movements due a finite amount of cognitive resources (Miller, 1994). The external manifestation of the operator exceeding their cognitive capacity can be a jarring movement such as a whip pan or a snap zoom. As such, participants in this study might attribute a camera error to inexperience on the part of the operator; which would be conceptualized as both a physical and a cognitive error. It would be a physical error because the operator's muscle memory has not developed to the point where they can operate their camera implicitly and it would be a cognitive error because the operator has not developed their cognitive abilities to the point where they can distribute their attention across their cognitive workload effectively. The underdevelopment of those areas fits the perceptions of an inexperienced camera operator. For those operators who have developed their physical skills to the point they no longer need to mentally attend to them, they face additional cognitive challenges in their job.

In the professional literature, the skill mentioned more than any other is the camera operator's ability to know what to shoot next (Boston \& Hoover, 2013; Gross et al., 2005; Jones, 1969b; Zumoff \& Negin, 2015). This ability, to know what to shoot next, is conceptualized on several levels. First, camera operators should know what to shoot next to help advance the overall narrative of the event. This requires camera operators to pay attention to both the director, and the overall narrative of the game so they can deduce what the next shot should be for the broadcast. Second, camera operators are given specific assignments prior to each event and they are required to learn what their next shot will be for any given scenario (Cury, 2017; O’Neil, 1989; Owens, 2016b). This ensures “what if” situations are accounted for (Owens, 
2016b). Finally, camera operators must think about their next shot in relation to the current shot being used in the broadcast (Zumoff \& Negin, 2015). If their shot is too similar to the current shot and the director takes it, it will be a jump cut (Lewis \& Greer, 1990). Operators are expected to recognize when their shots are similar to other cameras and either re-frame their shot, or switch to another subject that is unique from the one currently on-the-air. In summary, for a camera operator to know what to shoot next, they must know their assignment for every situation, be aware of the overall narrative being told, and know how the shot they are attempting to capture fits with the shot currently in use. This task, of being mentally alert and attentive, requires mental stamina and is susceptible to cognitive fatigue.

One of the challenges camera operators confront is cognitive fatigue. Sports broadcasts last for at least two hours, and motorsports broadcasts can take up to 24 hours to complete. While camera operators are not required to cover an entire 24-hour broadcast, they regularly spend many consecutive hours operating their camera. For example, the average length of a baseball game is 3 hours, 5 minutes (Lennon, 2017), NASCAR races average more than 3 hours per race (Bruce, 2015), and the average length of a college football game is 3 hours, 24 minutes (McMurphy, 2017). All of these times do not include the additional hour, or hours, the operator spends on-camera prior to the start of the event. Jones (1969b) explained why operating a camera for a broadcast should be conceptualized as a high cognitive workload. Jones says that camera operators should never become spectators of the event themselves. He identified that a lapse in concentration could result in missing key moments of the event. Jones went on to say operators must focus their attention first on the content being produced and if they do that, they probably wouldn't even know who won or what happened in the event because they were concentrating on their work so much. For operators to concentrate so intently on their task they become unaware 
of who won or lost the game, it would indicate they are working under a high cognitive workload.

Camera operators are faced with both high cognitive workload situations and long task vigilant activities. Both of these situations present unique challenges for the operators and could result in cognitive based task performance errors. High cognitive workloads are a concern for camera operators because research has found that a person's reaction times slow in situations requiring a higher mental workload (Smit, Eling, \& Coenen, 2004). Because a camera operators' job requires them to react quickly, yet smoothly at all times when their camera is being used live, if they experience mental fatigue from high cognitive workload they may be more likely to make a task performance error. In other situations, there are camera positions where the camera operator will work for long periods of time and not have their shots used in the broadcast. During those times, the operator could go into a mental state of under-arousal, which could lead to a higher likelihood of task disengagement (Pattyn, Neyt, Henerickx, \& Soetens, 2008). A variety of mental workload conditions can potentially affect a camera operator's ability to perform their camera movements during a broadcast.

The cognitive challenges camera operators face includes mentally controlling their physical movements until they become implicit, attending to the directors' needs and expectations, attending to the overall narrative unfolding in the game, knowing their assignments and how their camera shots integrate with the show as a whole, and working through mental fatigue. A lapse in any one of these areas could result in a task performance air while on-the-air. The operators' communication skills are the final area the final area outlined in this study.

Communication skills of the camera operator. While there is very little professional literature directly addressing the communication skills employed by camera operators, it is the 
camera operators' communication skills which allow them to perform their physical and cognitive tasks in meaningful ways. Camera operators are expected to know the lingo of the business, possess highly developed listening skills, and develop connected relationships with their directors.

The first communication skill developed by novice camera operators is learning the language of the job. The terminology used in television is unique from other production industries (Caldwell, 2008; Mamer, 2003) and should be conceptualized as a distinct speech community (Caldwell, 2008; Philipsen, 1997; Philipsen, Coutu, \& Covarrubias, 2005). Shyles (1997) refers to the terminology of camera movement as a unique language between the director and the camera operators. Camera operators who are unable to comprehend the language used in broadcast sports productions are unlikely to provide the director with the specific shots they have been asked to shoot. Furthermore, camera operators who do not comprehend the language of live television productions, and how the communication between the crew creates the show, run the risk of making a whip pan or snap zoom on-the-air. While it is extremely unlikely that a camera operator who is completely unfamiliar with the language of television would be hired to work on a top-level sports broadcast, the possibility still exists and there are examples of such scenarios occurring (J. Dickerson, personal communication, August 25, 2017). Once a camera operator is familiar with the language used in television, they can begin to focus on the listening skills utilized during a broadcast.

During a broadcast, a camera operator must listen to two distinct sources of communication at the same time: the director and the announcers. These multiple voices are talking at the same time and the camera operator must isolate them and focus their attention on one or the other. The camera operator has the ability to control the volume level of each source 
and they must set the audio levels to fit their personal preference. It has been shown the human auditory system can suppress specific voices while attending to others (Mesgarani \& Chang, 2012), known as the "cocktail-party phenomenon" (Cherry, 1953). Confounding the operators' ability to decode the speech from the director and announcers is the external noise from the venue. Examples of noise include the crowd noise, a public address system, noise from race cars, or any external noise that interferes with the operators' ability to understand what is being said over headsets. In loud environments, it is possible the external noise around the camera operator could become so loud that the camera operator could no longer accurately understand the communication from the director. Research in this area has found it is more difficult to accurately process speech in noisy environments, such as those common to broadcast sports camera operators, and some people are more prone to communication errors when there is lexical interference (Lam, Xie, Tessmer, \& Chandrasekaran, 2017). Lexical interference refers to interference from other speech patterns/voices. As a camera operator attempts to listen to the directors instructions, the announcer audio could become lexical interference. In situations where the camera operator can no longer accurately understand the communication from the director, they are susceptible to making a task performance error on-the-air.

Research on speech-in-speech recognition and speech-in-noise situations has provided evidence that camera operators may be able to improve their communication abilities through training. Van Engen (2012) conducted an experiment that measured the potential effects of training in speech-in-speech and speech-in-noise situations. The participants, who were native English speakers, were randomly assigned to one of four groups: control group, English training, Mandarin training, and speech-shaped noise training. Each participant took a series of listening tests that induced noise in the form of English babble, Mandarin babble, or speech-shaped noise. 
The results found that participants asked to ignore speech-shaped noise, speech babble, were able to identify significantly more keywords during their training than did those participants who attempted to ignore babble based on the actual spoken languages. Their results indicate it is more difficult for a person to tune out other voices than general noise. In practical terms, camera operators should be able to tune out the crowd noise easier than an over-modulated announcer when they are trying to listen to the director. The post-test comparisons found that while the participants in the speech-shaped noise group were more accurate during their practice training, compared with those in the language-based conditions, they did not significantly improve their overall performance between their first test and second tests. In contrast, both the English and Mandarin groups made significant improvements in their accuracy rates following training. While the previously mentioned results are significant, the most important finding of the Van Egnen study was that speaker familiarity resulted in more accurate responses by the listeners in the English and Mandarin conditions.

There are several implications of the Van Egnen (2012) study for broadcast sports camera operators. First, the ability to recognize a directors' voice may result in improved communication, as the camera operator should be able to isolate the director's voice more easily. Similarly, camera operators working with a director for the first time might have a more difficult time isolating the director's voice and as a result, they might be more susceptible to task performance errors during a broadcast. A practical implication of this study is that camera operator's may need to be careful how they adjust the volume levels of the director and the announcers. Announcer audio that is too loud might have a greater detrimental effect on their listening abilities than crowd noise, which is a consistent noise and easy for them to tune out. 
Composition. Camera composition is an intuitive skill developed and refined over many years of professional practice (Jones, 1969a; Ward, Bermingham, \& Wherry, 2000). In the present study, camera composition, also referred to as framing, is conceptualized as the arrangement of objects within the video frame over time. Because television is a constantly changing medium, the operator's compositional skills have to be considered within the framework of their image composition over time, as a single static frame is not an adequate representation of how well a camera operator has framed their shot for a broadcast. In that context, composition over time, we can begin to understand how a camera error can communicate a variety of meanings to those who work in the broadcast sports industry.

When a camera operator makes a potential performance error, the error may be evaluated holistically by professionals who account for the multiple facets of the mistake over time; thus, influencing their overall impression of why the mistake occurred and whether or not they consider the camera movement to be a mistake at all. Professionals are expected to evaluate a camera operator's camera movement both before, during, and after a possible mistake has occurred. For example, if a camera operator makes a sudden movement of the camera, such as a whip pan or a snap zoom, but is able to end the fast, technically incorrect, movement with a perfectly composed image, professionals may see this as a sign of competence because the operator was able to overcome a potential mistake, the whip pan or snap zoom, and still maintain their final composition of the image. Going back to the early experiments of Heider and Simmel (1944) and the attributions of movement in inanimate objects, the movement of objects can communicate both emotional meaning and intention to others. By extension, the movement of a video frame as a camera operator maintains, or attempts to maintain, their shot composition communicates information about the camera operator to those who are capable of reading the 
language of broadcast sports productions. By ending a fast, technically incorrect, movement on a perfectly composed image, and then maintaining their composition over time with confident movement of the camera, professional operators may be able to minimize the impact of errors which occur during the broadcast.

\section{Technical Director}

While a majority of the literature, and this study, is focused on the relationship between the director and the camera operator, another technical crew member should be mentioned; as their work can have a direct impact on the director, the camera operator, and the production as a whole. In a broadcast sports production, the Technical Director (T.D.) is responsible for selecting the specific camera, tape, or graphics source the director has called for (Owens, 2016b). This is a daunting task when you consider modern switchers, the devices used to route the various signals, contain hundreds of buttons and require hours of pre-production programming for each show.

Not only must T.D.'s select the correct source, they must do so under less than ideal conditions at times. Sometimes a director can be so engrossed in the cut they do not have time to call out which camera to use. Instead, they might point with their hand or snap their fingers at the camera they want to use and the T.D. is expected to respond by selecting the correct camera (Zettl, 2003). The T.D. must interpret all of the director's commands and ensure the correct camera is always selected during the broadcast.

When a T.D. makes a mental or physical error in selecting the next camera, it can result in an interruption of the broadcast. One possible outcome is a cut to a camera that is in the middle of quickly reframing a shot. In that situation, the camera would make a whip pan or snap zoom on-the-air, through no fault of the camera operator, who was caught unaware of the tally, or the director, who had called for a different camera. Further, this type of mistake by a T.D. 
would be difficult to identify as the result of the T.D. without hearing the actual communication that had taken place between the director and the T.D. leading up to the mistake. A viewer of the broadcast would see a random cut occur and likely determine the mistake was the fault of the director or the camera operator. It is also worth noting that a T.D. can help avoid a poor cut by serving as a second set of eyes for the director. If a director becomes lost and calls out the wrong camera, it is often the T.D. who either holds off on cutting to that camera despite the director's commands, or will quickly point out to the director an error is about to take place if they cut to the wrong camera. For this reason, directors will handpick T.D.'s for their shows who understand their cut and will help them create a better overall product. The T.D. serves a vital role in ensuring the continuity of the production by carefully following the commands of the director and assisting them as needed.

\section{Categorizing Live Sports Productions}

Live television sports broadcasts are a form of mass communication utilizing both audio and visual media to reach a mass public. Conceptualizing how live sports productions are related to, and separate from, other forms of mass communication begins with their fundamental differences and expands to the nuances that define each sub-category as unique. All mass media, at the most basic level, can be divided into two categories: live content and edited content. Live sports productions are part of the live content category, although they may encompass edited elements within their productions. Live productions are defined as media content created in realtime, as the event is occurring. The media content from a live production location goes directly to a broadcast distribution point, and immediately out to the viewing public. Any editing decisions in a live production occur in real-time, as the event is taking place and as the signal is being viewed by an audience. Once the content has been distributed, it cannot be changed. With 
these distinguishing features, being able to create all editing choices as the event occurs, the technical infrastructure of live productions has been engineered to pass a visual signal from a camera, directly to the viewing public in real-time. The live production category is defined by the fact that the sequential order of the content cannot be changed once it has left the location where it was produced. Complementing the live form of visual communication is the edited content category.

The second category of production content is that of edited media. This category encompasses virtually every film and documentary ever produced and a great deal of content that has been broadcast on television. Edited content is defined in this study as visual content that goes from a camera, or a remote production location, to a storage device with the intent, or the option, of adjusting the sequential order of the content, the length of the content, or any errors in the content prior to the content being broadcast to the general viewing public. In other words, images from a camera are stored for later use and are not seen by a mass audience as they are captured as they are captured from the camera. The media device storing the content could be the camera itself, an external recording device, a remote production truck, or a broadcast production center where the images are being sent. Once captured, the content is then rearranged, manipulated, or prepared for direct-from-tape playback that will be integrated into the broadcast. In the context of live sports productions, mass media in the edited content category is also referred to as "taped" content and/or "pre-produced" content. The defining characteristic of the edited category is that the visual content is first captured and not sent out to the viewing public in real-time. In addition, there is a specific intent to adjust to content in some way after it has been captured. These two categories, live productions and edited productions, define all forms of mass media production work. While there are certainly some techniques and theories which carry over 
from one category to the other, careful consideration must be paid to any cross-category comparisons.

Possibly the most distinguishing feature separating the two categories, live and edited, is that in live productions there are no second chances to execute a camera movement. Once a camera has been taken live, the camera operator has a direct signal path to the viewers at home and every movement the operator makes with the camera is immediately seen by the viewers. For this reason, live television sports productions demand that camera operators perfect their camera technique until they can perform every movement flawlessly (Jones, 1969a). Every camera shot used in a live production is of equal importance while it is being used live on-theair. This could partially explain why task performance errors in live sports production often receive strong overt reactions by those in the industry when they occur.

In contrast to live productions, where the content is created in real-time and every shot must be perfect while it is on-the-air, edited productions employ a workflow in which the content is produced over a period of time and camera shots may have the potential to be re-shot if they are not perfect the first time. In film productions, content can be shot with a "master shot," then additional shots can be added to the material that will later be edited into the final product (Barrance, 2017; O'Leary, 2003). While it is clearly not ideal for a camera operator from any production category to make a mistake, an edited production has the option of re-shooting a scene, or not including a shot, in the final edited version of the media. After being captured, the footage then goes through a post-production process to adjust the audio, add special effects, titles, and more (Dems, 2010). Typical production times to create a high level film are eight weeks in the production phase, capturing the content, and six months in the post-production phase, editing the film (Wild, 2016). The long post-production timelines of edited films are in 
sharp contrast to the short production timelines of live sports productions, which have no postproduction phase.

There are a number of other distinguishing features which separate live sports productions from edited productions. This includes the terminology used by the production crews, lighting and how it is manipulated, typical frequency of the production schedule, preplanning for each event, and the type of workforce utilized. When selecting a theory or technique to apply from one category to another, these factors must be considered as a way of establishing the level of relevance the theory or technique will have across categories. 


\section{CHAPTER II: ATTRIBUTION THEORY}

Recall that, in the lunch conversation with my co-workers who witnessed a camera mistake during a live sports broadcast, my co-workers immediately attempted to explain why the mistake occurred. As camera operators themselves, they had no trouble generating explanations of why the mistake had occurred. They each made different attributions about the cause of the mistake and then proceeded to watch the broadcast in an attempt to refine their initial attributions. This scenario, of people from a unique community making causal attributions following a task performance error by another individual within their community, is best explained through attribution theory; a theory whose rational canon is that "people care less about what others do than about why they do it" (Gilbert \& Malone, 1995, p. 21). Following the performance error of the camera operator, my co-workers made attributions regarding the cause of the mistake based on their own subjective experience in similar situations and their implicit ability to read the contextual cues communicated through the broadcast. This chapter will establish how attribution theory can be applied as a social scientific tool to understand and explain the perceptions communicated to those in the broadcast sports production community when they evaluate another's performance. This chapter will conceptualize attribution theory, identify variables and biases of the attribution process, detail the measurement of attributions, and apply attribution theory to a live sports production setting.

\section{Attribution Theory Conceptualized}

Attribution theory, as it is applied in research studies, values the experience and expertise of the study participants. The theory is grounded in the idea that everyone, regardless of their position in life, is a naïve psychologist with intuitive knowledge of why people do what they do (Heider, 1958). An individual's attributions, or their explanations of events, form the basis of 
what can then become focused scientific research. Studies using attribution theory explore how and why individuals and groups make casual attributions about the world around them, with the attribution theorist's role being analysis, refinement, and enlargement of the common sense knowledge that participants implicitly bring to a study (Kelley, 1973). Accordingly, the aim of the present study is to analyze, refine, and expand on the attributions that participants from the broadcast sports community make regarding a camera operator's task performance error during a live sports broadcast.

Attributions are a natural part of everyone's life and are made every day without people realizing they are making them. People make intuitive attributions (Reb \& Greguras, 2010) as a way of understanding the actions of others and to make predictions about their future behavior (Heider, 1958). Through attributions, people are able to adapt to their environments so they can function more efficiently (Heider, 1958). This is especially true in organizational settings, where a person's ability to adapt and learn from their mistakes, and those of others, may be paramount to their continued employment. As freelancers, or people who work on a for-hire basis, members of the broadcast sports production community have no guarantee of future employment beyond their current written and verbal contracts; therefore, the intuitive attributions others make regarding their task performance errors may have important implications on their future hirability (Carless \& Waterworth, 2012). For this and other reasons, attribution theory has been found to be an appropriate fit for the study of temporary organizations (Martinko, Harvey, \& Dasborough, 2010) such as a broadcast sports production crew. The present study will be grounded in Weiner's (1992) attribution theory, with an emphasis on attributions actors and observers make in performance-based situations. 
While an individual's normal task performance may elicit attributions, attributions are most likely to occur following an unexpected, negative outcome of a task performance (Carless \& Waterworth, 2012; Martinko et al., 2010; Weiner, 1986). When success is the normal outcome, failures tend to stand out and thus they will generate a number of causal attributions (Weiner, 1992). In fact, performance errors may generate more attributions than a person needs to make a causal inference. However, while an infinite number of attributions can be pulled from memory, a person will select from a few that best fit the context of the situation (Weiner, 1986). Kelley (1973) posited that individuals would find an explanation that matches the observed behavior and unless there was a specific reason for further cognitive processing, they would stop searching for more elaborate answers. Since multiple attributions could be made to explain a task performance failure, we must consider the variables that affect the final attributions that people might select.

\section{Variables in Attribution Theory}

In achievement contexts, there may be a large amount of variance between the attributions raters make regarding a task performance error. The first step to explaining this potential variance in attributions is understanding that attributions are complex cognitive processes which account for a number of variables (Weiner, 1992). Heider (1958) did not see attributions as simple cognitive responses, rather he believed they were based on various factors that affected the decision making process. For example, attributions are contextually based (Heider, 1958; Kelley, 1973) and raters can make causal attributions based on the variables they can see or infer (Hewstone, 1983), and they may not account for the contextual elements which they cannot see or have no experience with (Gilbert \& Malone, 1995). While the research indicates that the internal traits of ability and effort are the strongest variables in performance 
based attributions (Moore, Swift, Sharek, \& Gino, 2010; Struthers, Weiner, \& Allred, 1998), attributions are complex and the research has not been applied to a broadcast sports production setting. Beginning with the correspondence bias, key variables will be examined as they apply to a broadcast sports production setting.

\section{Correspondence Bias in Measurement}

Heider (1958) and Kelley (1973) had originally hoped that attribution theory would lead to predictions of behavior through causal attributions. However, multiple studies have since shown that attributions are often misjudged and, as a result, correlations between variables are difficult to make (Gilbert \& Malone, 1995; Weiner, 1992). Attribution misjudgments occur because, as humans, our cognitive processes are not always based on logical, rational choices. Whether conscious or unconscious, there are often subjective biases present in the evaluation process, which color and shape the attributions we make of others' behaviors. Probably the most commonly cited bias in attribution theory is that individuals do not accurately account for the many situational factors that could influence another person's behavior in a given scenario. These miscalculations, which privilege dispositional, internal factors more than situational, external factors, are known as the correspondence bias (Gilbert \& Malone, 1995; Hopthrow, Hooper, Mahmood, Meier, \& Weger, 2017; Moore et al., 2010) or the fundamental attribution error (Ross, 1977). Ross saw naïve psychologists as taking their own personality traits and experiences and applying them broadly across a wide range of applications. He believed that, in attribution theory, the participant was too close to the situation to judge it objectively and when looking at others behaviors, observers tended to jump to quick conclusions that did not take into account other environmental factors. Gilbert and Malone expanded on the points raised by Ross, 
and they offer insight on whether or not the biases we find in attribution research will have an appreciable effect on our results.

In a review of literature, Gilbert and Malone (1995) outlined four distinct mechanisms of the correspondence bias: lack of awareness, unrealistic expectations, inflated categorizations, and incomplete corrections. According to Gilbert and Malone, these mechanisms are usually not differentiated and are commonly attributed as just the correspondence bias. Beginning with a lack of awareness, each of these biases could potentially influence the present study if they are not accounted for in the investigation. A lack of awareness refers to the difficulty of expressing situational factors to others. While someone can point to the specific achievements of a person, they may not see the way that the situational factors influenced the other person's behavior. If an evaluator cannot see the external factors, whether they be physical, behavioral, or psychological (Gilbert \& Malone, 1995), then those factors will not be taken into account when making an attribution. In the present study, a situational factor could include the noise level of the environment. In a noisy production environment, a camera operator may not have been able to hear a director "ready" and "take" their camera and they might be caught unprepared to make an on-air movement. The observers in the present study will not experience a noise level equal to what a camera operator might experience in real life, and they are therefore unlikely to account for noise and other situational factors in their attributions, unless they have been in a similar situation themselves. In which case, a second bias could be present in their attributions unrealistic expectations.

Unrealistic expectations can stem from both underestimations as well as overestimations of situational factors (Gilbert \& Malone, 1995). Gilbert and Malone found evidence that this occurred when observers could easily imagine being in the same position as the person they were 
observing. In such cases, participants used simple heuristics to process the information and they compared it with their own actions in the same situation. The result was that observers placed unrealistic expectations on those they were observing. This finding aligns with social comparison theory (Festinger, 1954), which says that if an evaluator sees themselves as similar to the person being evaluated, they might assume that the other person is acting in ways consistent with how they would act in a similar situation. The end result is that the observer could make inflated estimates of either the internal or the external factors, or both (Wallace \& Hinsz, 2009). In the previous example of noise effecting the camera operator, a camera operator making attributions about another camera operator might overestimate the effect of the noise and attribute their mistake solely to that cause, when in fact the camera operator could have been attempting an intentional camera movement and they made a mistake executing it due to a lack of ability.

A third type of bias occurs when we place others in categories prior to making our evaluations. Feldman (1981) found that, whether consciously or unconsciously, we place coworkers into performance categories and our subsequent evaluations are colored by the specific category prototype utilized. If the person is expected to perform well, categorized as a high performer, they will be evaluated poorly if they do not meet the expectation for that categorical behavior. Gilbert and Malone (1995) explained that people assess a persons' behavior, but they do not do so objectively. People assess others behavior based on their perceptions of the persons behavior and whether that perception fits with their expectations. In the present study, participants who perceive a camera operator to have a close director relationship with the director might categorize the camera operator as what is colloquially known as a "core camera operator." Crew members who are categorized as "core" members of the crew may be evaluated less severely than crew members who are perceived as "fill-in" operators. 
Finally, Gilbert and Malone (1995) found that even when all of the situational factors are accounted for, there may be another form of attribution bias present which affects the dispositional, internal attributions. Gilbert and Malone indicated that even when an observer's expectations match a subject's performance, there may still be a form of correspondence bias due to incomplete corrections of the dispositional, internal factors. Incomplete corrections stem from people making attributions, then correcting for them incompletely due to a lack of attentional resources. In other words, an individual could make an attribution about a person, realize after the fact that other factors had constrained the person's behavior, but not have the mental resources or the time to make a full re-evaluation of their previous attributions (Gilbert, Krull, \& Pelham, 1988). This bias could be relevant to real-world evaluations of camera operators. Directors may be prone to making sudden attributions following a camera mistake during a broadcast. Soon after the mistake, the director may be told additional information regarding the cause of the mistake, but in that situation they might lack the attentional resources to make a full attributional correction while they are in the cognitively demanding broadcast environment. This places even greater importance on the need for camera operators to avoid task performance errors during a broadcast because those errors likely have a negative impact on their overall performance ratings, even when the error was caused by factors that were out of their control. With these four distinct factors, lack of awareness, unrealistic expectations, inflated categorizations, and incomplete corrections, making up the correspondence bias, the next question to address is how robust the bias is.

While most of us probably believe we make bias free evaluations of others because we are aware of these potential biases, research has shown the correspondence bias is robust and is likely still influencing our attributions, even when we attempt to counter it. Moore et al. (2010) 
found that the correspondence bias was very robust and even when evaluators were fully aware of the situational factors, they continued to underestimate the influence of them. Moore et al.'s conclusion was that people would continue to be judged strictly on their performance, with little regard for the external challenges they faced.

While the correspondence bias is robust and likely to persist in some way, it has been shown that there are techniques for reducing its effects. Hopthrow et al. (2017) conducted three experiments studying the correspondence bias and found that participants who conducted a mindfulness exercise were able to reduce the effects of the correspondence bias. Ultimately, while the correspondence bias can be reduced, it is not expected to be eliminated entirely. In fact, the correspondence bias may yield some of the most interesting results of the present study by explaining how and why performance evaluations vary between categories of participants.

\section{Timing}

When an attribution is made, the timing of events could be as vital as the attribution itself, especially when the attribution is made based on visual evidence. In visual evidence, one of the key variables of attribution theory is the timing of the event (Heider, 1958; Michotte, 1963). The timing of the event is an important variable because it serves as a cue for the observer to attribute a particular action to a particular cause. If there is a large enough time gap between an initial action and a secondary reaction, then a causal relationship is not likely to be inferred (Kassin \& Baron, 1985). Michotte found that when a reaction occurs within 75 milliseconds of an action, people will attribute the reaction directly to the action in what is known as a launching effect. However, if a reaction occurs between 75 milliseconds and 200 milliseconds after the initial contact, people may see the reaction as a delayed launch. In those situations the reaction 
may or may not be attributed to the initial action. Finally, when a reaction occurs more than 200 milliseconds after an initial action, the two events are seen as unique and unrelated.

In broadcast sports productions, there could be a launching effect (Michotte, 1963) associated with a task performance error. For example, if a director cuts to a camera just as the camera operator is making a jarring camera movement, some observers may attribute the jarring movement, which made it on-the-air, to the director who made the cut as the camera operator was adjusting their shot. These observers may be attributing the task performance error of the operator to the timing of the director's cut, which preceded the operator's performance error by less than 200 milliseconds. However, if a director cut to a camera and several seconds later the camera operator made a task performance error, raters would not attribute the task performance error to the director, they would attribute the error solely to the camera operator. Ultimately, the timing of events creates perceptions of causal attributions and effects the number of possible attributions made. Closely timed actions and reactions become causally linked and ambiguously timed events may generate more attributions because they represent either a causal relationship or independent events, depending on the attributions of the observer.

\section{Task Difficulty}

In the broadcast sports community, different camera positions require different skill sets. Most camera positions require the operator to stand for extended periods of time without breaks. Other camera positions require an operator to balance a heavy camera on their shoulder throughout the broadcast and walk or run with it to capture specific shots. Still other camera positions are cognitively demanding and require the operator to manage a list of assignments in order to stay in-sync with the director. Still other camera positions are perceived as difficult tasks because of the director, who may be demanding of the operators during the broadcast. Because 
camera operators perceive the various camera positions to vary in task difficulty, their attributions of ability and effort may be influenced by their perceptions of the task difficulty, similar to results found in other studies (Kun \& Weiner, 1973). In a failure condition, which is the focus of the present study, when a task is perceived as difficult, ratees are not seen as failing as a result of low ability or a lack of effort. Instead, their failure is attributed to situational factors. However, when a task is perceived to be easy and a failure occurs, the failure is often attributed to a lack of ability and effort. It is expected that raters in the present study who perceive a camera position as difficult will rate the operator's ability and effort as high in a success condition. Following a failure condition, raters who perceive a camera position to be of high task difficulty are expected to attribute the cause of the failure to situational factors rather than a lack of ability or effort.

The expectation of task difficulty attributions influencing attributions of ability and effort assumes an ordering effect in the present study. The assumption is that when the ability and effort of a ratee are not provided prior to observing a task performance error, people will evaluate and make attributions of the task difficulty first, then make attributions of the person's ability and effort. However, there is evidence that the ordering effect could also work in the opposite direction and attributions of ability and effort could lead to attributions of task difficulty, in that order. In a series of studies on causal attributions in coworker interactions, Struthers, Miller, Boudens, and Briggs (2001) manipulated attributions of ability and effort prior to a task performance error. They hypothesized that high ability and high effort ratees would receive benevolent attributions following a task performance failure. They based their hypothesis on the concept that high ability and high effort are not associated with failure, therefore the task failure would be perceived as a temporary setback that would not occur in the future. They 
predicted that the blame for the failure would, therefore, be attributed to the external factor of task difficulty. While they did not directly measure task difficulty in their studies, they found that following a failure ratees with high ability and high effort received both benevolent and malevolent support from coworkers, providing overall support for their hypothesis. Those with high ability and high effort were expected to perform the best on future tasks and were seen as the least responsible for the failure. By extension, if they were the least responsible for the failure then the failure was attributed to the external factors of task difficulty or luck. A word of caution is that the highest performers were also the most likely to have their future efforts sabotaged by their coworkers.

In a similar 2 x 2 research design by Carless and Waterworth (2012), factors of ability and effort were manipulated through scenarios and workers in the high ability and high effort condition were perceived as less internally responsible for a performance failure compared to workers in the other three conditions. Further, workers in the high ability and high effort condition had the highest expectations of future performance. The study added support that attributions of ability and effort effect attributions of task difficulty. When ability and effort are perceived as high, failure is attributed to the task being difficult. The overall conclusion is that regardless of the order effect, there appears to be a correlation, in the form of a positive relationship, between the situational attributions of task difficulty and the dispositional attributions of ability and effort.

\section{Social Perceptions}

Social perceptions of the relationship between the director and the camera operator may be one of the variables in the study of broadcast sports productions. While the director/operator relationship has not been studied directly before now, indications are that the social context of a 
situation can influence subsequent performance ratings. Because people perceived as having high abilities are socially admired (Weiner, 1995), it follows that people who are socially admired may be seen as having high abilities. In broadcast sports productions, a socially admired position is a close relationship between a director and a camera operator. While the relationship of a director and camera operator should have no influence on performance ratings in a purely objective setting, recall that attributions are made based on the context of the situation (Heider, 1958) and multiple psychological cues influence raters' attributions when making performance evaluations (Struthers et al., 1998). There is reason to believe the relationship between the director and the camera operator may have a subjective influence on performance ratings. In experiments conducted within organizational settings, supervisors have been found to make performance evaluations based on the quality of the relationship they have with their subordinates; with higher performance ratings given to those subordinates who have a close relationship with them (Geertshuis, Morrison, \& Cooper-Thomas, 2015; Liden \& Graen, 1980). In a study by Wilhelm, Herd, and Steiner (1993), they found that supervisors who shared a close relationship with a subordinate attributed a subordinates' high-performance work to internal factors, such as the subordinates' abilities and effort, and their low-performance work to external factors outside of the subordinates control. Conversely, supervisors perceived subordinates they were not in a close relationship with as succeeding more to external factors and performing poorly due to more of their internal factors. While perceptions of a relationship in broadcast sports has not been tested to date, the research seems to indicate that a camera operator in a socially desirable, close relationship with a director should expect significantly more positive performance ratings than a camera operator in a socially undesirable, distant relationship with a director when making the same task performance error. This is in line with the tenants of 
attribution theory, which state that the context of the situation influence the attributions made (Weiner, 1992).

\section{Similarity to Target}

A body of research on group attributions suggests that the degree to which the observer perceives themselves as similar to the actor being observed can bias the attributions made about an actor's performance (Cox \& Beier, 2014; Rupp, Vodanovich, \& Crede, 2006; Wallace \& Hinsz, 2009). Wallace and Hinsz found that group members made inflated attributions of both internal and external factors compared with attributions made by individuals. The inflated attributions occurred whether the group members were assessing members of their own group, or if they were assessing members of another group. They also found that ability, effort, and task difficulty attributions were stable factors while luck varied over time. The indication is that the similar-to-me phenomenon (Rand \& Wexley, 1975) may carry over to group situations. Individuals who view other groups as similar to groups that they have been in will likely make attributions similar to the attributions they would have made about their own individual and group performances. Broadcast sports camera operators, as well as other crew members working in live sports broadcasting positions, are likely to view other broadcast sports camera operators as members of similar groups to which they themselves belong. Therefore, broadcast sports camera operators are expected to make inflated internal and external attributions about the causes of a task performance error. Likewise, those who have never operated a camera for a broadcast sports production will make significantly different attributions of a performance error.

\section{Measuring Attributions of Performance}

Measurements of attributions attempt to quantify, or explain, the perceptions participants make about causal behavior. The present study will use a quantitative approach to the 
measurement of attributions. The measurement of attributions is primarily aimed at identifying the degree to which participants attribute a behavior to controllable factors and whether the behavior is expected to be repeated in similar situations (Weiner, Frieze, Kukla, Reed, Nest, \& Rosenbaum, 1971). Observers make their judgments of causality based on their perceptions of the event; the actual cause of the phenomenon is not directly observable to them (Weiner, 1992). In performance settings, attributions typically include measurements of ability, effort, task difficulty, and luck (Martinko et al., 2010). These four measures determine if a behavior is attributed to internal stable factors (ability), internal unstable factors (effort), external stable factors (task difficulty), or external unstable factors (luck). Stable factors (i.e., ability and task difficulty) are seen as likely to occur again, while unstable factors (i.e., effort and luck) may or may not occur again in similar situations. Rudolph, Harari, and Nieminen (2015) developed the attributional model of dynamic performance appraisal that will be employed in the present study to quantify attributions of ability, effort, task difficulty, and luck following a task performance failure.

When measuring attributions of performance, Rudolph et al.'s (2015) proposed an attributional model of dynamic performance appraisal. Their model posited that performance ratings were influenced by attributions of performance based on dynamic performance characteristics, such as performance trend and performance variability. They utilized a Multidimensional Observer Attributions for Performance Scale (MOAPS). Their scale consisted of 24 items and took measures of ability, effort, task difficulty, and luck. As previously mentioned, these four measures represent the internal-stable attributions of ability, the internalunstable attributions of effort, the external-stable attributions of task difficulty, and the externalunstable attributions of luck. 
In their first study, Rudolph et al. (2015) found evidence that performance ratings were influenced by performance trends, which were associated with the internal attributions of ability and effort. They found that positive performance trends resulted in a more positive performance evaluation rating including higher ratings of ability and effort. In their second study, they manipulated both the performance trend and the variability of the performance, also known as the consistency of the person's performance. They found that the amount of variability, the consistency of the work, influenced the magnitude of the effects from the performance trends on attributions. In their words, inconsistency in a performance attenuated the internal attribution effects of ability and effort. In their third and final study, they extended their findings to include a research design incorporating greater variability of performance and utilizing evaluators with actual experience making performance evaluations. They found that, just like in the second study, high variability of the workers performance mediated the effects of the performance trend. Their results were not entirely consistent with the anticipated correspondence bias (Gilbert \& Malone, 1995).

Participants of the Rudolph et al.'s (2015) study attributed upward performance trends to easier tasks, and downward performance trends to more difficult tasks while the correspondence bias had predicted that the performance trends would be attributed exclusively to internal factors, not external factors such as task difficulty. However, consistent with the correspondence bias, their findings found that the task difficulty did not appear to influence the overall judgments of performance, it was still the internal attributions which determined the performance rating. Their results suggest that external effects, such as variability, influence performance ratings much less than the internal effects, such as performance trend. They concluded that the observer's internal attributions served to mediate the performance trend and final performance rating. This was in 
line with other research findings showing that performance characteristics, such as performance trend and variability, influenced performance ratings, with performance trend being the more influential factor (Reb \& Greguras, 2010).

A second measurement goal of the present study was future hirability. Because a freelance camera operator's future work may be based on attributions made during subjective performance ratings, determining potential factors which could influence their future work recommendations was relevant to this study. Participants who attributed a task performance error to stable internal factors were expected to show lower scores on future hirability because raters did not see those stable internal factors as changing in the future (Weiner, 1992). Measurement of future hirability were loosely based on scales used by Charles and Waterworth (2012) in a study of ability and effort attributions on future hirability decisions. Their results were consistent with attribution theory (Weiner, 1985) and attributions of ability and effort influenced future hiring recommendations. In a task performance failure scenario, attributions about the cause of the failure were clearly linked to hiring recommendations.

Attribution literature indicates attributions are most likely to occur following a mistake made during an important event (Dalal, 1988; Weiner, 1986). Mitchell and Wood (1980) tested for the impact of task seriousness on attributions and found a correlation: supervisors made attributions in part as a function of the seriousness of the task being performed. Because there is no empirical evidence suggesting a task performance error like a whip pan or snap zoom is considered an important error, four importance scales were created to evaluate the participant's perceptions of how important the task error was to the camera operator, director, other crew members, and the audience. Categorical differences in levels of perceived importance may lead to variance in attributions made following a task performance error. Additionally, a three-item 
scale was created and included in the study to measure the participant's perceived frequency of a camera operator making a task performance error similar to the one they watched in the sample video. If a similar performance error is perceived to be a frequent occurrence, attributions are expected to have little variety in their causal explanations. However, if the performance error is found to occur infrequently, participants' attributions are expected to be varied and it will add validity to the type of performance error used in the present study.

\section{Applying Attribution Theory to Live Sports Broadcasting}

Attribution theory is particularly applicable to contexts where observers develop causal explanations for a subject's performance mistakes, even when based on just a single instance of the event. Kelley (1973) said it was possible for people to make causal inferences based on just a single observation of an event given that, in most cases, people have experience with the situations they are being exposed to. The participants in the current study were expected to have some amount of experience with camera mistakes in sports broadcasts, and therefore be capable of making causal attributions based on watching a single instance of a performance error. This allows for concise delivery of the content to the participants via a single example, without the need to present several different performance errors that could potentially confound the study's findings. Attribution theory allows the participants to pull from their vast professional experience as they make causal attributions. Furthermore, co-workers may be the best choice for making performance evaluations in work-team environments as they are directly affected by the performance outcomes (Struthers et al., 1998).

There has been some noted ambiguity as to the cause of certain camera mistakes which occur in a broadcast productions and attribution theory is positioned to empirically answer who is perceived to be at fault in those cases. Owens (2016b) detailed the scenario used in the present 
study when he speculated that "sometimes the camera operator may take the initiative to begin to get a particular shot and the director accidentally cuts to that camera in the middle of the move to get to the shot" (p. 165). Importantly, "such a cut is the director's mistake, not the camera operator's (unless the director has called for a specific shot on that camera and the operator is out freelancing on his or her own" (p. 165). This is also a scenario in which the T.D. may have inadvertently selected the wrong camera, in which case it is neither the fault of the director or the camera operator. This scenario is quite similar to the one incorporated into the survey employed in the present study (see video link in Appendix). Soon after a director cuts to a camera, the camera operator snap zooms out fast enough for the image to become blurred. While the camera movement has been identified as a potential task performance failure (Jones, 1969a; Owens 2016b; Smith, 1991; Thompson, 1998), there is no empirical research examining possible implications of the mistake to the camera operator or what factors may influence others' attributions of the cause of the mistake. By applying attribution theory to the outlined scenario, we will gain a better understanding of which factors, internal or external, are perceived to be the cause of the error.

The type of task performance error chosen for this study appears to be uncommon in the field of broadcast sports productions, an important element of attribution theory. Uncommon task performance errors generate additional attributions as to the causes of the failure (Dalal, 1988; Weiner, 1986). In the author's personal experience, the type of task performance error examined in the present study occurs infrequently and has generated a wide range of colorful responses by directors, with a variety of reasons being provided by production personnel for why they occurred. Attribution theory may explain why members of the broadcast sports community can become emotionally excited when they see a rare task performance error occur. 
While attributions can be made based on a single instance, it is important to note that raters might evaluate someone based on their overall prior experience with the person, not on the single instance they are rating (Borman, 1978). This is in line with the attribution research showing that performance trends have more of an influence on ratings than the variance in performance (Rudolph et al., 2015). People may attribute a single poor performance to an inconsistency in an overall positive performance trend. In the present study, while ratees will have no prior knowledge of the camera operators' past performance abilities, they might perceive a close relationship with the director as an indication of a positive past performance trend and their attributions could follow.

Freelance camera operators are recommended for work based on others' expectations of their future performance. Attribution theory is positioned to demonstrate how a performance error could potentially affect a camera operators' future freelance work. In a study by Carless and Waterworth (2012), professional recruiters were asked to evaluate a fictitious applicant following a task failure. Scenarios manipulating the perceived ability and effort of the fictitious applicant, low/high ability and low/high effort, were presented to recruiters and they were asked to make judgments of future job performance, responsibility for the failure, and the likelihood of making a hiring recommendation. Consistent with Weiner's (1985) attribution theory in performance settings, the fictitious applicant's perceptions of ability and effort correlated with the recruiter's expectations of future job performance, responsibility for failure, and whether or not they received a hiring recommendation. The results of the study indicate that following a performance error, camera operators perceived to have high levels of both ability and effort are the most likely to receive a future hiring recommendation. Camera operators receiving low evaluations in both ability and effort are expected to receive low ratings of future hiring 
recommendations. How others perceive a camera operator's ability and effort is expected to influence the hiring recommendations they provide for that camera operator.

Adding to the body of research specific to the attributions of ability and effort in performance settings, Taggar and Neubert (2008) explored attributions of free-riders in group settings, with group members evaluating other's task performances. In a group setting, Taggar and Neubert found that individuals were judged most harshly if they were seen by their peers as having high ability, but lacking effort when contributing to the team. And, group members low in both ability and effort, were judged significantly more positive than the members from the high ability and low effort condition. Consequently, it seems reasonable to conclude that peers working in live sports broadcasting will judge individuals perceived as having high ability and low effort more harshly than individuals perceived as low in both ability and effort.

\section{Research Questions and Hypotheses}

As the literature has shown, there are a multitude of variables which appear to influence the causal attributions live sports production personnel make regarding other's task performance errors. While all of the potential variables could be explored across multiple studies, there are too many variables to be addressed in a single study. As such, two of the possible factors were selected as the independent variables in the present study: the camera operator's relationship with the director and the camera operator's known fatigue level.

Beginning with the relationship of the director and the camera operator, the literature indicates that certain social perceptions influence performance attributions (Nieminen et al., 2013). However, it is unclear how, or if, the relationship of the camera operator and the director will influence participants causal attributions of a task performance error in a live sports production. 
$\mathrm{RQ}_{1}$ : Will the perceived type of relationship (close or distant) between a camera operator and a director result in significant differences in attributions of a camera operator's (a) ability, (b) effort, (c) luck, and (d) task difficulty?

While the influence of the relationship between the camera operator and the director is unclear, the literature strongly indicates that the camera operator's fatigue level, a situational factor, is unlikely to have a significant impact on the causal attributions participants make.

$\mathrm{H}_{1}$ : Knowledge of a camera operator's fatigue will not result in significant differences in attributions of the camera operator's (a) ability, (b) effort, (c) luck, or (d) task difficulty. As the two variables, relationship type and fatigue, have never been tested in a live sports production task performance setting, it is unclear if there will be any interaction effects between them. Of the four possible combinations, there may be interaction effects that occur in certain combinations.

$\mathrm{RQ}_{2}$ : Will there be any interaction effects between the relationship type and the operator's fatigue level when making attributions of a camera operator's (a) ability, (b) effort, (c) luck, and (d) task difficulty?

In addition to general interaction effects of the variables, there may be categorical differences which yield significant results. Specifically, differences in the attributions between the camera operators and directors who participate in the study. Each category of participants brings their own unique set of experiences and perspectives to the study, and those categorical differences may be seen in the attributions they make.

$\mathrm{RQ}_{3}$ : Will camera operators and directors make significantly different attributions of a camera operator's (a) ability, (b) effort, (c) luck, and (d) task difficulty? 
The technical literature indicates the task performance error utilized in the present study is an important failure for a camera operator. Numerous real-life experiences have supported the literature and shown this type of performance error is capable of generating appreciable responses from those within the live sports production community. However, it is unclear how variations in the participants' perceptions of importance may, or may not, influence their perceptions of causal attributions. A research question is being proposed to examine possible correlations between the importance of the mistake and the causal attributions participants make. $\mathrm{RQ}_{4}$ : Will perceptions of importance have a significant effect on attributions of a camera operator's (a) ability, (b) effort, (c) luck, and (d) task difficulty?

One of the potential links between the scholarship of the present study and the broadcast industry is the examination of how attributions might affect the future hirability of a camera operator. Perceptions of ability and effort have been previously shown to determine future hiring recommendations in other situations (Carless \& Waterworth, 2012). However, in the present study the perceptions of ability and effort were not directly manipulated by the independent variables as they were in the previous studies. In addition, previous research has not been applied to live sports production communities. As a result, attributions of ability, effort, luck, and task difficulty, and their influence on future hiring recommendations, are posed as research questions in the present study.

RQ5: Will the internal attributions of (a) ability and (b) effort predict future hiring recommendations?

RQ6: Will the external attributions of (a) luck and (b) task difficulty predict future hiring recommendations? 
While the frequency of task performance errors, similar to the one used in the present study, is expected to be low, there may be a correlation between perceptions of error frequency and attributions of the camera operator's task difficulty. Participants who perceive the scenario as a frequent occurrence, may attribute the camera operator's performance as a difficult task; as evidenced by the fact that they believe this to happen on a frequent basis to other camera operators and therefore it must be a difficult task if it occurs frequently with many operators. Those participants who perceive the task performance error as a very rare occurrence will likely perceive the task difficulty to be lower. They may reason that if the error rarely occurs, then the task is likely not very difficult because many other operators were able to perform the same task without frequent errors.

$\mathrm{H}_{2}$ : The perceived frequency of the task performance error will predict attributions of task difficulty.

The literature indicates that following a task performance error, as participants' perceptions of task difficulty increase, attributions of both ability and effort will also increase. Participants reason that a failure at a difficult task is not the result of someone's ability or effort, because many others have failed at the same task. Rather, the difficult task itself explains the failure. Conversely, when the task difficulty is perceived as being low, perceptions of ability and effort will also be low; as participants reason that when someone fails at a relatively simple performance task, where others tend to succeed, the failure is probably due to the person's lack of ability and effort.

$\mathrm{H}_{3}$ : Attributions of task difficulty will show a positive relationship with the internal attributions of (a) ability and (b) effort. 


\section{CHAPTER III: METHOD}

The aim of the present study was to design a research study based on previous attribution research as applied to the field of live sports communication. This chapter will articulate the methodology, decisions, and research design of the study.

\section{Participants}

Participants for the present study were recruited from among the broadcast sports production community. Initially, email invitations were sent to 90 personal contacts in the broadcast sports production community. Following email invitations, the author created two social media posts on Facebook inviting individuals from the broadcast sports community to contact the author if they were interested in participating in a study regarding perceptions of whip pans and snap zooms. Finally, some participants asked for the survey to be sent to them via SMS text message. In those situations, the author sent a text with a link to the survey directly to the participant. All participants were asked to complete the survey and then forward it to others in the broadcast sports production community. In this way, a snowball sampling technique was utilized.

In total, 84 participants completed the study. Of those who reported their gender, 70 were male and five were female. The average age of participants was 46.3 years $(S D=14.34)$. Seventy participants identified themselves as working in broadcast sports, with an average experience level of 23.61 years $(S D=12.56)$. Within that group, 32 participants identified themselves as having some experience as a broadcast sports director, with an average of 9.91 years of experience $(S D=10.93)$. Sixty-seven participants identified themselves as having some experience as a broadcast sports camera operator, with an average of 17.76 years of experience 
$(S D=12.76)$. Twenty-nine participants identified themselves as having professional experience as both a director and a camera operator.

Because this study investigated live sports broadcasts, also known as remote productions, categorical data were collected about participants roles on a production and the type of sports they typically cover when working on a remote production. Only three participants, of the 76 who answered, identified themselves as not working on remote productions. The majority of the participants identified as remote-technical personnel $(n=40)$, followed by remote-production personnel $(n=31)$ and remote-other personnel $(n=2)$. Remote-technical would include positions such as camera operator, tape operator, T.D., video, or other similar position. Remote-production would include positions such as director, producer, talent, or other similar position. Remote-other would involve positions such as truck maintenance personnel, or logistics support positions. In total, $96.0 \%$ of the participants in the present study identified themselves as working on a remote production in some capacity, with a relatively even distribution between technical and production personnel. In addition to asking participants about their categorical role on a remote production, participants were asked to identify the type of sports broadcasts they work on during a typical year.

Nearly all participants identified themselves as covering some type of sporting event. Of the 84 participants whose data, or some portion of the data, were used in the overall study, eight participants did not answer the type of sports productions they typically work. Of the remaining 76 participants, $97.3 \%$ indicated they typically work in some form of live sports broadcasts, with only two participants not selecting a specific type of sport from the options available. Participants were asked to select which sports they frequently covered, with the option of selecting more than one sport. The most common sports covered by the participants were 
American football $(n=63)$, basketball $(n=62)$, baseball $(n=44)$, soccer $(n=33)$, motorsports $(n$ $=33)$, and hockey $(n=24)$. Only five participants indicated they cover only a single sport throughout the year, with four of those participants selecting motorsports and one participant selecting football as the single sport they cover. All other participants selected more than one sport.

Additionally, to understand the production level participants worked at, they indicated if they typically worked at an international, national, regional, or local level. Participants indicated they typically work on national $(n=43 ; 51.2 \%)$, regional $(n=23 ; 27.4 \%)$, or international $(n=$ $6 ; 7.1 \%)$ level of broadcast production work. Only four participants (7.1\%) indicated they worked at a local level of broadcast sports productions. Eight (9.5\%) participants did not indicate the level of production they typically work on. Holistically, the participants in the present study came from both technical and production backgrounds, had experience working on different types of broadcast sports productions, and worked on productions at the national or regional level.

\section{Procedures}

Participants were asked in an email, text message, or social media message to follow a link to a university-hosted webpage with the informed consent message. Upon clicking their agreement to the informed consent, participants were randomly assigned and automatically rerouted to one of four survey conditions hosted on the Qualtrics survey software platform. The four surveys represented each of the four conditions of the independent variables in the study: known fatigue/close relationship, unknown fatigue/distant relationship, unknown fatigue/close relationship, and unknown fatigue/distant relationship. A roughly equal number of participants completed each condition. Within the surveys, participants read a short scenario and then 
watched a 31-second video clip embedded into Qualtrics via YouTube. After watching the video, participants were then asked to complete a 56-item questionnaire.

A scenario-based questionnaire and short integrated video were chosen as the most appropriate procedures for the present study. Kassin and Baron (1985) found that questionnaires that present the survey participant with scenarios have so far been an effective method of testing and proving attribution theory. Additionally, Borman (1978) called for rating scales to be formatted in ways that the raters were familiar with and do not require the raters to make judgments outside of their area of expertise. Because the participants work in the broadcast sports television industry, a broadcast sports video clip similar to what they would encounter in their work environment was chosen as the example of a task performance error.

\section{Scenarios}

Four fictitious scenarios were written to establish the working conditions leading up to the task performance error by the camera operator from the real-life broadcast perspective. The scenarios were designed to manipulate the relationship between the camera operator and the broadcast director using language with which the survey participants would likely be familiar.

The first independent variable that was manipulated involved the relationship between the director, James, and the camera operator, Troy. The names James and Troy were chosen as pseudonyms. In the close relationship scenario, their relationship was described as being close and it was said that the director sought advice from the camera operator as well as requested that specific camera operator to work with him on other shows. In an effort to avoid a performance trend bias (Rudolph et al., 2015) and isolate the relationship between the camera operator and the director, the camera operator's performance during past broadcasts was not mentioned. In the distant relationship scenario, the relationship between the director and the camera operator was 
described as confrontational. Phrases such as "struggled to get along," "different ideas," "nothing in common," and "doesn't like working with" were used to describe the relationship in the distant condition. Again, in an effort to avoid a performance trend bias, care was taken to avoid any mention of how the camera operator performed during past broadcasts with the director.

Manipulation of the fatigue variable occurred through a fictitious backstory presented in the scenarios. In the backstory, the camera operator, Troy, was said to be arriving directly from another show; a scenario which was likely familiar to the survey participants, in that such travel is known to be fatiguing because the final show day of the operator's previous broadcast would have been a long work day followed by a couple hours of taking down the equipment. After the long show day, the operator would probably only have had a few hours of sleep before catching an early morning flight to the show he was currently working. In addition to coming from another show, the production setup for the current show was described as being particularly difficult. The crew was said to have problems with the radio frequency (RF) cameras, or wireless cameras, as well as being required to work late into the night to move a camera position. The late night work was followed by an early crew call on the day the task performance error was said to occur. To enhance the perception of fatigue, the operator was described as already having shot several shows prior to the one where he made the task performance error. The scenario presented a number of fatiguing situations that are believed to be common to broadcast sports production personnel. In the fatigue unknown condition, the backstory was left out of the scenario and the survey participant was simply told that the camera operator showed up for the broadcast in Moscow.

The combination of the two variables, with two scenarios each, created a total of four conditions to be tested. Across the conditions, 18 participants completed the Close Relationship- 
Fatigue Known condition, 20 participants completed the Distant Relationship-Fatigue Known condition, 16 participants completed the Close Relationship-Fatigue Unknown condition, and 16 participants completed the Distant Relationship-Fatigue Unknown condition.

\section{Video Selection}

Selection of the video for the present study required a thorough examination of many sporting events. The specific parameters of the study were that first, the task performance error had to occur on a broadcast sports production being sent out to a national or international audience. To ensure ecological validity, regional based broadcasts were excluded from consideration, but live Internet streams with a worldwide audience were included. Second, the task performance error had to occur soon after the director cut to the camera that made the task performance error. A task performance error that occurs just after a cut adds ambiguity to the situation and allows for additional causal attributions to be made by the observers. Finally, the task performance error had to be a clear error that would be obvious even to a lay viewer of the content. This ensured that all participants, regardless of position and years of experience, would be able to make attributions of why the mistake occurred.

With those requirements in place, a search was undertaken to find a previously aired sports broadcast that was now accessible to the public as an online archive. Archival broadcast footage was found on the video hosting site YouTube and downloaded directly to an external hard drive using a video download software program. While task performance errors are generally difficult to find in top-level broadcast sports productions, one that meets all of the requirements is even more difficult to locate. As such, video editing techniques were employed to speed up the search process. Once downloaded, the clips were imported into a video editor and placed on a timeline where they could be viewed at four times the normal playback speed. When 
performance errors were found, the video editor allowed for quick rewinding of the footage to confirm if the content met all of the requirements. At least 20 sports broadcasts were examined in full or in part before finding a performance error that met all of the studies requirements.

The clip eventually chosen for this study came from a July 2017 motorsports broadcast in Moscow, Russia. The footage begins with a tight shot of a man's hand, with his palm flat and facing upward. The camera operator, running what is known as a "pit camera," then widens out to reveal a Red Bull Gran Touring (GT) style race car in a covered garage area. The director then cuts to a second pit camera that has a tight shot of a pit board in the foreground and a silver Mercedes GT race car in the background. The camera operator then makes a somewhat fast zoom into the driver of the Mercedes car, which immediately begins to leave the garage and the camera operator is left struggling to keep up and focus their soft image as the car pulls away down pit lane. The director then cuts to the camera in the Red Bull garage. Immediately following the cut, the camera operator in the Red Bull garage "snap zooms" out from a tight shot of the garage wall to a full wide shot of the car and the garage space. When the snap zoom happens, the entire image becomes blurred until the operator is fully zoomed out. The full video clip is available at https://youtu.be/N3JM33FjIsc.

The operator's snap zoom, which exemplifies a task performance error, occurred three frames after the cut was made to the camera in question. Three video frames equals a 100 millisecond delay from the time the camera image was first seen until the time of the task performance error. According to Michotte (1963), 100 milliseconds falls within the window of ambiguity and participants could perceive the camera mistake in three ways: as a direct result of the switch to that camera, as a delayed result of switching to that camera, or they could perceive the task performance error as an isolated from the switch to that camera. In the direct and 
delayed conditions, attributions for fault could be placed on either the camera operator who made the error, or the director who made the cut. In those cases, it is expected that participants will make higher attributions of luck. Those participants who perceived the camera operator's error to be unassociated with the timing of the director's cut are expected to attribute responsibility solely to the camera operator through lower attributions of luck.

\section{Survey Format}

Two versions of the survey were posted for participants to take, the difference being how the video displayed to the participants. When the survey launched, the university had not yet provided authorization for YouTube videos to played as embedded content as part of the survey. As such, participants who agreed to the informed consent would read through their randomly assigned condition and then click on a URL link that would open the video file in a separate browser window. After watching the video, participants were required to either close the window with the video file, or click back into the window with the survey. In either case, participants would then complete the survey questions.

While the initial survey was being distributed, the university authorized the video to be embedded directly into the Qualtrics survey. Once the authorization was given a second, duplicate survey was posted, and the new link was distributed from that point on to participants. Because the survey relied on a snowball sampling technique, both versions of the survey kept active and available to the participants during the data collection period. The two versions of the survey were coded to identify which version of the survey a participant took. The two versions were then tested for any significant differences, but none were found. The testing procedures and the findings are detailed in the next chapter. 


\section{Measures}

\section{Observer Attributions}

Observer attributions of performance were captured using MOAPS, a 24-item scale, developed by Rutherford, Harari, and Rudolph (2013) and implemented by Rudolph et al. (2015). The four attribution characteristics of ability (stable-internal attribution), effort (unstableinternal attribution), task difficulty (stable-external attribution), and luck (unstable-external attribution) were captured using six survey items per attribution. Participants answered all questions using Likert-type responses ranging from 1 (Strongly Disagree) to 7 (Strongly Agree). Items were modified from the original scale to read "Troy's performance...," which matches the name of the camera operator in the conditions provided to the participants. Items in each attribution category were then summed and averaged to create aggregate subscale scores. Higher mean scores on a subscale indicate a participant attributed more of the camera operator's performance to that factor. Rudolph et al.'s (2015) two-study design, where the scale was originally applied, reported confirmatory factor analysis showing the MOAPS scale had produced clean factor loadings for each of the four MOAPS subscales as well as acceptable reliabilities $($ Ability $=.92$ and .88, Effort $=.91$ and .86 , Task Difficulty $=.94$ and .96 , and Luck $=.94$ and .96). The internal consistency reliability estimates, found in the present study, for the subscales were also acceptable (see Table 1).

\section{Importance Scales}

Four scales, created for this study, measured observers' perceptions of the importance of the task performance error. Each scale consisted of three items, which collectively measured perceptions of importance to the Director $(\alpha=.80)$, the Camera Operator $(\alpha=.76)$, the Production Crew $(\alpha=.67)$, and the Viewing Audience $(\alpha=.82)$. The questions were arranged on 
Likert-type scales with response options ranging from 1 (Strongly Disagree) to 7 (Strongly Agree) or from 1 (Not at all Important) to 7 (Very Important). Exploratory factor analysis (EFA) was run for each of the four scales.

Table 1

Descriptive Statistics and Reliability Estimates for Ability, Effort, Task Difficulty, and Luck

\begin{tabular}{lcccc}
\hline Scale & $n$ & $M$ & $S D$ & $\alpha$ \\
\hline Effort & 81 & 4.23 & 1.33 & .84 \\
Ability & 81 & 4.19 & 1.41 & .88 \\
Task Difficulty & 84 & 4.44 & 1.45 & .93 \\
Luck & 79 & 4.53 & 1.31 & .87 \\
\hline
\end{tabular}

Note. Subscales were composed of six items in each scale.

Importance to crew. The EFA procedure for the perceived importance of the mistake to the rest of the production crew provided an acceptable one-factor solution. Both the KMO measure (.630) and Bartlett's test $\left[\chi^{2}=38.887(3), p<.001\right]$ were acceptable. The single-factor solution, consisting of three items, explained $45.19 \%$ of the variance with a 1.35 eigenvalue. See Table 2 for factor loadings.

Importance to viewing audience. Like the importance to the crew scale, the EFA for the scale measuring the importance of the mistake to the viewing audience provided an acceptable single-factor solution. Both the KMO measure (.700) and Bartlett's test $\left[\chi^{2}=87.824\right.$ (3), $p<$ 
$.001]$ were acceptable. The one-factor solution, consisting of three items, explained $62.57 \%$ of the variance with a 1.87 eigenvalue. See Table 3 for factor loadings.

Table 2

Factor Loadings for Importance to Production Crew Scale

\begin{tabular}{ll}
\hline Survey Item & Loading
\end{tabular}

25. Overall, how important is Troy's performance to the rest of the WTM production crew.

27. In general, Troy's performance is significant to the rest of the WTM production crew.

26. Troy's performance probably isn't significant to the rest of the WTM production crew. [recoded]

Note. Underlined factor coefficients indicate acceptable loadings.

Importance to the camera operator. The EFA procedure on the importance to the camera operator scale provided an acceptable one-factor solution. Again, both the KMO measure (.697) and Bartlett's test $\left[\chi^{2}=60.361(3), p<.001\right]$ were acceptable. The single-factor solution, consisting of three items, explained $53.45 \%$ of the variance with a 1.60 eigenvalue. See Table 4 for factor loadings.

Importance to director. Another EFA procedure tested the importance to the director scale. Once again, an acceptable one-factor solution resulted. Both the KMO measure (.676) and 
Bartlett's test $\left[\chi^{2}=85.768(3), p<.001\right]$ were acceptable. The single-factor solution, consisting of three items, explained $61.56 \%$ of the variance with a 1.84 eigenvalue. See Table 5 for factor loadings.

Table 3

Factor Loadings for Importance to Viewing Audience Scale

\begin{tabular}{ll}
\hline Survey Item & Loading
\end{tabular}

30. In general, Troy's performance is significant to the viewers at home watching $\underline{.893}$ the WTM broadcast?

28. Overall, how important is Troy's performance to the viewers at home watching .762 the broadcast.

29. Troy's performance probably isn't significant to the viewers at home watching $\underline{.706}$ the WTM broadcast. [recoded]

$\begin{array}{rr}\text { Eigenvalue } & 1.87 \\ \text { \% of Variance } & 62.57 \\ & .82\end{array}$

Note. Underlined factor coefficients indicate acceptable loadings.

\section{Future Hiring Recommendations}

A single scale consisting of four items was created to measure participant expectations of future hiring recommendations. Participants were asked how likely the director, other camera operators, other crew members, and themselves would be to recommend Troy, the camera operator, for future work on other shows. The response options ranged from 1 (Not Likely) to 7 (Very Likely). An EFA was run and an acceptable one-factor solution resulted. Both the KMO 
measure (.846) and Bartlett's test $\left[\chi^{2}=235.266(6), p<.001\right]$ were acceptable. The single-factor solution, consisting of three items, explained $80.41 \%$ of the variance with a 3.21 eigenvalue. The scale had an overall alpha coefficient reliability of .90 , which was a very good reliability (see Table 6).

Table 4

Factor Loadings for Importance to the Camera Operator Scale

Survey Item $\quad$ Loading

33. In general, Troy's performance is significant to him. .781

31. Overall, how important is Troy's performance to Troy, the camera operator.

32. Troy's performance probably isn't significant to him. [recoded]

$\begin{array}{cr}\text { Eigenvalue } & 1.60 \\ \text { of Variance } & 53.45\end{array}$

Cronbach's alpha .76

Note. Underlined factor coefficients indicate acceptable loadings.

\section{Frequency of Task Performance Error}

A single scale consisting of three items was created to measure the perceived frequency of the task performance error seen in the sample video. Response options ranged from 1 (Strongly Disagree) to 7 (Strongly Agree). Through iterative EFA procedures, survey question 45 was eliminated due to a low primary factor loading. In a final EFA procedure, questions 43 and 
44 loaded at acceptable levels as a two-item scale $(\alpha=.71)$. Both the KMO measure (.500) and Bartlett's test $\left[\chi^{2}=28.369(1), p<.001\right]$ were acceptable. See Table 7 for factor loadings.

Table 5

Factor Loadings for Importance to the Director Scale

Survey Item $\quad$ Loading

34. Overall, how important is Troy's performance to James, the director.

36. In general, Troy’s performance is significant to James, the director.

35. Troy's performance probably isn't significant to James, the director. [recoded]

Note. Underlined factor coefficients indicate acceptable loadings.

\section{Manipulation Checks}

Questions 41 and 42 served as manipulation checks for the independent variables.

Question 41 asked participants how fatigued they perceived the camera operator to be, with response options ranging from 1 (Not at all Fatigued) to 5 (Very Fatigued). Question 42 asked participants to rate the type of relationship between the camera operator and the director, with response options ranging from 1 (Distant) to 5 (Close). 
Table 6

Factor Loadings for Recommendation of Future Hirability Scale

Survey Item

Loading

40. How likely are the other WTM production crew members to recommend Troy

$\underline{.925}$

for work on another show?

39. How likely are the other WTM camera operators to recommend Troy for work on another show?

38. How likely would you be to recommend Troy for work on another show?

37. How likely is James, the director, to recommend Troy for work on another show?

Eigenvalue

$\%$ of Variance

80.41

Cronbach's alpha

.90

Note. Underlined factor coefficients indicate acceptable loadings.

Table 7

Factor Loadings for Perceived Frequency of Mistake

Survey Item

Loading

44. This kind of camera mistake is unusual in live sports productions. [recoded] .754

43. This type of camera mistake occurs frequently in live sports productions.

Eigenvalue $\quad 1.56$

$\%$ of Variance

78.45

Cronbach's alpha

Note. Underlined factor coefficients indicate acceptable loadings. 
To conduct the manipulation check of the fatigue known and unknown conditions, an independent samples $t$-test was conducted. The Levene's test for variance was not significant ( $F$ $=1.27, p=.26$ ), so equality of variances was assumed. A significant difference was found between the condition types, $t(73)=4.66, p<.01,95 \% \mathrm{CI}[.46,1.16]$. Confidence intervals $(\mathrm{CI})$ should be interpreted as meaningful when a zero does not appear between the lower and upper bound CI's. Participants' scores in the fatigue known condition $(M=4.18, S D=.68)$ were significantly higher than participants' scores in the fatigue unknown condition $(M=3.36, S D=$ $.83)$.

A second independent samples $t$-test was conducted to check the manipulation of differences between the relationship conditions. The Levene's test for variance was not significant $(F=2.60, p=.11)$, so equality of variances was assumed. A significant difference was found between the condition types, $t(73)=14.19, p<.01,95 \%$ CI $[2.22,2.95]$. Participants' scores in the close relationship condition $(M=4.32, S D=.66)$ were significantly higher than participants' scores in the distant relationship condition $(M=1.74, S D=.89)$.

\section{Survey Type}

To test for differences between the two types of survey used in the present study, a series of 10 independent samples $t$-tests were run. The $t$-tests compared the mean scores for the following scales: attributions of effort, ability, task difficulty, and luck, frequency of the mistake, hiring recommendation, and the importance to the crew, viewers, camera operator, and director. Results showed no statistically significant differences between the two versions of the survey for any of the variables. 


\section{Open-ended Questions}

Two open-ended questions were included in the survey. Question 46 asked participants to describe how they would react to the same task performance error if they were the director of the show and Question 47 asked participants to express in their words why they believed the task performance error had occurred. The responses to these questions will be analyzed in a separate research report.

\section{Descriptive Statistics}

Descriptive statistics were also collected. In their respective order, categorical information included: years of overall television experience, years as a camera operator and/or director, primary type of production work, audience reach of normal production work, sports covered, role within the organization, gender, and age.

\section{Data Analysis}

To examine the effects of relationship type and fatigue on observer attributions of ability and effort, a multivariate analysis of variance (MANOVA) was conducted, with the four dependent variables being the observer attributions of ability, effort, task difficulty, and luck. The MANOVA was also used to examine possible interaction effects between the conditions and the attributions participants made. The MANOVA was followed by an analysis of covariance (ANCOVA) which examined the effects of the conditions, through MOAPS, on the future hiring recommendations the participants made. The purpose of the design, and testing the conditions directly on future hiring recommendations, was to provide more distinct numerical differences between the dependent variables, making potential interaction effects within the independent more easily identifiable and interpretable. 
Four simple regression tests were calculated to predict attributions of ability, effort, luck, and task difficulty based on the perceived importance of the performance error. Additionally, four simple regressions were run to predict the same four attributions based on the perceived frequency of the task performance error. A multiple linear regression was conducted to predict future hiring recommendations based on the internal attributions of ability and effort. To test if the external attribution of task difficulty would have a positive correlation with the internal attributions of ability and effort, two simple regressions were run. 


\section{CHAPTER IV: RESULTS}

\section{Tests of Differences}

\section{MANOVA Results}

The first research question asked if the relationship with the director would significantly influence attributions. RQ1 found that attributions of ability were only influenced by the relationship type (close vs. distant) when the fatigue of the camera operator was unknown. In all other conditions, and across all other attributions, the relationship with the director was not found to have a significant influence on attributions.

The MANOVA testing RQ1 included the four randomly assigned conditions (close relationship/fatigue know, distant relationship/fatigue known, close relationship/fatigue unknown, distant relationship/fatigue unknown) as the independent variables. The dependent variables were attributions of Effort, Ability, Task Difficulty, and Luck. Homogeneity of variance-covariance was found, as assessed by Box's Test of equality of covariance $F(30$, $12795.08)=1.52, p=.03$. Descriptive statistics from the MANOVA are shown in Table 8 .

The multivariate model was shown to be significant (Pillai's trace $=.324, F(12,213)=$ $\left.2.15, p=.01, \eta^{2}=.09\right)$. The univariate analysis of Ability was statistically significant $(F(3,72)=$ $\left.2.88, p=.04 ; \eta^{2}=.11\right)$ across one of the conditions, while attributions of Effort $(F(3,72)=1.74$, $\left.p=.16 ; \eta^{2}=.07\right)$, Task Difficulty $\left(F(3,72)=2.28, p=.08 ; \eta^{2}=.09\right)$, and Luck $(F(3,72)=2.26$, $\left.p=.08 ; \eta^{2}=.09\right)$ showed no statistically significant differences across the conditions. When the fatigue of the camera operator was unknown, the attributions of the camera operator's ability in the close relationship condition $(M=4.78, S D=1.39)$ were significantly higher than the attributions of the camera operator's ability in the distant relationship condition $(M=3.55, S D=$ 1.37). 
Table 8

Descriptive Statistics for the MANOVA

\section{Attribution}

\begin{tabular}{|c|c|c|c|c|c|}
\hline & & Effort & Ability & Task Difficulty & Luck \\
\hline Condition & $n$ & $\begin{array}{c}M \\
(S D)\end{array}$ & $\begin{array}{c}M \\
(S D)\end{array}$ & $\begin{array}{c}M \\
(S D)\end{array}$ & $\begin{array}{c}M \\
(S D)\end{array}$ \\
\hline CR-FK & 19 & $\begin{array}{c}4.12 \\
(1.42)\end{array}$ & $\begin{array}{c}3.81 \\
(1.64)\end{array}$ & $\begin{array}{c}4.87 \\
(1.13)\end{array}$ & $\begin{array}{c}4.68 \\
(1.03)\end{array}$ \\
\hline DR-FK & 23 & $\begin{array}{c}4.27 \\
(.928)\end{array}$ & $\begin{array}{c}4.34 \\
(.985)\end{array}$ & $\begin{array}{c}4.04 \\
(1.38)\end{array}$ & $\begin{array}{c}4.27 \\
(1.26)\end{array}$ \\
\hline CR-FU & 17 & $\begin{array}{c}4.60 \\
(1.40)\end{array}$ & $\begin{array}{c}4.78 \\
(1.39)\end{array}$ & $\begin{array}{c}4.91 \\
(.931)\end{array}$ & $\begin{array}{c}4.13 \\
(1.44)\end{array}$ \\
\hline DR-FU & 17 & $\begin{array}{c}3.61 \\
(1.43)\end{array}$ & $\begin{array}{c}3.55 \\
(1.37)\end{array}$ & $\begin{array}{c}4.14 \\
(1.78)\end{array}$ & $\begin{array}{c}5.17 \\
(1.48)\end{array}$ \\
\hline
\end{tabular}

Note. $\mathrm{CR}=$ Close Relationship, $\mathrm{DR}=$ Distant Relationship, $\mathrm{FK}=$ Fatigue Known, and FU = Fatigue Unknown.

The first hypothesis predicted knowledge of the camera operator's fatigue would not significantly influence attributions of Effort, Ability, Task Difficulty, or Luck. H1 was partially supported. Attributions in the Known Fatigue condition were not significantly different from the attributions in the Unknown Fatigue condition, with the exception of attributions of luck in a Distant Relationship. In the distant relationship condition, knowledge of the camera operator's fatigue resulted in significantly different attributions of luck. The results of the MANOVA comparing the fatigue known and unknown conditions can be found in Table 9. 
Table 9

Fatigue Known and Unknown MANOVA Comparisons

$95 \% \mathrm{CI}$

\begin{tabular}{lcccccc} 
Dependent Variable & \multicolumn{2}{c}{ Conditions } & Mean Difference & $p$ & $L L$ & $U L$ \\
\cline { 5 - 6 } & CR-FK & CR-FU & -.485 & .67 & -1.61 & .64 \\
& DR-FK & DR-FU & .657 & .39 & -.42 & 1.74 \\
Ability & CR-FK & CR-FU & -.968 & .14 & -2.15 & .21 \\
& DR-FK & DR-FU & .781 & .27 & -.35 & 1.91 \\
Task Difficulty & CR-FK & CR-FU & -.034 & 1.00 & -1.21 & 1.14 \\
& DR-FK & DR-FU & -.103 & .99 & -1.23 & 1.02 \\
Luck & CR-FK & CR-FU & .547 & .59 & -.60 & 1.69 \\
& DR-FK & DR-FU & -.901 & .14 & -2.00 & .20
\end{tabular}

*Note. Results are from Tukey HSD post hoc test. CR = Close Relationship, DR = Distant Relationship, $\mathrm{FK}=$ Fatigue Known, and FU = Fatigue Unknown. $\mathrm{CI}=$ confidence interval; $\mathrm{LL}=$ lower limit, $\mathrm{UL}=$ upper limit.

As a confirmatory measure of the results, independent samples $t$-tests were run to compare the means scores between the Known and Unknown fatigue conditions in each relationship type. In the Close Relationship condition, Levene's test for variance was not found to be significant for Effort $(F=.21, p=.64)$, Ability $(F=.53, p=.47)$, Task Difficulty $(F=.30$, $p=.58)$, or Luck $(F=1.11, p=.29)$, so equal variances were assumed. Non-significant results emerged for all attributions of effort $t(37)=-.84, p=.40,95 \%$ CI $[-1.29, .53]$, ability $t(37)=-$ $1.43, p=.16,95 \%$ CI $[-1.73, .29]$, task difficulty $t(39)=.93, p=.35,95 \%$ CI [-.43, 1.19], and luck $t(36)=1.38, p=.17,95 \%$ CI $[-.25,1.34]$. 
In the Distant Relationship condition, Levene's test for variance was found to not be significant for Effort $(F=1.29, p=.26)$, Ability $(F=2.99, p=.09)$, Task Difficulty $(F=2.94, p$ $=.09)$, or Luck $(F=.55, p=.46)$, so equal variances were assumed. Non-significant results emerged for the attributions of effort $t(40)=1.97, p=.05,95 \%$ CI $[-.01,1.51]$, ability $t(40)=$ $1.46, p=.15,95 \%$ CI $[-.21,1.33]$, and task difficulty $t(41)=-.31, p=.75,95 \%$ CI $[-1.13, .82]$ Significant differences were found for the attribution of luck $t(39)=-2.08, p=.04,95 \%$ CI [$1.75,-.02]$ in the distant relationship condition, when comparing the known and unknown fatigue conditions. Participants of the unknown fatigue condition $(M=5.17, S D=1.48)$ were more likely to perceive Troy's mistake as the result of luck compared with the participants in the known fatigue condition $(M=4.28, S D=1.24)$.

\section{ANCOVA Results}

The second research question asked if interaction effects would occur between the conditions. No significant interaction effect was found between the conditions. However, in testing the research question it was found the conditions themselves significantly affected future hiring recommendations.

Based on the MANOVA results in RQ1, and the minimal differences in attributions found between the condition types, it was determined a one-way ANCOVA should be used to test RQ2. In the ANCOVA, the four, randomly assigned conditions served as the independent variables and Future Hiring Recommendations served as the single dependent variable, while attributions of Effort, Ability, Task Difficulty, and Luck were controlled for.

The ANCOVA showed a significant multivariate effect between the condition and perceptions of hiring recommendations, $F(3,62)=11.25, p<.01, \eta^{2}=.54$. A post hoc Tukey HSD test showed significant differences between the close relationship condition (fatigue known 
condition, $M=5.93, S D=.98$; fatigue unknown condition, $M=6.01, S D=1.03$ ) and the distant relationship condition (fatigue known, $M=4.31, S D=.96$; fatigue unknown, $M=4.28, S D=$ 1.20) and perceptions of hiring recommendations, independent of the known and unknown fatigue conditions. The fatigue condition was found to have no significant impact on the perceptions of hiring recommendations participants made, indicating there were no statistically significant interaction effects between the variables.

\section{Research Question Three}

The third research question asked if directors and camera operators made significantly different attributions regarding the cause of the mistake. With only three participants identifying themselves as having directing experience with no camera operating experience, RQ3 lacked an adequate number of director-only participants to make a statistically valid comparison across four conditions. As such, RQ3 could not be answered.

\section{Regression Models}

\section{Research Question Four}

The fourth research question asked if the Perceived Importance of the mistake could predict attributions of Effort, Ability, Task Difficulty, and Luck. No significant predictors were found between the importance of the mistake and the attributions participants made.

To test RQ4, four simple regressions were run, with the four Perceptions of Importance scales serving as the predictor variables and the four individual attributions of Effort, Ability, Task Difficulty, and Luck serving as the outcome variables in each regression. In all four regressions, missing cases were excluded pairwise. The descriptive statistics of the importance scales are provided in Table 10. 
The first regression investigated if the importance of the mistake could predict attributions of effort by the camera operator. While not significant, the results indicated $4.5 \%$ of the variance in attributions of effort were predicted by the importance of the mistake, $R_{\text {adj }}^{2}=$ $.011, F(4,69)=.806, p=.52$. The regression analysis of attributions of ability also showed nonsignificant results, with importance of the mistake predicting just $1.0 \%$ of the change in ability, $R_{\text {adj }}^{2}=-.047, F(4,69)=.175, p=.95$. The regression analysis of attributions of task difficulty also found non-significant findings, with the importance of the mistake predicting $3.0 \%$ of the changes in task difficulty, $R_{\text {adj }}^{2}=-.025, F(4,70)=.548, p=.70$. The final regression attempted to predict attributions of luck, and it also found non-significant findings with the importance of the mistake predicting $10.5 \%$ of the variance in attributions of luck, $R^{2}$ adj $=.051, F(4,67)=1.96$, $p=.11$.

Table 10

Descriptive Statistics of Perceived Importance Scales

\begin{tabular}{lccc}
\hline Scale & $n$ & $M$ & $S D$ \\
\hline Perceived importance to the rest of production crew & 76 & 4.57 & 1.32 \\
Perceived importance to the viewer & 78 & 3.71 & 1.64 \\
Perceived importance to the camera operator (Troy) & 78 & 6.06 & 1.04 \\
Perceived importance to the director (James) & 79 & 6.08 & 1.03 \\
\hline
\end{tabular}

Note: Importance scales were measured using Likert questions ranging from 1 (Not at all important or Strongly Disagree) to 7 (Very Important or Strongly Agree). 


\section{Research Questions Five and Six}

RQ5 asked if the internal attributions of ability and effort could predict future hiring recommendations and RQ6 asked if the external attributions of task difficulty and luck could predict future hiring recommendations. The internal attributions and the attributions of luck were not found to predict future hiring recommendations, but the task difficulty was found to positively predict future hiring recommendations.

A simple regression was run to test RQ5, with attributions of ability and effort serving as the predictor variables and recommendation to hire serving as the outcome variable. Missing data were excluded pairwise. Descriptive statistics are for hiring recommendation and attributions of ability and effort are available in Table 11.

Table 11

Descriptive Statistics for Hiring Recommendation and Effort and Ability

\begin{tabular}{lccc}
\hline Scale & $n$ & $M$ & $S D$ \\
\hline Hiring Recommendation & 78 & 5.08 & 1.35 \\
Effort & 81 & 4.23 & 1.33 \\
Ability & 81 & 4.19 & 1.41
\end{tabular}

Note: Hiring Recommendation scales were measured using Likert questions ranging from 1 (Not Likely) to 7 (Very Likely).

The first of the two regressions examined if the internal attributions of Effort and Ability could predict Future Hiring Recommendations. While not significant, the results indicated 1.5\% 
of the variance in hiring recommendations was predicted by the internal attributions, $R_{\text {adj }}^{2}=-$ $.013, F(2,72)=.539, p=.58$.

Similar to RQ5, RQ6 asked if the external attributions of Task Difficulty and Luck could predict Future Hiring Recommendations. It was found that attributions of task difficulty predicted future hiring recommendations, but attributions of luck did not. Descriptive statistics for hiring recommendations and the external attributions are provided in Table 12.

Table 12

Descriptive Statistics for Hiring Recommendation and Task Difficulty and Luck

\begin{tabular}{lccc}
\hline Scale & $n$ & $M$ & $S D$ \\
\hline Hiring Recommendation & 78 & 5.08 & 1.35 \\
Luck & 79 & 4.53 & 1.31 \\
Task Difficulty & 84 & 4.44 & 1.45 \\
\hline
\end{tabular}

Note: Hiring Recommendation scales were measured using Likert questions ranging from 1 (Not Likely) to 7 (Very Likely).

In the regression model, the external attributions of Luck and Task Difficulty served as the predictor variables and Hiring Recommendation functioned as the outcome variable. Missing cases were excluded pairwise. Results of the regression indicated $12.2 \%$ of the variance in hiring recommendations was positively predicted by the external attributions, $R_{a d j}^{2}=.097, F(2,70)=$ $4.84, p=.01$. Task difficulty was found to be a significant predictor based on an analysis of the regression coefficients, $\beta=.363, t=3.11, p=.003,95 \% \mathrm{CI}[.12, .55]$. As participants perceived the task of the camera operator to be more difficult, they were more likely to recommend the 
camera operator for future work. Attributions of luck were not found to predict future hiring recommendations, $\beta=-.117, t=-1.00, p=.32,95 \% \mathrm{CI}[-.36, .12]$. The task difficulty and luck did not produce Tolerance or Variance Inflation Factor (VIF) statistics indicating collinearity. Beta weights for task difficulty and luck are reported in Table 13.

Table 13

Beta Weights of Task Difficulty and Luck Predicting Future Hiring Recommendations

\begin{tabular}{lccc}
\hline & \multicolumn{3}{c}{ Future Hiring Recommendation } \\
\cline { 2 - 4 } Variable & $B$ & SE B & $\beta$ \\
\hline Task Difficulty & .338 & .109 & $.363 *$ \\
Luck & -.120 & .120 & -.117 \\
$R^{2}$ & & .122 & \\
$F$ & & $4.84 *$ & \\
\hline Note. $* p<.05$ & & & \\
\hline
\end{tabular}

\section{Hypothesis Two}

The second hypothesis expected the perceived frequency of the mistake to predict the attributions of task difficulty. H2 was not supported. Specifically, the frequency of the error did not predict the participants perceptions of the task difficulty.

To test $\mathrm{H} 2$, a simple regression was run with the Perceived Frequency of the mistake serving as the predictor variable and Task Difficulty as the outcome variable. Missing cases were excluded pairwise. While not being significant, the regression analysis indicated $0.2 \%$ of the 
change in task difficulty was predicted by the frequency of the mistake, $R_{a d j}^{2}=-.011, F(1,73)=$ $.178, p=.67$.

\section{Hypothesis Three}

The third hypothesis predicted attributions of task difficulty would be positively correlated with attributions of ability and effort. H3 was supported and task difficulty predicted both attributions of ability and effort.

Two simple regressions were used to test H3, with attributions of Task Difficulty serving as the predictor variable in both regressions and the outcome variables being attributions of Ability and Effort. In both regressions, missing cases were excluded pairwise. Results of the first regression indicated $18.2 \%$ of ability is predicted by the attributions of task difficulty, $R^{2}{ }_{a d j}=$ $.172, F(1,79)=17.60, p<.01$. Task difficulty positively predicted ability; as perceptions of task difficulty increased, perceptions of ability also increased. The regression coefficients indicated the task difficulty, $\beta=.427, t=4.19, p<.01,95 \% \mathrm{CI}[.21, .61]$, was a significant predictor. The tolerance and VIF statistics did not indicate collinearity. Beta weights for the regression are reported in Table 14.

A second simple regression was run to test if task difficulty would also predict attributions of effort. Results of the second regression found that $14.7 \%$ of the variance in attributions of effort were predicted by attributions of task difficulty, $R^{2}$ adj $=.136, F(1,79)=$ $13.60, p<.01$. Task difficulty positively predicted effort and as perceptions of task difficulty increased, perceptions of effort also increased. The regression coefficients indicated the task difficulty, $\beta=.383, t=3.68, p<.01,95 \% \mathrm{CI}[.16, .54]$, was a significant predictor. The tolerance and VIF statistics did not indicate collinearity. Beta weights for the regression are reported in Table 15. 
Table 14

Beta Weights of Task Difficulty Predicting Ability

Task Difficulty

\begin{tabular}{lccc}
\cline { 2 - 4 } Variable & $B$ & $S E B$ & $\beta$ \\
\hline Ability & .414 & .099 & $.427 *$ \\
$R^{2}$ & & .172 & \\
$F$ & & $17.60 *$ & \\
\end{tabular}

Note. ${ }^{*} p<.01$

Table 15

Beta Weights of Task Difficulty Predicting Effort

Task Difficulty

\begin{tabular}{lccc}
\cline { 2 - 4 } Variable & $B$ & $S E B$ & $\beta$ \\
\hline Ability & .351 & .095 & $.383 *$ \\
$R^{2}$ & & .147 & \\
$F$ & & & \\
& & & \\
& & & \\
\end{tabular}

Note. ${ }^{*} p<.01$

\section{Correlations among Variables}

Bivariate correlation tests were used to identify potential relationships between the frequency of the mistake, hiring recommendations, and the four attributions from the MOAPS scale. A very strong positive correlation was found between the attributions of effort and ability, 
$r(77)=.85, p<.01$. Task difficulty was moderately, positively correlated with hiring recommendations, $r(76)=.33, p<.01$, as well as attributions of effort $r(79)=.38, p<.01$, ability $r(79)=.42, p<.01$, and luck $r(77)=.28, p=.01$. Correlation results are presented in Table 16.

Table 16

Pearson Correlations for MOAPS Scale

\begin{tabular}{lccccc}
\hline & 1 & 2 & 3 & 4 & 5 \\
\hline FREQ & - & & & \\
REC & -.064 & - & & \\
Effort & -.042 & .105 & $.858^{*}$ & - & - \\
Ability & -.016 & .121 & $.383^{*}$ & $.427 *$ & $.283^{*}$ \\
TASK & .049 & $.330 *$ & -.069 & -.085 & \\
Luck & .282 & -.014 & & & \\
\hline
\end{tabular}

Note . FREQ = Frequency, REC $=$ Hiring Recommendations, TASK = Task Difficulty, * $=$ significant at the $\mathrm{p}<.01$ level.

A second set of bivariate correlations was run to assess possible relationships between the frequency of the mistake, future hiring recommendations, the importance of the mistake, and the experience level of the participants. A strong positive correlation was found between the perceived importance of the mistake to the viewer and the perceived importance of the mistake to the rest of the production crew, $r(74)=.71, p<.01$. A strong positive correlation was also found between the perceived importance of the mistake to the camera operator and the perceived 
importance of the mistake to the director, $r(76)=.72, p<.01$. The perceived importance of the mistake to the crew and the camera operator was moderately correlated in a positive direction, $r(73)=.27, p<.05$. A moderate positive correlation also existed between the perceived importance of the mistake to the crew and the director, $r(74)=.43, p<.01$. Another moderate positive correlation was identified between the perceived importance of the mistake to the viewer and the director, $r(76)=.32, p<.01$.

In addition to the correlations between the perceived importance measures, a moderate positive correlation was found between the number of years of experience a participant had as a camera operator and their future hiring recommendation, $r(64)=.34, p<.01$. The number of overall years a participant had in the television industry was moderately correlated in a negative direction with the perceived frequency of the mistake, $r(72)=-.26, p<.05$. Overall years of television experience also had a negative, moderate correlation with the perceived importance of the mistake to the production crew, $r(70)=-.44, p<.01$, as well as the viewers, $r(72)=-.32, p<$ .01. A strong positive correlation was also found between the participants years of experience as a camera operator and their overall years of television production experience, $r(65)=.66, p<$ .01. Correlation results are presented in Table 17. 
Table 17

Pearson Correlations for Frequency, Hiring Recommendation, Importance, and Experience

\begin{tabular}{|c|c|c|c|c|c|c|c|c|}
\hline & 1 & 2 & 3 & 4 & 5 & 6 & 7 & 8 \\
\hline FREQ & - & & & & & & & \\
\hline REC & -.064 & - & & & & & & \\
\hline IV & .130 & -.097 & - & & & & & \\
\hline IC & .127 & -.013 & $.717^{*}$ & - & & & & \\
\hline IO & -.021 & .157 & $.274 *$ & .129 & - & & & \\
\hline ID & .208 & .057 & $.431 *$ & .326 & $.729 *$ & - & & \\
\hline EO & -.233 & $.343^{*}$ & -.197 & .183 & .070 & -.072 & - & \\
\hline ED & .205 & .198 & -.073 & -.283 & -.155 & -.180 & .164 & - \\
\hline ETV & -.262 & .204 & $-.441 *$ & $-.327 *$ & .122 & -.041 & $.662 *$ & .271 \\
\hline
\end{tabular}




\section{CHAPTER V: DISCUSSION}

The present study attempted to investigate and explain, through attribution theory, why broadcast sports professionals occasionally show strong emotional reactions to certain camera mistakes they witness while watching sports broadcasts. Unlike average viewers, who tend to show no overt reactions to camera mistakes during a broadcast, when broadcast sports professionals see a task performance error by a camera operator, they sometimes react as if the performance error is a very important event. The performance errors they witness, defined as whip pans and snap zooms, are reported to occur infrequently and often under ambiguous circumstances, making causal attributions for the errors difficult. And, yet, it is not uncommon for broadcast sports professionals who see one of the mistakes to posit multiple explanations for why the mistake occurred. Clearly, camera mistakes in live sports broadcasts trigger a reaction in certain people and an interesting communication phenomenon. A camera mistake communicates a variety of meanings to those who work in the broadcast sports industry.

Attribution theory was deemed the best theoretical fit for examining the phenomena. On multiple occasions, the author had previously observed broadcast sports professionals naturally make causal attributions following performance errors by a camera operator. The study aimed to tap into an already observed characteristic of broadcast sports professionals. Additionally, attribution theory had a large body of literature specific to both performance settings and organizational setting, both of which could help guide the study. While broadcast sports professionals were a virtually undocumented group prior to the present study, attribution theory provided a clear direction for implementation of the research design. The independent variables were selected and operationalized based on the extant literature and the author's personal experience with broadcast sports productions. 
The variables chosen for examination in the present study were the fatigue of the camera operator and the relationship between the camera operator and the director of the broadcast. Fatigue was chosen because camera operators in sports broadcasting often work under physically and mentally demanding conditions. This includes long, physical hours setting their cameras, possibly multiple days in a row spending many hours operating their cameras and doing the work while away from home and traveling for both national and international sporting events. Therefore, the question was asked if professionals would change their attributions if they were aware the camera operator was fatigued at the time the operator made the mistake.

The professional literature had indicated broadcast sports directors valued their relationships with their camera operators and it was believed that a positive relationship with a trusted camera operator could help the overall broadcast (Owens, 2016b; Rose, 1999). A body of academic literature provided support that a positive, close relationship with a supervisor would result in higher performance ratings for a subordinate (Geertshuis et al., 2015; Liden \& Graen, 1980). Therefore, it was determined the second independent variable would be the relationship between the camera operator and the director. Scenarios were crafted describing a camera operator in either a close or distant relationship with their director. The descriptions of the relationships were carefully designed to avoid any mention of the camera operator's past work performance, abilities, or effort, which likely would have led to perceptions of a performance trend by the camera operator and may have influenced the participants' attributions (Rudolph et al., 2015).

In addition to testing the two independent variables, with two conditions each, scales were developed to examine the participants' perceptions of how important the mistake was, as well as how frequently participants perceived that type of mistake to occur in their own careers. 
Both the importance, and frequency, of the mistake were thought to have a measurable influence on the attributions the participants made. Another measurement scale in the research design was the participants' likelihood of recommending the camera operator for future work. In an industry where camera operators rely on the recommendations of their peers to maintain their careers, this scale was considered an important indicator of the level of reward or punishment a camera operator would receive following a task performance error. Both the independent variables and the attributions were tested with the future hiring recommendations scale. Additional categorical information collected in the survey instrument included the number of years participants had worked in television, the level of broadcasting they typically worked, and the role they generally filled on a remote sports production.

Distribution of the survey was conducted through personal emails and social media messages. The study's author, a broadcast sports professional himself, maintained a contact list of other professionals from the broadcast sports industry. Emails were sent to those professionals, inviting them to participant in the study and forward the survey to other professionals they knew in the business. In this way, a snowball sampling technique was employed to reach broadcast sports professionals, the intended target participants of the study. The study found several important findings that may add to the body of literature on attribution theory and help future research about broadcast sports professionals.

Through attributions, it was revealed that the relationship with a director may have a significant impact on a camera operator's career. A close relationship between a director and a camera operator resulted in higher ratings of the camera operator's abilities, and higher recommendations for future work. Another finding was that task difficulty served as an important contextual cue in at least two of the results. Task difficulty was shown to predict 
participants' attributions of effort and ability, as well as serve as a predictor for future hiring recommendations. As expected, the fatigue condition did not generate any effects on the attributions the participants made about the camera operator. The general frequency of the mistake and the perceived importance of the mistake were not found to be contextual cues the participants used, as neither generated meaningful effects. All of these findings appear to be in keeping with extant literature, which indicates participants use contextual cues and their own experience when making attributions (Heider, 1958; Kelley, 1973; Weiner, 1992). The results, however, raise theoretical questions about how participants make their attributions: as individuals or as members of a group.

The present study answers the call for research to be conducted from the viewpoint of those who create the content (Corner \& Roscoe, 2016; Wallace \& Hinsz, 2009). While access to the sports broadcasting community has been historically limited, the present study was able to obtain participants from both production and technical personnel working at the highest levels of sports broadcasting. Their unique, highly developed talents provided the study with a level of insight seldom found in previous research. The results are expected to hold value across all levels of broadcasting. In an industry where formal training is rarely, if ever, offered to full-time freelancers, perhaps the greatest impact of the present study will come from the educational setting - as future broadcasters are positioned to learn the information in a formal setting and apply it early in their careers, potentially using it to advance their careers and improve their production work. 


\section{Summary of Findings}

\section{Research Question One}

The first research question asked if the relationship with the director would significantly influence the attributions participants made about the camera operator. The answer to the research question was that under certain conditions, the relationship with the director might influence attributions, as attributions of ability were only found to be significantly higher in a close relationship with the director when the fatigue of the camera operator was unknown. In all other conditions, the relationship with the director did not influence attributions of the camera operator. The results seem to imply that under some circumstances, professionals may perceive a camera operator in a close relationship with their director to have higher levels of ability compared with a camera operator in a distant relationship with their director. Participants in the present study may have been using the relationship with the director as a contextual cue about the camera operator's abilities. This finding was in keeping with the literature, which indicated a high-quality relationship with a supervisor was likely to lead to higher evaluations of a subordinates' performance (Geertshuis et al., 2015; Liden \& Graen, 1980). Camera operators in close relationships with their directors appear to be perceived as having higher levels of ability.

An alternative explanation for the findings is that the participants perceived the camera operator in a close relationship with the director as more likely to make a mistake due to a lack of ability than the camera operator in a distant relationship with the director. In other words, camera operators in close relationships with their directors seemed to have less ability to perform their jobs than camera operators in distant relationships with their directors. While this explanation is certainly possible, it goes against a body of literature showing subordinates in close relationships with their supervisors receive a variety of positive benefits as a result of the 
close relationship (Chen \& Chiu, 2008; Geertshuis et al., 2015). If the alternative explanation were correct, camera operators would be at a disadvantage for developing close relationships with their directors.

Another consideration of RQ1 is the possibility of Type I or Type II errors in the data set. While attributions of ability were found to be significantly influenced by the type of relationship in the unknown fatigue condition, they showed no significant differences in the known fatigue condition. This could imply that knowledge of the camera operator's fatigue had strong enough effects to influence the relationship condition. Or, the significance in the findings in the single condition was simply a chance occurrence and the null hypothesis should have been accepted. Likewise, there may have been significant effects within the other attributions that did not surface due to a low number of participants, thus creating a Type II error situation. Both Type I and Type II errors are a possibility that should not be discounted when drawing conclusions about the results found in RQ1.

A potential theoretical implication of RQ1 is that participants may perceive the relationship between the director and the camera operator as an internal attribution, not an external attribution, as attributions of ability were found to be significantly different and ability has been conceptualized as an internal attribution. This would imply the camera operator was perceived as having internal control over their relationship with the director. Further, participants perceived the relationship with the director to be a stable trait that would last over time, as ability has been identified in the literature as a stable, internal trait (Weiner, 1995).

\section{Hypothesis One}

Hypothesis one predicted knowledge of the camera operator's fatigue would not result in significant differences in the attributions participants made about the camera operator's 
performance. H1 was found to be only partially supported. While there were no significant differences in attributions across most of the conditions, in the distant relationship condition knowledge of the camera operator's fatigue was found to significantly influence the participants attributions of luck. Participants who were unaware of the camera operator's fatigue level were more likely to attribute the mistake to luck than participants who were aware of the camera operator's fatigue level. This finding was partially in-line with the body of literature indicating external situational factors, such as fatigue, would not influence participants' performance attributions (Gilbert \& Malone, 1995; Moore et al., 2010). And yet, fatigue did influence attributions of luck in one of the conditions, raising questions about the influence of the situational factors in the study of live sports broadcasts.

The results of $\mathrm{H} 1$ could be indicating the participants were accounting for, and negating, the camera operator's fatigue level when they made their attributions of the camera operator's performance. This explanation would align with the body of literature indicating situational factors may have less of an influence on the attributions people make compared with internal factors (Moore et al., 2010). This could explain why the hypothesis was almost fully supported and only attributions of luck, in a single condition, were significant. It may also provide some partial support for the correspondence bias, which says participants do not always account for situational factors accurately, as people are either overcompensating or undercompensating for them (Gilbert \& Malone, 1995), resulting in minimal differences in the attributions people make.

However, an alternative explanation should be considered, as the results did not line up exactly with the previous literature on the correspondence bias and there was a significant finding within the results. Zaccaro, Peterson, and Walker (1987) provide a framework for an alternative explanation of the findings. They found reason to believe that in group performance 
situations, the self-serving bias is weakened, and attributions may become focused on group factors, internal or external, rather than the individual factors found in most performance studies. In the present study, the results could be in-line with Zaccaro et al.'s theoretical perspective, which posits that in cohesive groups, such as a broadcast sports production crew, contextual factors may take on additional importance in forming attributions. When a mistake occurs in a group setting, the situational factors may become stronger contextual cues in the attribution process, resulting in increased significance from those areas, as found in the results of $\mathrm{H} 1$.

Another possibility is that the study lacked a sufficient number of participants to draw strong, or accurate, conclusions from the results. The significant results attributed to luck may have simply been an artifact of Type I error. With more participants, the significant findings might disappear, thus confirming H1 fully. Similarly, there may have been findings that were significant in reality but were rejected in the study due to not enough participants to form meaningful patterns in the statistics. With so few participants across the four conditions, Type I and Type II errors are a possibility that should be considered before definitive conclusions are reached from the results.

Assuming the results of $\mathrm{H} 1$ are valid and not in error, the findings may provide some theoretical support that broadcast sports professionals generally perceive fatigue as an external, situational construct that is beyond the immediate control of the camera operator. They may perceive the camera operator's fatigue level to be a result of factors the camera operator cannot change. As a result, they may be consciously accounting for those factors and attempting to correct for them when making their evaluations. This may also indicate that professionals, while not receiving sympathy or benefits for being fatigued, will also not be penalized with lower performance evaluations as a result of being fatigued. 


\section{Research Question Two}

Research question two asked about possible interaction effects between the conditions being tested (relationship and fatigue). No support was found for RQ2, as no significant interaction effects occurred between the conditions. This could indicate the two conditions, relationship type and fatigue, are theoretically unique constructs that do not influence each other. Or, it could indicate that the combined effects of the variables were not enough to generate measurable interaction effects in the tests. In testing RQ2, it was found that the relationship with the director was correlated with future hiring recommendations of the camera operator. Camera operators in a close relationship with the director were more likely to be recommended for future work.

There are several possible explanations for why the relationship with the director was found to influence future hiring recommendations. First, the findings may be indicating the participants perceived a close relationship with the director to be an indication of higher levels of performance, and therefore the camera operator would be more likely to succeed in future work. Alternatively, professionals may have interpreted a camera operator in a close relationship with the director as more likely to be hired in the future as a direct result of the relationship, not as a result of the camera operator's performance in the clip. In that case, participants may have perceived the relationship status as having more influence on the camera operator's future work than the camera operator's actual performance. A final interpretation of the results is that the participants may have associated the relationship with the director as a performance trend, which has been shown to serve as an indication of future performance expectations (Rudolph et al., 2015). 
Research question two was originally planned to be tested using the attributions found in the MOAPS scale. However, after results from RQ1 showed minimal, non-significant differences in attributions across the conditions, it was determined the original path for testing RQ2 should be modified; as testing for interaction effects between variables would be more viable if significant differences were shown in the results. Therefore, RQ2 was tested using the relationship and fatigue conditions as the independent variables and future hiring recommendations as the dependent variable, while controlling for attributions. The adjusted testing model proved successful and significant findings appeared between the conditions: the relationship with the director was found to significantly influence future hiring recommendations. The significant results allowed for testing of interaction effects between the conditions. It was found that while each condition generated independent, main effects on the dependent variable, no interaction effects were found; meaning the two conditions were not dependent on each other.

There are also some potential explanations for why the conditions showed no interaction effects. Theoretically, it seemed plausible that the effects of one condition might be strengthened, or weakened, based on the nature of the second condition. However, if the two conditions were perceived by the participants as internal and external conditions, we would not expect to see interaction effects, as was the case in the present findings. The body of literature on attribution theory is clear that internal and external attributions are unique constructs (Moore et al., 2010; Rudolph et al., 2015; Weiner, 1995) and internal attributions should not affect external attributions. Another possibility is that the interaction effects were present, but the effects were not great enough to make a statistical difference in the measurements. 
The finding, that the close relationship condition resulted in a higher likelihood of the camera being recommended for future work, was in keeping with the previous literature on supervisor-subordinate relationships in organizations. The literature had indicated that a highquality relationship between a supervisor and subordinate would result in higher performance ratings for the subordinate (Geertshuis et al., 2015; Liden \& Graen, 1980). By extension, if the camera operator was perceived to be of a higher skill level because of their relationship with the director, they may have been seen as likely to perform at a higher level in the future. The implication of the relationship finding is that professionals may perceive the relationship with the director as an indication of stable abilities over time, therefore they are more likely to recommend them for future work. This finding would be in agreement with the findings in RQ1, which associated the relationship with the director as the stable attribution of ability. The findings in RQ2 add to the body of literature on supervisor-subordinate relationships in organizational settings.

\section{Research Question Three}

Research question three asked if the director and the camera operator would make distinct attributions regarding the cause of a mistake. RQ3 was not tested since only three participants had directing experience and no camera operating experience. RQ3 was posed because directors, being physically removed from the actual sporting environment while they direct a show, may have perceived the attributions of the operator differently than camera operators. While there was sufficient theoretical reason to ask if the two groups made distinct

attributions following a task performance error, there was simply not enough participants in one of the categories to make a comparison. 


\section{Research Question Four}

Research question four asked if the importance of the mistake could predict the attributions the participants made. RQ4 was not supported, as results found the importance of the mistake did not predict any of the attributions: effort, ability, task difficulty, or luck. The results appear to indicate professionals do not consider the importance of the mistake as a factor when making attributions regarding why a mistake occurred. Interestingly, the results seemed to indicate that a camera mistake is much more important to a director and camera operator than it is to the rest of the crew and the viewing audience.

A possible explanation for this finding is that while the importance of a mistake may be a strong trigger for generating attributions, it is likely not a good predictor of influencing attributions. Attributions are derived from a variety of contextual cues (Heider, 1958; Kelley, 1973; Weiner, 1992), and the results indicate the perceived importance of the mistake may not be one of the key contextual cues broadcast sports professionals use when making their evaluations. This makes logical sense, as attributions are related to causes of events and the importance of the mistake may have no apparent association with why the mistake occurred. In addition, this may simply indicate that professionals of different production levels all consider this type of mistake to be equally important, therefore, it did not result in significant differences in their attributions. While importance measures showed no predictive value for attributions, testing of the measures ultimately uncovered a distinct difference in the participants' perceptions of importance.

After examining the mean scores of the importance measures, a noticeable difference in the participants' perceived importance of the mistake appeared across the four scales: two of the scales produced distinctly average mean scores in importance and two of the scales were produced above-average mean scores in the perceived importance of the event. This finding 
confirmed the professional literature, which indicated this type of mistake was an important event to the camera operator (Jones, 1969a) and directors (Gross et al., 2005). Further, the correlation results showed strong, positive correlations between the importance of the mistake to the viewers and the crew, as well as the director and the camera operator. This is the first evidence of a phenomena where broadcast sports professionals may be strongly differentiating in their evaluations of performances. While they believed the mistake was very important to the director and the camera operator, they acknowledged the same mistake may have been much less important to the average viewer and the rest of the production crew. This finding, and the possible theoretical implications, could be investigated more in future research designs.

\section{Research Questions Five and Six}

Research questions five and six asked similar questions about two different groups of attributions: internal and external. Both research questions attempted to determine if participants' attributions could predict future hiring recommendations. RQ5 was not supported, while RQ6 found partial support and attributions of task difficulty were found to predict future hiring recommendations.

Research question five. RQ5 asked if the internal attributions, effort or ability, might predict future hiring recommendations. Although posed as a research question, based on previous applications of attributions theory (Struthers et al., 1998), it was expected that participants who perceived the camera operator to have high levels of ability would be more likely to recommend the camera operator for future work. The results, however, found that participants' attributions of effort and ability did not predict their future hiring recommendations. The results seemed to indicate that participants may have based their future hiring recommendations on factors other than the camera operator's perceived levels of ability and effort. This finding was in contrast to 
some of the previous research on attributions in organizational contexts, which indicated attributions of ability and effort were likely to predict the participants' future hiring recommendations (Carless \& Waterworth, 2012). Beginning with an examination of the research design used in the present study, and continuing into the discussion of research question six, there are several possible explanations for the findings.

A difference between the present study and some of the previous study designs applying attributions in organizational contexts, was that in previous studies, effort and ability were manipulated as independent variables with the intent to measure the effects of those attributions specifically on future hiring recommendations (Carless \& Waterworth, 2012). In the present study, the research design used perceptions of ability and effort as dependent variables and the study was designed to avoid overt manipulation of the effort and ability attributions. While the participants may have inferred the camera operator's effort and ability levels from the condition scenarios, as would be expected in a study of attributions, effort and ability were not specifically mentioned in the scenarios. Recall, one of the aims of the study was to examine the effects of the relationship with the director. Based on the review of literature, there was theoretical reason to believe that manipulating the camera operator's perceived effort and ability in the scenarios may have moderated or mediated the effects of the relationship condition. An additional concern was that the relationship with the director was described in the scenarios as occurring over a period of several years; therefore, mention of the camera operator's effort and ability while working with the director probably would have established a performance trend which would have likely led to influencing future hiring recommendations (Reb \& Greguras, 2010; Rudolph et al., 2015). To provide theoretical clarity of the results, and avoid a performance trend, an attempt was made to 
not directly mention the camera operator's effort and ability. With these study's design parameters in mind, we can offer these explanations of why the results may have occurred.

One of the explanations for the results found in RQ5 could be that the study design worked so well at nullifying the effects of ability and effort that it resulted in those attributions not being used to predict future hiring recommendations. If the study had been effective in eliminating all perceptions of a performance trend, participants may have had no clear contextual cues of the camera operator's ability and effort to make future estimations. Thus, while they could attribute the camera operator's immediate ability and effort, through the MOAPS survey instrument, lacking a performance trend, they may have been uncertain of how the operator would perform in the future. While this explanation is possible, it would go against the body of literature indicating the participants were capable of making valid attributions of both ability and effort from a single instance, then making future estimations of performance based on the attributions they made (Hewstone, 1983). Because ability is conceptualized in the literature as a stable, internal trait, ability is expected to remain consistent in the future (Weiner, 1992). Therefore, participants should have been able to provide an estimation of the participants' future hiring recommendation based on their attributions of the operator's performance.

Another possible explanation for the findings in RQ5 is that attributions of ability and effort actually did predict future hiring recommendations, but the effects were so small they could not generate a statistically significant difference in the findings. While plausible, this explanation would also be contrary to the body of literature on attributions, which indicates that in terms of effect size, ability and effort generally have the greatest effect sizes (Moore et al., 2010; Struthers et al., 1998). According to past literature, we would expect the internal attributions to generate statistically significant effects and the external attributions to generate 
statistically non-significant effects, yet the exact opposite results were found in the present study, as RQ6 showed significant results. Together, RQ5 and RQ6 seem to indicate there is another explanation for the findings, one which may not have been mentioned in some of the previous attribution literature.

Likely, the most plausible explanation for the results of RQ5 is that the statistical analysis was correct: broadcast sports professionals are probably not relying on the internal attributions of ability or effort when they make estimations of their peers' future hirability. Examining the design of the present study, there are several potential reasons why this is the most plausible explanation for the findings. The first reason begins with a discussion about the participants of the present study.

While the number of research studies utilizing undergraduate students as participants has historically been high in psychology (Wintre, North, \& Sugar, 2001) and the social sciences (Henrich, Heine, \& Norenzayan, 2010), the present study asked professionals in broadcast sports to participate in the research. The categorical data showed the participants in the present study had more than 23 years of average experience working in television. With such veteran broadcasters, it is possible they may perceive their peers working at a high level in their industry as having relatively equal amounts of ability; thus, discounting attributions of ability as a determining factor for how much future work a camera operator may receive. Recall, the camera operator in the scenario was described as a veteran camera operator with 15 years of experience, likely enough experience to be considered a veteran in the broadcast sports industry. Participants may have intuitively deduced that a camera operator could not maintain a career, at that level, for 15 years if the camera operator did not have at least a relatively equal amount of ability to that of their peers; as those who lack ability in broadcast sports typically do not advance to the higher 
levels of broadcasting, as they are simply not asked to work again and thus forced to pursue careers in other areas.

While this line of reasoning rests on the assumption that professionals may be using a different set of contextual cues when they evaluate veteran camera operators, compared with when they evaluate novice camera operators, it offers an explanation of the findings in the present study. This explanation is also in-line with previous research on group attributions, which has identified that, within group contexts, attributions of performance errors do not function the same way as individual's attributions and within group settings external attributions may be used to explain performance failures (Zaccaro et al., 1987).

In addition, as mentioned in the review of literature, Feldman (1981) found evidence that participants may categorize people prior to making their evaluations of them. RQ5 may be an example of this categorizing taking place. As noted, participants may have read the contextual cues, that the camera operator is a veteran of 15 years and placed the camera operator into a category of ability and effort prior to making their attributions. This is a form of the correspondence bias (Gilbert \& Malone, 1995), as the attributions derived from the categorical placement are biased.

Taken holistically, the implication is that because of the participants' tacit knowledge, the camera operator's ability and effort levels may not have been consciously considered when the participants estimated the operator's future hirability. The participants in the present study likely used contextual cues other than ability or effort to make their evaluations. This leads us to an examination of the results found in research question six.

Research question six. RQ6 asked if the external attributions of task difficulty or luck could predict future hiring recommendations for a camera operator. Task difficulty was found to 
predict future hiring recommendations, but luck was not. That luck was not a statistically significant predictor of future hiring recommendations was not an unexpected finding (Wallace \& Hinsz, 2009). However, that task difficulty predicted future hiring recommendations was a possibly unique finding that requires further examination. In RQ6, the more difficult a participant perceived the camera operator's task, the more likely they were to recommend the operator for future work following a task performance error. Together with the findings in RQ5, the results of RQ6 seem to indicate that established broadcast sports professionals may rely on task difficulty as a key predictor when estimating a veteran camera operator's future hirabilty.

One of the possible explanations for the findings in RQ6 was identified in RQ5: the participants in the present study were experienced broadcast sports professionals and therefore, they may have used contextual cues unique from those identified in the previous attribution literature. In this case, they appear to have used the perceived difficulty of the camera position to predict future hirability. While the literature on attributions in individual contexts discounted the potential effects of the external attributions (Gilbert \& Malone, 1995; Moore et al., 2010), Zaccaro et al. (1987) found reason to believe that the external attribution of task difficulty would indeed generate statistically significant effects on future hiring recommendations.

According to Zaccaro et al. (1987), as the actions of a group become more interdependent, it becomes more difficult for the participants to distinguish the individual efforts people make. Attributions of group performances were theorized to be based on perceptions of the groups collective effort, not the individual attributions. While a task failure attributed to the difficulty of the task may result in an individual being less likely to be recommended for future work (Struthers et al., 1998), the same explanation in a group setting may be a legitimate measure of future performance and result in increased estimations of hirability. When examining 
group attributions of task performance failures, Zaccaro et al. (1987) recommended including a third measurement of attributions that included group internal and external attributions, in addition to the traditional two internal and external measures of attributions for the individual. The literature would seem to support the explanation that participants likely used task difficulty to determine future hirability, not attributions of ability or effort.

Research questions five and six. Together, the results of research questions five and six generate their own unique set of explanations. Recall, the research questions found that task difficulty was the only attribution functioning as a predictor variable for future hiring recommendations. A possible explanation for these results is that two levels of evaluations may be taking place in broadcast sports: one for novices and one for veterans. This may be a form on in-group/out-group evaluations taking place (Beatson \& Halloran, 2015). Novice camera operators, perceived as out-group members, may be evaluated on ability while veteran camera operators, perceived as in-group members, may be evaluated for future work based on the difficulty of the tasks they perform in the broadcast. The distinction of in-group members and out-group members would help explain why attributions of ability did not predict future hirability but task difficulty did. While this is a possibility, it would require additional research to examine the theoretical implications of a dual evaluation system before definitive conclusions could be reached.

Another possible explanation for the findings in RQ5 and 6 is that there are not two levels of evaluations taking place and the findings were in-line with the past research on group attribution theory applied to a task performance context. Zaccaro et al. (1987) found that as interdependence increased, so too did group-serving ascriptions. This was also found to be the case in another study designed to examine differences in individual and group attributions. 
Group members were found to attribute failures in a group more to external factors than internal factors compared with the attributions of failure made for individuals (Wallace \& Hinsz, 2009). Perhaps the best measure of a group member's future hirability was how well they performed at a difficult task. As the task became more difficult, they were perceived as being more competent and hirable, despite a single performance error by the group. The implication of this explanation is that future research on broadcast sports may be best approached from the perspective of group attributions, not individual attributions.

\section{Hypothesis Two}

Hypothesis two predicted the perceived frequency of the mistake would predict attributions of task difficulty. There was no support for this hypothesis, as the perceived frequency of the mistake did not predict the attributions of task difficulty. This result indicates professionals may not be associating the frequency of the mistake with their estimations of how difficult the task is. Further, they may not be associating the frequency of the mistake with any attributions, as the correlation tests showed no significant correlations between the frequency of the mistake and the four attribution measures. This seems to indicate that professionals make their evaluations of mistakes in isolation of the frequency factor.

Another potential explanation is that the connection between frequency and task difficulty required participants to make a cognitive association that was not naturally present in the study design. The underlying assumption of the hypothesis was that the participants would reason through the questions asked in the survey instrument and they would likely conclude that if a mistake was made frequently, then it was a difficult task for the camera operator because many other camera operators were making the same mistake. However, because the task difficulty questions were scattered throughout the MOAPS scale, and the frequency questions 
were isolated as a unique scale within the survey instrument, the participants likely had no reason to make an association between the frequency of the mistake and the difficulty of the task. The hypothesis may have been anticipating a level of reasoning beyond the design of the study.

Yet another possible explanation for the findings comes from the underlying assumption of the hypothesis, which assumed that participants would demonstrate a similar-to-me effect (Rand \& Wexley, 1975) and they would thus project their own perceptions of the error frequency onto that of the camera operator in the study. However, participants may have perceived the error by the camera operator to be a one-time event, not a frequent occurrence. In other words, the participants were probably not associating the general frequency of the performance error with the perceived frequency of the error for that specific, individual camera operator.

The implication of this finding is that the frequency of a performance error should be tested using a different research design. It is difficult to imagine a scenario in which the frequency of an error does not influence some attributions of a camera operator's performance. In the industry, professionals who make frequent performance errors are typically not invited back to work on a production crew because they are perceived as lacking in the ability to perform a task in a way that others can. However, if multiple camera operators attempt to perform a task and they all make frequent errors, the perception is that the task is difficult, and the camera operators are not lacking in ability, because they all made the same performance errors. There is a need for further clarification of how frequency is theoretically associated with attributions and under what conditions it may become a contextual cue that participants use to make their performance evaluations. 


\section{Hypothesis Three}

Hypothesis three anticipated attributions of task difficulty would predict attributions of effort and ability in a positive correlation. This hypothesis was supported and as attributions of task difficulty increased, attributions of both effort and ability increased as well; thus, confirming the hypothesis and the direction of the predicted correlation. This result may lend support to the previous literature findings indicating that when someone fails at a difficult task, evaluators blame the difficulty of the task for the failure and not the ability or effort of the person attempting the task (Kun \& Weiner, 1973). Similarly, if someone fails at a relatively easy task, the person will probably be perceived as having low levels of ability and effort, because they could not complete a simple task.

This result may also lend support to a possible ordering effect: when levels of ability and effort are unknown, participants will make attributions of task difficulty followed by attributions of ability and effort. In addition, this may lend support to the correspondence bias (Gilbert \& Malone, 1995) and the categorical placement of participants (Feldman, 1981). If the ability and effort of the camera operator were unknown and difficult to estimate, participants may have considered the task difficulty first and then placed the camera operator in a higher or lower level of ability and effort, based on the category they perceived the camera operator to fit.

Another explanation to consider for the results of $\mathrm{H} 3$ is that when the participants perceived the difficulty of the task as the cause of the performance error, they also attributed the cause of the mistake to the camera operator's lack of ability and effort. This could mean the camera operator was perceived as lacking the ability and effort needed to perform a difficult task. This would imply that while professionals may acknowledge a task is difficult for a camera operator, they still expect the camera operator to perform at the level necessary for 
accomplishing the task. Camera operators who make a performance error, when others succeed, may be seen as having lower levels of both ability and effort relative to their peers, despite the task difficulty.

The outcome of hypothesis three supported previous literature examining attributions for possible effects beyond the initial attributions made by the participants (Kun \& Weiner, 1973). Similar to RQ6, while the attributions of task difficulty were not directly influenced by the conditions being tested, task difficulty significantly correlated with two additional measures in the study. In this case, task difficulty predicted attributions of ability and effort. The implication is that in future research, rather than testing for differences in attributions and stopping the analysis process, researchers may want to consider extending their analysis of attributions to a second theoretical level and examine the ways in which attributions might correlate with other measures in the study. As seen in the present study, non-significant findings at the first level of attributions does not mean non-significant findings will be found at the second level of analysis; thus, justifying a robust theoretical approach that accounts for multiple levels of analysis.

\section{Implications}

The findings from the present study have practical implications for the broadcast sports industry and theoretical implications that may help guide future research on attribution theory and sports communication.

\section{Relational Implications}

First, this may be the first-time empirical evidence of the broadcast sports industry has shown measurable effects of the relationship between the camera operator and the director. As networks plan and design future broadcast infrastructures, they may want to consider how they can leverage this knowledge, and the implications of it, on future productions. The findings 
certainly showed some support of the previous statements made by directors, who said selecting the right production crew made a difference in the quality of their production (Wood, 2014). The results in the present study support the perception that close relationships between the director and the crew can positively influence a production environment. These perceptual differences could be tested in future studies to determine if they result in objectively significant differences in the quality of the production. In an industry focused on technological advancements, it may be in the industry's best interests to also consider the social cohesion of the production crew when designing and implementing productions.

Professionals, who work at the level of broadcasting like those in the present study, may not make evaluations of their peers' performances based solely on perceptions of ability and effort, because at their level, they might be assuming everyone has the ability to do the job and they may be categorizing people accordingly. Consequently, they may be using other factors, such as task difficulty and the relationship with the director, as key factors when making evaluations of a camera operator's performance. For a different group of participants, using different scenarios, ability and effort may be important; but for these seasoned professionals, ability and effort were likely not key factors in their attributions.

\section{Task Difficulty}

Task difficulty seemed to emerge as one of the key factors professionals used to make attributions of a task performance error and when they estimated another person's future hirability. A practical implication of these findings is that professionals who accept, or seek out, more difficult camera assignments may see tangible benefits simply for attempting the more difficult task. One of the potential benefits is that their peers may perceive them as having higher levels of ability, even after a task performance error. The perception of higher abilities by the 
camera operator may help them establish a positive performance trend over time, which could lead to more hiring recommendations. Additionaly, task difficulty by itself appears to lead to more future hiring recommendations for a camera operator. The implication is that camera operators may benefit from attempting difficult tasks, as failure at a difficult task is likely to be blamed on the task and not the operator.

One of the theoretical implications found in the present study was the connection between attributions of task difficulty and the attributions of effort and ability, as task difficulty was found to positively predict effort and ability. This finding was in agreement with previous research showing a connection between attributions of task difficulty and attributions of effort and ability (Carless \& Waterworth, 2012). When participants in the present study perceived the task to be difficult, they also perceived the camera operator to have higher levels of both effort and ability. This connection provides some theoretical understanding of how the participants considered the external attribution of task difficulty. Based on that understanding, future research may want to examine how participants reach their conclusions about the perceived difficulty of a task. Especially when one considers that neither the relationship with the director or the fatigue of the camera operator was found to significantly influence attributions of task difficulty. If different evaluations of the task difficulty were made, participants likely used contextual information from the video clip, and not the information presented in the conditions, to make their attributions. Regardless of which scenario a participant read, every scenario described the camera operator's task in the production in the same way. Only the variables of fatigue and the relationship with the director were manipulated in the scenarios; yet, the participants' evaluations of the task difficulty varied enough to make significant statistical predictions. This could also indicate that task difficulty is not subject to the same ordering effects as the internal attributions. 
While participants may categorize a camera operator's ability and effort prior to seeing their work, they may not evaluate the task difficulty of the job until they have seen the camera position for themselves and watched the performance of the camera operator. Because task difficulty is an external attribution, it may be less influenced by the categorization process compared with the internal attributions. In the review of literature, this ordering effect was anticipated, and, in this instance, the results supported the expected outcome. Regardless of when, or how, the participants made their attributions of task difficulty, the results imply they were associating the camera operator's effort and ability with their perceptions of the task difficulty.

\section{Group Attributions}

The findings in the present study seem to indicate that broadcast sports professionals may be best understood from the perspective of group attributions, rather than the perspective of individual attributions (Bazarova \& Hancock, 2012). The findings, such as task difficulty predicting future hiring recommendations while ability and effort did not, indicate the participants could be pulling from a wide range of contextual cues about the situation, including the group as a whole and how the individuals' performance may be influencing the group. This study may add support to using an expanded theoretical model of attributions within group contexts. Zaccaro et al. (1987) called for an extended measurement of attributions within group research, including the internal and external attributions of the group. The implication is that future research designs may want to consider expanding their theoretical models to include group attributions in an effort to provide finer detail within the findings and enhance their explanatory power. 


\section{Training and Development for Current Professionals}

The results of the present study may help guide current professionals in their careers. Knowledge of how social relationships might improve performance ratings and crew cohesion, and increase a person's chances for future work, may change the perspectives of some production crew members. Additionally, understanding how crew members' perceptions of task difficulty could lead to increased perceptions of a person's ability, effort, and future hiring recommendations, is the type of information current professionals can immediately use to bolster their careers. In an industry driven by monetary and technological developments, the social science perspective offer in the present study could help professionals adapt and adjust to the constantly changing work environment.

\section{Pedagogical Implications}

Pedagogically, the present findings indicate that academic institutions offering courses on broadcast sports production techniques may want to encourage, or require, students to pursue some form of communication training as part of their course curriculum. Specifically, courses on organizational and small group communication, to include conflict management strategies, could provide students with an advantage when they enter the work force. As shown in the present study, it may also help aspiring professionals sustain their careers, even if they have been working in the industry for years. While television production courses have traditionally focused on providing technical skills training, and rightly so as the industry is driven by technology, institutions may want to consider how the technical skills from broadcasting courses can be integrated with the organizational communication skills from communication courses. Equipping students with strong organizational, small group, and interpersonal communication skills and 
how to apply them to broadcasting could result in more effective integration into the industry and continued success in their broadcast sports careers.

To further support aspiring professionals as they learn the skills and techniques of broadcast sports productions, textbook authors may want to include a section in their work outlining the potential benefits of positive working relationships between crew members; as those relationships were shown to have implications for the production. Furthermore, authors who have previously addressed the social relationships in a production crew, and a number of authors have discussed the topic, now have empirical evidence to guide their work. By addressing the topic of relationships in broadcast sports early in a young professional's career, through textbooks and professional literature, it may allow aspiring professionals more opportunities to develop their interpersonal skills prior to entering the industry and working on full-scale broadcast sports productions.

\section{Theoretical Implications for Academics}

Theoretically, the study expanded attribution theory into the area of sports communication. Kelley (1973) posited that participants could make causal inferences based on a single instance when the participants had experience with the situation they were viewing. This was the case in the present study, as participants were able to generate attributions based on a single example of a familiar performance error. The study provided strong theoretical support that attributions are derived from perceptions of an event, as the actual cause of the event is not directly observable to them (Weiner, 1992).

The present studied showed support for previous literature indicating people may put others into performance categories prior to making evaluations of their performance (Feldman, 1981; Gilbert \& Malone, 1995). This was supported through the design of the study, which asked 
participants to read a scenario prior to watching the video clip. Participants likely placed the camera operator into a category by the time they had finished reading the scenarios. In the fatigue unknown condition, participants who perceived the camera operator to be in a close relationship with the director likely categorized the camera operator as having a high ability, thus explaining why they rated the camera operator as having higher levels of ability following the mistake.

The findings also provided some possible theoretical support for the idea that people in close relationships are socially admired and, therefore, perceived as having higher levels of ability. While previous literature had shown people with high abilities were socially admired, the present study provides some support that the correlation, between ability and social desirability, may work in the opposite direction. The finding was in-line with previous literature showing workers who maintained quality relationships with their supervisors received higher performance ratings (Geertshuis et al., 2015; Linden \& Graen, 1980) and literature findings showing people made performance evaluations based on prior experiences with a person and not just a single instance (Borman, 1978). The relational findings of the present study supported previous theory and findings indicating relationships are one of the contextual factors people account for when making performance evaluations.

The relationship with the director showed significant differences in attributions of ability and that was a meaningful theoretical finding. Ability, being a stable, internal factor, indicates participants expected the camera operator in the close relationship to perform well in the future. This implies that the participants would be more likely to recommend the camera operator in the close relationship with the director for future work, and the study findings supported that theoretical connection. That attributions of ability and measures of future hiring 
recommendations were both positively correlated with the relationship with the director indicates participants may be conceptualizing the relationship with the director as an internal attribution of the camera operator.

The results related to the fatigue of the camera operator have some interesting theoretical implications. Despite fatigue effecting an individual, and possibly being within an individual's control, fatigue was not found to be considered an internal attribution in the present study. Rather, the findings appear to indicate fatigue was considered an external, situational attribution. Consistent with the literature on external attributions, the fatigue condition generated no significant differences in the attributions the participants made regarding the cause of the mistake. The literature had stressed that external, situational factors may not significantly influence attributions (Gilbert \& Malone, 1995; Moore et al., 2010) and the findings of the fatigue condition lined up with this description. How the fatigue condition was regarded may provide some support for the correspondence bias, or it could have other theoretical implications. While research on the correspondence bias examined attributions within traditional performance settings, it did not cover the possibly unique work environment of a live sports broadcast production. In a traditional work environment, performance can be measured over long periods of time and performance trends can be used to make evaluations of an employee's work. One or two bad days in the middle of a positive performance trend may not be a big deal to a traditional employee, as their bad days can be offset within the context of their overall performance. In contrast, camera operators are under a great deal of pressure to deliver their best performance for every production they work, because every shot that goes on-the-air matters. Due to the nature of the industry, camera operators may be evaluated over a period of hours or days, not weeks or months. When a camera operator has a bad day, or even just a single mistake 
in a broadcast, their performance is immediately seen by hundreds of thousands, to billions, of audience members. This difference in performance evaluations may have influenced the participants' conceptualization of the camera operator's fatigue and how much it should account for their evaluations. While participants may have felt bad for the camera operator, or related to the situation they saw them in, the participants were not influenced by the operator's fatigue level when they made their attributions. The participants of the present study made attributions as if the fatigue of the operator was an external attribution in the sense that it did not significantly influence any of the attributions made. The manipulation check confirmed the participants in the fatigue condition perceived the camera operator to be significantly more fatigued than the participants who did not know the camera operator's fatigue level, so we know the participants were aware of the fatigue level. And, yet, it was as if the participants completely ignored the camera operator's fatigue level and made their attributions based on other contextual factors.

This appears to provide support to the idea of the correspondence bias by Gilbert and Malone (1995) who said that participants can account for the situational factors when they can easily imagine themselves in the position of the person being evaluated. With such veteran professionals as the participants of the present study, it is easy to make a case that the participants were able to imagine themselves in the same position as the camera operator and therefore they easily accounted for the situational factors, perhaps to the point of overestimating the effects of those factors. This may require future investigation to understand why participants chose to not utilize the information about the fatigue when making their attributions.

\section{Limitations}

This study contained several noteworthy limitations. These include the video used in the survey, the number of participants, and the generalizability of the results, to name a few. These 
aspects of the study have been identified to acknowledge the limitations of the results, and to assist future research designs.

\section{Survey Video}

One of the potential limitations of the current study was the video clip shown to the participants. While the video met the criteria of a snap zoom, according to the literature, the error occurred under arguably ambiguous circumstances. Because the error occurred within 100 milliseconds of the director selecting the camera, the fault of the error was open to interpretations. Fault for the mistake could have been placed on the camera operator, the director, the T.D., or any combination of the three. Consequently, there may have been some question as to how much fault for the mistake belonged to the camera operator. As a result of the ambiguity regarding who the mistake should be attributed to, the participants' attributions of the camera operator may have been ambiguous; possibly explaining why the MOAPS scale did not load as four distinct factors when examined through a confirmatory factor analysis. Participants may have been hesitant to assign attributions of fault to the camera operator if they believed the mistake was not in any way a result of the operator. While the video clip selected for this study may have created some ambiguity regarding the attributions made by the participants, there were specific reasons for selecting the clip.

The type of camera mistake selected for use in the survey instrument, one in which a operator is caught between conflicting duties and may or may not be at fault for the mistake, was believed to be more likely to occur in a broadcast than a mistake in which the camera operator makes a mistake completely on their own. At the network television level of sports productions, camera operators are extremely unlikely to make a mistake of their own volition without any additional factors coming into play. Camera operators who make mistakes of that type frequently 
are not recommended for future work, and subsequently they rarely work at the network television level of sports productions. Operators who work on a regular basis at the network television level are extremely talented and mistakes often occur within ambiguous circumstances, such as the one used in the present study and described in the literature as most likely to generate multiple attributions (Martinko et al., 2010; Weiner, 1986). The intention of selecting a clip with ambiguous circumstances was to increase the real-world validity, even at the expense of statistical and theoretical clarity.

\section{Number of Participants}

Another potential limitation of the study was the number of participants. With four conditions being tested, and a limited number of participants to spread across the conditions, the statistical power of the results was decidedly low. In addition, very few participants identified themselves as directors, which limited the potential comparisons one could make between the categories of participants. Future studies should either attempt to contact more participants, or limit the number of conditions to no more than two per study to ensure stronger statistical power and maximize possible comparisons.

Another consideration for future research is extending the data collection process over a longer period. While most participants completed the study soon after receiving the invitation to participate, not after receiving multiple reminders, extending the data collection period may allow for additional participants to be contacted during the extended time frame. Compared with an email invitation to participant, the author found the response rate of the participants appeared to be higher when he invited participation during a face-to-face conversation. Over a longer data collection period, the author would likely come in contact with a number of different production crews, allowing for unique participant pools to be recruited each time he worked with a different 
production crew. However, for this technique to be most effective it would require a six to eightmonth data collection period, which may not be feasible for some studies and was not possible for the present study.

\section{Generalizability}

Finally, while significant results were found in the data, the generalizability of the results is of limited use. Broadcast sports are a niche industry and because there has been so little research on them, it is unclear yet if the present findings have applications outside of the broadcast sports community. The results seem to indicate that when applying attribution theory, broadcast sports may be best suited for group attribution research. Therefore, the findings of the present study are likely most applicable under those conditions. While there may be applications for the results within organizations also reliant on mission-critical cohesive group work, the results and conclusions from this study are likely limited to applications within the broadcast sports community until future research can clearly possible connections to other communities and organizations.

\section{Future Research}

The findings from the present study have raised as many questions as they have answered. While the findings on attributions produced telling results, only two variables were examined. In addition, the findings raised possible questions about the way broadcast sports professionals conceptualize internal and external attributions when making performance evaluations. Finally, the present study could have implications for future research examining the effects of technical changes currently taking place in the broadcast sports industry. 


\section{Independent Variables}

The present study used only two independent variables in the research design. While the relationship with the director and the fatigue of the camera operator were deemed to be reasonable variables for testing, there are a number of additional variables which could be tested in similar research designs. Variables of the camera operator could include positive and negative performance trends, years of experience at different categorical levels of broadcasting, descriptions of the situational factors potentially influencing their work, the effort put into the task or the perceived ability of the operator, and many more. Similarly, these variables could be tested with scenarios asking questions about the director or T.D.'s performances as well. There are a multitude of variables that could be applied, to several different positions in sports broadcasting, using attributions as the theoretical lens.

Methodologically, an exploration of potential variables could be approached from a qualitative research design. An exploratory qualitative approach may be a more efficient method of identifying the most likely factors influencing participants' attributions. An exploratory qualitative approach could then be followed by a quantitative research design, aimed at confirming the effectiveness of the variables and investigating effect sizes.

\section{Attribution Theory}

Internal and external attributions. While the present study examined the effects of relationship type and fatigue, both of those variables were presented in an exploratory sense and not defined explicitly as internal or external attributions. Because the internal attributions were mentioned as being the more influential than the external attributions (Rudolph et al., 2015; Ross, 1977), future research may consider specifically isolating the variables of the internal attributions of the camera operator. One variable known for influencing internal attributions 
would be that of a performance trend, which has been shown to be attributed to attributions of ability and effort (Rudolph et al., 2015). In the present study, the appearance of a performance trend was intentionally avoided as much as possible, as it had been shown to be more influential on attributions than variations within the trend (Rudolph et al., 2015), such as an isolated camera mistake in a broadcast. Future research could examine the effects of a performance trend on attributions in live sports productions. Because camera operators are expected to deliver their best work for every broadcast, a performance trend may, or may not, mediate the effects of a camera operator's isolated mistake during a broadcast, as was the case in previous literature (Borman, 1978; Rudolph et al., 2015). Similarly, effort may significantly impact the results of the findings in live sports broadcasts, as camera operators are expected to put forth their maximum effort at all times during a broadcast and variations of effort in live sports broadcasts may be perceived differently than in other areas of industry. Future research on the attributions of effort and ability may provide useful insights and additional applications for attribution theory.

Group attributions applied to broadcast sports productions. The findings of RQ's 5 and 6 indicate future researchers may want to examine if broadcast sports professionals make their attributions as individuals, or members of a cohesive group; as the differences have been identified as distinct. If broadcast sports professionals are found to make group attributions, additional research could be conducted to measure the degree to which broadcast sports professionals identify with their production crews. By identifying how broadcast sports professionals make attributions, and to what extent they do so, the findings from research involving broadcast sports professionals may be generalizable to other areas of research, organizations, and industries which share similar characteristics. 
Categorical attributions. Another potential area of future research came from the results of RQ5, RQ6, and H3. Associated with attributions and the correspondence bias, Feldman (1981) found evidence that people may put others into performance categories prior to making evaluations of them. This categorical process may have been present in the findings of RQ5 and 6 , as the findings appeared to not align with some of the expected attribution literature. Future research may examine if this categorical process is taking place and how it might function to influence the attributions professionals make of their peers. While the results of $\mathrm{H} 3$ were as predicted, and task difficulty predicted ability and effort, this may have been another example of the categorical process at work and participants categorized camera operators attempting a difficult task as having high levels of ability and effort. Future research could attempt to clarify if a categorical process was taking place, as well attempt to identify possible ordering effects.

\section{Technical Changes in Broadcast Sports Productions}

As remote sports productions begin to transition away from an "all-hands on-site" remote production model, to a production model which separates the physical location of the director from that of the camera operators by possibly thousands of miles, future research could examine how the technological changes could affect the relationship between the camera operator and the director through minimalized, or delayed, communication. The present study indicated the relationship between the camera operator and the director might influence perceptions of a broadcast, as well as possibly affect the future hiring recommendations for the camera operator. These findings may add support to the argument that the social aspect of a production may be as important as the technological aspects. Future research may build on the findings of the present

study to provide socially oriented, research-based solutions to the changing technological environment broadcast sports professionals work in. 


\section{Conclusion}

Broadcast sports television is a high stakes industry where the products are often watched live by millions of viewers. As professionals apply their craft with the skill of master artisans and visionaries, every shot in the broadcast counts. There are no "do-overs," as the narrative must be shaped on-the-fly by the director and the crew working in unison towards a common goal. When it goes right, the production crew is a synchronized, cohesive organism drawing the audience in with each descriptive shot as they create a memorable social experience for the masses. At those times, when the production crew is functioning like one of the top teams they are covering, each crew member is aware of what every other member is doing; the sublime moments that are sport are forever immortalized by broadcast professionals the audience is not even unaware of. In contrast, when a broadcast goes wrong, and a jarring camera movement may break the audiences' attention and pull it away from the event itself, directors could lose their composure, camera operators may be severely reprimanded, and the synergy of the group could evaporate. The glorious, yet unforgiving nature of the industry, means careers hang in the balance with every production and paramount importance is placed on identifying, and correcting, the causes of possible mistakes in a broadcast.

This conceptualization of a broadcast sports production environment may explain why my co-workers became so excited when they witnessed a camera mistake during a track-andfield broadcast. They knew the camera operator had made a serious mistake and there would likely be repercussions for what had taken place. My co-workers may have felt some degree of sympathy for the camera operator who made the mistake, because most camera operators have likely been in the same position, or been on a crew when it has happened. However, it was probably more important to my co-workers to understand why the mistake happened in the first 
place, so they could avoid making the same mistake in their own work. A long career in television requires one to learn from not only their own mistakes, but from the mistakes of others as well.

This study, through attributions, provided a first-look at how broadcast sports professionals process and evaluate potential camera mistakes in a production. The study made the case that through attributions, camera mistakes in live sports broadcasts communicate meanings to the individuals who work in the live sports broadcast industry. The results of the present study are believed to be in-line with previous literature on attribution theory; specifically, that when making attributions of a situation, participants rely on multiple contextual cues and their own experiences to make judgments regarding the cause of the mistake (Heider, 1958; Kelley, 1973; Weiner, 1992). This includes categorical cues (i.e., the camera operator's relationship with the director), contextual cues (i.e., the sequence showing the camera mistake as well as how the clips before and after the mistake communicated the context of the situation to the participants), and experiential cues (i.e., such as participants possibly knowing that a handheld camera on a car race is a difficult camera to operate due to the noise in the garage area and the physically demanding nature of the camera itself). All these cues may have been used to inform participants of the mistake and why it happened, as was seen through the attributions they made.

The attributions made by the participants indicate that the type of relationship between the camera operator and the director could influence both the perceived ability of the camera operator and the likelihood that the camera operator would be recommended for future work following a camera mistake. A close relationship with the director showed positive benefits for the camera operator's attributions of ability and resulted in the camera operator receiving higher 
recommendation scores for future work compared with the camera operator who had a distant relationship with the director. These findings have helped establish connections between broadcast sports communication and previous literature on attribution theory and organizational communication.

Perceptions of camera movement, consciously identified and articulated by broadcast sports professionals through attributions, may someday assist in understanding how average viewers perceive a broadcast based on the movement of the images. The results of the present study may be used to guide future broadcast sports productions on effective communication practices for directors, camera operators, and the rest of the production crew. 


\section{REFERENCES}

Ahronson, A., \& Cameron, J. E. (2007). The nature and consequences of group cohesion in a military sample. Military Psychology, 19(1), 9-25. doi:10.1080/08995600701323277

Barrance, T. (2017, October 19). Making a film: Organising filmmaking process. Learn About Film. Retrieved from http://learnaboutfilm.com/making-a-film/organising-filmmakingprocess/filming/

Bazarova, N. N., \& Hancock, J. T. (2012). Attributions after a group failure: Do they matter? Effects of attributions on group communication and performance. Communication Research, 39(4), 499-522. doi:10.1177/0093650210397538

Beatson, R. M., \& Halloran, M. J. (2015). Effect of hierarchy legitimacy on low status group members' attributions for ingroup and outgroup failures. Psychological Reports: Relationships \& Communications, 116(2), 586-595. doi:10.2466/21.pr0.116k25w4

Bettinger, B. (2009). Modeling the cost of television advertisements. TV By The Numbers. Retrieved from http://tvbythenumbers.zap2it.com/tv-advertising/what-determinesprimetime-tv-ad-prices-a-reader-runs-the-numbers/

Block, B. (2001). The visual story: Seeing the structure of film, TV, and new media. Woburn, MA: Butterworth-Heinemann.

Bodenheimer, G., \& Phillips, D. T. (2015). Every town is a sports town. New York, NY: Hachette Book Group.

Borman, W. C. (1978). Exploring upper limits of reliability and validity in job performance ratings. Journal of Applied Psychology, 63(2), 135-144. doi:10.1037/0021-9010.63.2.135

Boston, J., \& Hoover, G. (2013). TV on wheels: The story of remote television production. Roseville, CA: Alphagraphics. 
Boyle, R., \& Haynes, R. (2009). Power play: Sport, the media and popular culture. Edinburgh, United Kingdom: Edinburgh University Press.

Bruce, K. (2015, April 27). Brian France discusses shorter race lengths. NASCAR. Retrieved from http://www.nascar.com/en_us/news-media/articles/2015/4/27/nascar-chairman-ceobrian-france-sprint-cup-series-shorter-races.html

Caldwell, J. T. (2008). Production culture. Durham, NC: Duke University Press.

Carless, S., \& Waterworth, R. (2012). The importance of ability and effort in recruiters' hirability decisions: An empirical examination of attribution theory. Australian Psychologist, 47, 232-237. doi:10.1111/j.1742-9544.2011.00038.x

Challenger, Gray, \& Christmas, Inc. (2014). Challenger March Madness report: Employers brace for productivity decline, but small price to pay for higher morale. Challenger, Gray, \& Christmas, Inc. Retrieved from http://www.challengergray.com/press/pressreleases/march-madness-could-cost-employers-12b

Chen, C.C., \& Chiu, S.F. (2008). An integrative model linking supervisor support and organizational citizenship behavior. Journal of Business Psychology, 23(1), 1-10. doi:10.1007/s10869-008-9084-y

Cherry, E. C. (1953). Some experiments on the recognition of speech, with one and with two ears. The Journal of the Acoustical Society of America, 25, 975-979. doi:10.1121/1.1907229

Chidester, P. J. (2009). "The toy store of life": Myth, sport and the mediated reconstruction of the American hero in the shadow of the September 11th terrorist attacks. Southern Communication Journal, 74(4), 352-372. doi:10.1080/10417940802510365 
Clements, R. (2016, April 14). 2016 Sunday Night Football schedule begins with Patriots at Cardinals. Sporting News. Retrieved from: http://www.sportingnews.com/nfl/news/2016sunday-night-football-nbc-schedule-broadcasts-patriotscardinals/1wqnx4suiwwks18vp3tgjzxi18

Corner, J., \& Roscoe, J. (2016). Outside and inside television: A dialogue on value. Journal of Media Practice, 17(2-3), 157-167. doi:10.1080/14682753.2016.1249207

Cox, C. B., \& Beier, M. E. (2014). Too old to train or reprimand: The role of intergroup attribution bias in evaluating older workers. Journal of Business Psychology, 29, 61-70.

Cressman, D. L., \& Swenson, L. (2007). The pigskin and the picture tube: The National Football League's first full season on the CBS television network. Journal of Broadcasting \& Electronic Media, 51(3), 479-497. doi:10.1080/08838150701457537

Cury, I. (2017). Directing \& producing for television. New York, NY: Focal Press.

Dalal, A. K. (1988). Attributional approach to achievement and social behavior. In A. Dalal (Ed.), Attribution theory and research (pp. 3-14). Daryaganj, India: Wiley Eastern Limited.

Darwin, C. (1872/1890). The expression of the emotions in man and animals. New York, NY: D. Appleton and Company.

Dems, K. (2010, July 12). What are the five stages of filmmaking? Bright Hub. Retrieved from http://www.brighthub.com/multimedia/video/articles/77345.aspx

Evans, C. R., \& Dion, K. L. (1991). Group cohesion and performance. Small Group Research, 22, 175-186. doi:10.1177/1046496491222002

Evans, T., Iosifidis, P., \& Smith, P. (2013). The political economy of television sports rights. Hampshire, England: Palgrave Macmillan. 
Fehr, B. (2004). Intimacy expectations in same-sex friendships: A prototype interaction-pattern model. Journal of Personality and Social Psychology, 86, 265-284.

Feldman, J. M. (1981). Beyond attribution theory: Cognitive processes in performance appraisal. Journal of Applied Psychology, 66, 127-148. doi:10.1037/0021-9010.66.2.127

Festinger, L. (1954). A theory of social comparison processes. Human Relations, 7, 117-140.

Flint, J. (2011, December 15). NFL signs TV rights deals with Fox, NBC and CBS. Los Angeles Times. Retrieved from http://articles.latimes.com/2011/dec/15/business/la-fi-ct-nfl-deals20111215

Gaines, C. (2015, December 7). ESPN has lost more than $\$ 2$ billion because of cord cutting. Business Insider. Retrieved from http://www.businessinsider.com/espn-cord-cuttinglosses-2015-12

Gantz, W., Wang, Z., Paul, B., \& Potter, R. (2006). Sports versus all comers: Comparing TV sports fans with fans of other programming genres. Journal of Broadcasting \& Electronic Media, 50(1), 95-118. doi:10.1207/s15506878jobem5001_6

Geertshuis, S. A., Morrison, R. L., \& Cooper-Thomas, H. D. (2015). It's not what you say, it's the way that you say it: The mediating effect of upward influencing communications on the relationship between leader-member exchange and performance ratings. International Journal of Business Communication, 52(2), 228-245. doi:10.1177/2329488415572784

Gilbert, D. T., Krull, D. S., \& Pelham, B. W. (1988). Of thoughts unspoken: Social inference and the self-regulation of behavior. Journal of Personality and Social Psychology, 55(5), 685694. doi:10.1037/0022-3514.55.5.685

Gilbert, D. T., \& Malone, P. S. (1995). The correspondence bias. Psychological Bulletin, 117, 21-38. doi:10.1037//0033-2909.117.1.21 
Gillespie, B. J., Lever, J., Frederick, D., \& Royce, T. (2015). Close adult friendships, gender, and the life cycle. Journal of Social and Personal Relationships, 32(6), 709-736. doi: $10.1177 / 0265407514546977$

Gross, L. S., Foust, J. C., \& Burrows, T. D. (2005). Video production: Discipline and techniques. New York, NY: McGraw-Hill.

Hartman, K. (2009, November). The communicative practices of American sport: The trinity of myth, sport, and the hero. Paper presented at the meeting of the National Communication Association, Chicago, IL.

Heider, F. (1958). The psychology of interpersonal relations. New York, NY: John Wiley \& Sons.

Heider, F., \& Simmel, M. (1944). An experimental study of apparent behavior. The American Journal of Psychology, 57(2), 243-259. doi:10.2307/1416950

Henrich, J., Heine, S. J., \& Norenzayan, A. (2010). The weirdest people in the world? Behavioral and Brain Sciences, 33, 61-135. doi:10.1017/S0140525X0999152X

Hewstone, S. (Ed.). (1983). Attribution theory: Social and functional extensions. Oxford, England: Basil Blackwell.

Hopthrow, T., Hooper, N., Mahmood, L., Meier, B. P., \& Weger, U. (2017). Mindfulness reduces the correspondence bias. The Quarterly Journal of Experimental Psychology, 70(3), 351-360. doi:10.1080/17470218.2016.1149498

Jarvis, P. (1998). The essential TV director's handbook. Woburn, MA: Focus Press.

Jensen, J. A., Turner, B. A., Delia, E., James, J., Greenwell, T. C., McEvoy, C., ...Walsh, P. (2016). Forty years of BIRGing: New perspectives on Cialdini's seminal studies. Journal of Sport Management, 30, 149-161. doi:10.1123/jsm.2015-0340 
Johansson, G. (1973). Visual perception of biological motion and a model for its analysis. Perception \& Psychophysics, 14(2), 201-211. doi:10.3758/bf03212378

Johnson, A. J. (2001). Examining the maintenance of friendships: Are there differences between geographically close and long distance friends? Communication Quarterly, 49, 425-436. doi:10.1080/01463370109385639

Johnson, A. J., Haigh, M. M., Craig, E. A., \& Becker, J. H. (2009). Relational closeness: Comparing undergraduate college students' geographically close and long-distance friendships. Personal Relationships, 16, 631-646. doi:10.1111/j.1475-6811.2009.01243.x

Jones, P. (1969a). Cameraman. In R. Spottiswoode, B. Happe, E. Vast, D. P. Buckmaster, P. C. Poynter, \& A. Kraszna-Krausz (Eds.), The focal encyclopedia of film \& television techniques (pp. 106-112). New York, NY: Focal Press.

Jones, P. (1969b). The techniques of the television cameraman. New York, NY: Hastings House.

Kashy, D. A., \& Levesque, M. J. (2000). Quantitative methods in close relationships research. In C. Hendrick \& S. Hendrick (Eds.), Close relationships: A sourcebook (pp. 3-17). Thousand Oaks, CA: Sage.

Kassin, S. M., \& Baron, R. M. (1985). Basic determinants of attribution and social perception. In J. H. Harvey \& W. Gifford (Eds.), Attribution: Basic issues and applications. Orlando, FL: Academic Press.

Kelley, H. H. (1973). The process of causal attribution. American Psychologist, 28, 107-128. doi:10.1037/h0034225

Kelley, H. H., Berscheid, E., Christensen, A., Harvey, J. H., Huston, T. L., Levinger, G., . . . Peterson, D. R. (1983). Close relationships. New York: Freeman and Company. 
Kerr-Dineen, L. (2017, April 5). Why August National turns down hundreds of millions of dollars every year. USA Today. Retrieved from http://ftw.usatoday.com/2017/04/augustanational-the-masters-2017-television-rights-cbs-tournament

Koeppel, P. (2012, October 31). What determines the cost of TV advertising? Electronic Retailing Association. Retrieved from: http://retailing.org/blog/what-determines-cost-tvadvertising

Kun, A., \& Weiner, B. (1973). Necessary versus sufficient causal schemata for success and failure. Journal of Research in Personality, 7, 197-207. doi:10.1016/00926566(73)90036-6

Lam, B. P. W., Xie, Z., Tessmer, R., \& Chandrasekaran, B. (2017). The downside of greater lexical influences: Selectively poorer speech perception in noise. Journal of Speech, Language, and Hearing Research, 60, 1662-1673. doi:10.1044/2017_JSLHR-H-16-0133

Lennon, D. (2017, April 16). Shorter baseball games? Not yet. Newsday. Retrieved from http://www.newsday.com/sports/columnists/david-lennon/shorter-games-not-yet1.13473059

Lewis, C., \& Greer, T. (1990). The TV director/interpreter. Mamaroneck, NY: Hastings House. Liden, R. C., \& Graen, G. (1980). Generalizability of the vertical dyad linkage model of leadership. Academy of Management Journal, 23(3), 451-465. doi:10.2307/255511

Lynn, B. J. (2013). Camera operation techniques. Unpublished manuscript, School of Communication, Illinois State University, Normal, IL.

Lynn, B. J. (2016). Broadcast television speech communities. Unpublished manuscript, School of Communication, Illinois State University, Normal, IL.

Mamer, B. (2003). Film production technique. Belmont, CA: Wadsworth/Thomson Learning. 
Martinko, M. J., Harvey, P., \& Dasborough, M. T. (2010). Attribution theory in the organizational sciences: A case of unrealized potential. Journal of Organizational Behavior, 32, 144-149. doi:10.1002/job.690

McMurphy, B. (2017, January 7). Sun Belt commish: "Consensus" is that games must be shortened. ESPN. Retrieved from http://www.espn.com/collegefootball/story/_id/18421234/commissioners-college-football-coaches-seek-shortergames-record-average-game-2016

Mesgarani, N., \& Chang, E. F. (2012). Selective cortical representation of attended speaker in multi-talker speech perception. Nature, 485, 233-237. doi:10.1038/nature11020

Michotte, A. (1963). The perception of causality. New York, NY: Basic Books.

Miller, G. A. (1994). The magical number seven, plus or minus two: Some limits on our capacity for processing information. Psychological Review, 101(2), 343-352. doi:10.1037//0033295x.101.2.343

Mitchell, T. R., \& Wood, R. E. (1980). Supervisor's responses to subordinate poor performance: A test of an attributional model. Organizational Behavior and Human Performance, 25, 123-138. doi:10.1016/0030-5073(80)90029-x

Morgan, D. (2016). Where are we?: Camera movements and the problem of point of view. New Review of Film and Television Studies, 14(2), 222-248.

doi:10.1080/17400309.2015.1125702

Moore, D. A., Swift, S. A., Sharek, Z. S., and Gino, F. (2010). Correspondence bias in performance evaluation: Why grade inflation works. Personality and Social Psychology Bulletin, 36(6), 843-854. doi:10.1177/0146167210371316 
National Football League. (2017). Flexible scheduling. NFL. Retrieved from: http://www.nfl.com/flexible-schedules

O'Leary, B. (2003). Camera movements in Hollywood's Westering genre: A functional semiotic approach. Criticism, 45(2), 197-222. doi:10.1353/crt.2004.0002

Oliver, L. W. (1988). The relationship of group cohesion to group performance: A research integration attempt (ARI Tech. Rep. No. 807). Alexandria, VA: U.S. Army Research Institute. doi:10.21236/ada199069

Oliver, L. W., Harman, J., Hoover, E., Hayes, S. M., \& Pandhi, N. A. (1999). A quantitative integration of the military cohesion literature. Military Psychology, 11(1), 57-83. doi:10.1207/s15327876mp1101_4

O’Neil, T. (1989). The game behind the game. New York, NY: Harper \& Row.

Owens, A. W., \& Infante, D. A. (1988). Television director communication as perceived by production personnel. Journal of Broadcasting \& Electronic Media, 32(4), 429-440. doi:10.1080/08838158809386714

Owens, J. (2016a). Television production $\left(16^{\text {th }}\right.$ ed.). New York, NY: Focal Press.

Owens, J. (2016b). Television sports productions. Burlington, MA: Focal Press.

Pattyn, N., Neyt, X., Henderickx, D., \& Soetens, E. (2008). Psychophysiological investigation of vigilance decrement: Boredom or cognitive fatigue? Physiology \& Behavior, 93, 369378. doi:10.1016/j.physbeh.2007.09.016

Philipsen, G. (1997). A theory of speech codes. In G. Philipsen, \& T. Albrecht (Eds.), Developing communication theories (pp. 119-156). Albany, NY: State University of New York Press. 
Philipsen, G., Coutu, L. M., \& Covarrubias, P. (2005). Speech codes theory. In W. Gudykunst (Ed.), Theorizing about intercultural communication (pp. 55-68). Thousand Oaks, CA: Sage.

Putterman, A. (2017, July 26). Pac-12 network will experiment with fewer commercial breaks, reduced halftime to shorten games. Awful Announcing. Retrieved from: http://awfulannouncing.com/league-networks/pac-12-network-will-experiment-fewercommercial-breaks-reduced-halftime-shorten-games.html

Rand, T. M., \& Wexley, K. N. (1975). Demonstration of the effect, "similar to me," in simulated employment interviews. Psychological Reports, 36, 535-544.

doi:10.2466/pr0.1975.36.2.535

Reb, J., \& Greguras, G. J. (2010). Understanding performance ratings: Dynamic performance, attributions, and rating purpose. Journal of Applied Psychology, 95, 213-220. doi: $10.1037 / \mathrm{a} 0017237$

Rose, B. G. (1999). Directing for television. Lanham, MD: Scarecrow Press.

Ross, L. (1977). The intuitive psychologist and his shortcomings: Distortions in the attribution process. In L. Berkowitz (Ed.), Advances in experimental social psychology (Vol. 10, pp. 173-220). New York, NY: Academic Press.

Rudolph, C. W., Harari, M. B., \& Nieminen, L. R. G. (2015). The effect of performance trend on performance ratings occurs through observer attributions, but depends on performance variability. Journal of Applied Social Psychology, 45, 541-560. doi:10.1111/jasp.12318

Runeson, S., \& Frykholm, G. (1981). Visual perception of lifted weight. Journal of Experimental Psychology: Human Perception and Performance, 7, 733-740. doi:10.1037//00961523.7.4.733 
Rupp, D. E., Vodanovich, S. J., \& Crede, M. (2006). Age bias in the workplace: The impact of ageism and causal attributions. Journal of Applied Social Psychology, 36(6), 1337-1364. doi:10.1111/j.0021-9029.2006.00062.x

Rutherford, K., Harari, M., \& Rudolph, C.W. (2013). A multidimensional measure of observer attributions for performance. Poster presented at the 28th annual meeting of the Society for Industrial and Organizational Psychology, Houston, TX.

Sandomir, R. (2016, November 28). ESPN pays top dollar for football, but audience isn't buying. New York Times. Retrieved from https://www.nytimes.com/2016/11/28/sports/football/monday-night-football-tv-ratingsespn.html

Schultz, B. (2002). Sports broadcasting. Woburn, MA: Butterworth-Heinemann.

Shyles, L. (1997). Video production handbook. Boston, MA: Houghton Mifflin Company.

Smit, A. S., Eling, P. A.T.M., \& Coenen, A. M. L. (2004). Mental effort causes vigilance decrease due to resource depletion. Acta Psychologica, 115, 35-42. doi:10.1016/j.actpsy.2003.11.001

Smith, D. (1991). Video communication: Structuring content for maximum program effectiveness. Belmont, CA: Wadsworth.

Struthers, C. W., Miller, D. L., Boudens, C. J., \& Briggs, G. L. (2001). Effects of causal attributions on coworker interactions: A social motivation perspective. Basic \& Applied Social Psychology, 23(3), 169-181. doi:10.1207/s15324834basp2303_3

Struthers, C. W., Weiner, B., \& Allred, K. (1998). Effects of causal attributions on personnel decisions: A social motivation perspective. Basic and Applied Social Psychology, 20(2), 155-166. doi:10.1207/s15324834basp2002_7 
Taggar, S., \& Neubert, M. J. (2008). A cognitive (attributions)- Emotion model of observer reactions to free-riding poor performers. Journal of Business Psychology, 22, 167-177.

Tagiuri, R. (1960). Movement as a cue in person perception. In H. P. David \& J. C. Brengelmann (Eds.), Perspectives in personality research. New York, NY: Springer.

Thompson, R. (1998). Grammar of the shot. Woburn, MA: Focal Press.

Valenti, S. S., \& Costall, A. (1997). Visual perception of lifted weight from kinematic and static (photographic) displays. Journal of Experimental Psychology: Human Perception and Performance, 23(1), 181-198. doi:10.1037//0096-1523.23.1.181

Van Engen, K. J. (2012). Speech-in-speech recognition: A training study. Language and Cognitive Processes, 27, 1089-1107. doi:10.1080/01690965.2012.654644

Wallace, D. M., \& Hinsz, V. B. (2009). Group members as actors and observers in attributions of responsibility for group performance. Small Group Research, 40(1), 52-71. doi: $10.1177 / 1046496408326576$

Ward, P., Bermingham, A., \& Wherry, C. (2000). Multiskilling for television production. Woburn, MA: Focal Press.

Weiner, B. (1985). An attributional theory of achievement motivation and emotion. Psychological Review, 92, 548-573.

Weiner, B. (1986). An attribution theory of motivation and emotion. New York, NY: SpringerVerlag.

Weiner, B. (1992). Human motivation. Newbury Park, CA: Sage.

Weiner, B. (1995). Judgements of responsibility. New York, NY: Guildford Press.

Weiner, B., Frieze, I., Kukla, A., Reed, L., Rest, S., \& Rosenbaum, R. (1971). Perceiving the causes of success and failure. In E. Jones, D. Kanouse, H. Kelley, R. Nisbett, S. Valins, 
\& B. Weiner (Eds.), Attribution: Perceiving the causes of behavior. Morristown, NJ: General Learning Press.

Wenner, L. A. (1990). Therapeutic engagement in mediated sports. In G. Gumpert \& S. L. Fish (Eds.), Talking to strangers: Mediated therapeutic communication (pp. 223-244). Norword, NJ: Ablex.

Wild, L. (2016, December 23). Lecture 5: Film production. Northern State University. Retrieved from http://www3.northern.edu/wild/th100/flmprod.htm

Wilhelm, C. C., Herd, A. M., \& Steiner, D. D. (1993). Attributional conflict between managers and subordinates: An investigation of leader-member exchange effects. Journal of Organizational Behavior, 14, 531-544. doi:10.1002/job.4030140603

Williams, R. L. (1988). Television production: A vocational approach. Sandy, UT: Vision Publishing Company.

Wintre, M. G., North, C., \& Sugar, L. A. (2001). Psychologists' response to criticisms about research based on undergraduate participants: A developmental perspective. Canadian Psychology/Psychologie Canadienne, 42(3), 216-225. doi:10.1037/h0086893

Wood, D. (2014, November). Studio directing. Televisual, 36-42.

Zaccaro, S. J., Peterson, C., \& Walker, S. (1987). Self-serving attributions for individual and group performance. Social Psychology Quarterly, 50, 257-263. doi:10.2307/2786826

Zettl, H. (2003). Television production book (8th ed.). Belmont, CA: Wadsworth/Thomson Learning.

Zumoff, M. \& Negin, M. (2015). Total sportscasting: Performance, production, and career development. Burlington, MA: Focal Press. 


\section{APPENDIX: SURVEY INSTRUMENT}

IV: 1. Fatigue: known-unknown (2 levels, represents internal factors)

2. Relationship with the director: close-distant (2 levels, represents external factors)

DV: Subjective performance rating

Attributions of Effort, Ability, Task Difficulty, and Luck

Scenario \#1: Close relationship with the director, fatigue known

Troy has been a full-time freelance camera operator for 15 years. He was hired to work a World Touring Masters (WTM Sports Cars) race in Moscow, Russia, to run a hand-held camera in the pits. This will be the 4th year in a row that Troy has worked this camera for this race series. James, the shows director, has developed a close working relationship with Troy. James likes to talk to Troy when he needs a second opinion about a new camera position, or when making a change in the production that involves the camera crew. At this point, James always requests Troy to be one of his hand-held camera operators in the pits at the races he works. Troy had to come directly from another show to the race in Moscow a couple of days ago. The set-up for the race has been especially difficult. There have been some problems with the RF cameras and last night they had to change a camera position. Troy didn't leave the track until just before midnight because he and several others had to wait for the track personnel to finish a scaffolding so they could build a hard-camera on it before going home. Today, he had to wake up early for a 6 a.m. crew-call because the first practice session started at 7 a.m. and they had to cover it for the Internet. Overall, Troy now on his fourth show of the day; a qualifying show that's being broadcast live on television to four countries and streamed over the Internet to an additional 12 countries. During the qualifying show, the director cut to Troy's camera and Troy snap zoomed 
out just as they took his camera. Below is a link to a video clip showing what happened. You can see the line-cut just before and after Troy's snap zoom. Troy is the camera operator in the blue Red Bull car's garage.

Video link: https://youtu.be/N3JM33FjIsc 
Scenario \#2: Distant relationship with the director, fatigue known

Troy has been a full-time freelance camera operator for 15 years. He was hired to work a World Touring Masters (WTM Sports Cars) race in Moscow, Russia, to run a hand-held camera in the pits. This will be the 4th year in a row that Troy has worked this camera for this race series. Troy has struggled to get along with the show's director, James. Troy has tried to talk with James about the show but it's clear they have different ideas about how the production should look. Outside of work, Troy's come to realize that he and James have nothing in common and they have no shared interests. Troy is at the point where he doesn't like working with James and he's pretty sure that James feels the same way about him. Troy had to come directly from another show to the race in Moscow a couple of days ago. The set-up for the race has been especially difficult. There have been some problems with the RF cameras and last night they had to change a camera position. Troy didn't leave the track until just before midnight because he and several others had to wait for the track personnel to finish a scaffolding so they could build a hardcamera on it before going home. Today, he had to wake up early for a 6 a.m. crew-call because the first practice session started at 7 a.m. and they had to cover it for the Internet. Overall, Troy now on his fourth show of the day; a qualifying show that was being broadcast live on television to four countries and streamed over the Internet to an additional 12 countries. During the qualifying show, the director cut to Troy's camera and Troy snap zoomed out just as they took his camera. Below is a link to a video clip showing what happened. You can see the line-cut just before and after Troy's snap zoom. Troy is the camera operator in the blue Red Bull car's garage.

Video link: https://youtu.be/N3JM33FjIsc 
Scenario \#3: Close relationship with the director, fatigue unknown

Troy has been a full-time freelance camera operator for 15 years. He was hired to work a World Touring Masters (WTM Sports Cars) race in Moscow, Russia, to run a hand-held camera in the pits. This will be the 4th year in a row that Troy has worked this camera for this race series. James, the shows director, has developed a close working relationship with Troy. James likes to talk to Troy when he needs a second opinion about a new camera position, or when making a change in the production that involves the camera crew. At this point, James always requests Troy to be one of his hand-held camera operators in the pits at the races he works. In Moscow, Troy was working a qualifying show that was being broadcast live on television to four countries and streamed over the Internet to an additional 12 countries. During the qualifying show, the director cut to Troy's camera and Troy snap zoomed out just as they took his camera. Below is a link to a video clip showing what happened. You can see the line-cut just before and after Troy's snap zoom. Troy is the camera operator in the blue Red Bull car's garage.

Video link: https://youtu.be/N3JM33FjIsc 
Scenario \#4: Negative relationship with the director; fatigue unknown

Troy has been a full-time freelance camera operator for 15 years. He was hired to work a World Touring Masters (WTM Sports Cars) race in Moscow, Russia, to run a hand-held camera in the pits. This will be the 4th year in a row that Troy has worked this camera for this race series. Troy has struggled to get along with the show's director, James. Troy has tried to talk with James about the show but it's clear they have different ideas about how the production should look. Outside of work, Troy's come to realize that he and James have nothing in common and they have no shared interests. Troy is at the point where he doesn't like working with James and he's pretty sure that James feels the same way about him. In Moscow, Troy was working a qualifying show that was being broadcast live on television to four countries and streamed over the Internet to an additional 12 countries. During the qualifying show, the director cut to Troy's camera and Troy snap zoomed out just as they took his camera. Below is a link to a video clip showing what happened. You can see the line-cut just before and after Troy's snap zoom. Troy is the camera operator in the blue Red Bull car's garage.

Video link: https://youtu.be/N3JM33FjIsc 
The following questions form the Multidimensional Observer Attributions for Performance Scale (MOAPS).

1. Troy's performance reflects the effort he put into his job.

Strongly Disagree 1

7 Strongly Agree

2. Troy's performance is probably due to his ability.

Strongly Disagree $1 \quad \ldots \ldots \ldots \ldots \ldots \ldots \ldots \ldots \ldots . \ldots$ Strongly Agree

3. Troy's performance is probably due to the fact that his job is harder than most.

Strongly Disagree 1

7 Strongly Agree

4. Troy's performance is probably due to chance factors.

Strongly Disagree 1

7 Strongly Agree

5. Troy's performance is a direct result of his efforts.

Strongly Disagree 1

7 Strongly Agree

6. Troy's performance reflects the fact that he has the ability to do his job.

Strongly Disagree 1

7 Strongly Agree

7. Troy's performance reflects the fact that he has a relatively difficult job.

Strongly Disagree 1

7 Strongly Agree

8. Troy's performance reflects the fact that he was unlucky.

Strongly Disagree 1

7 Strongly Agree

9. Troy's performance is probably due to effort on his part.

Strongly Disagree 1

7 Strongly Agree

10. Troy's performance is a direct result of his competence.

Strongly Disagree 1

7 Strongly Agree 
11. Troy's performance is a direct result of the difficulty of his job.

Strongly Disagree 1

7 Strongly Agree

12. Troy's performance is a direct result of luck.

Strongly Disagree 1

7 Strongly Agree

13. Troy's performance is likely influenced by his hard work.

Strongly Disagree 1

7 Strongly Agree

14. Troy's performance is likely influenced by his competence.

Strongly Disagree 1

7 Strongly Agree

15. Troy's performance is likely influenced by the difficulty of his job.

Strongly Disagree 1

7 Strongly Agree

16. Troy's performance is likely influenced by luck.

Strongly Disagree 1

7 Strongly Agree

17. Troy's performance may be due to his motivation.

Strongly Disagree 1

7 Strongly Agree

18. Troy's performance may be due to the fact that he has the talent to do his job.

Strongly Disagree 1

7 Strongly Agree

19. Troy's performance may be due to the fact that his job is not easy to perform.

Strongly Disagree $1 \quad \ldots \ldots \ldots \ldots \ldots \ldots \ldots \ldots \ldots \ldots . \ldots \ldots$ Strongly Agree

20. Troy's performance may be due to his luck.

Strongly Disagree $1 \quad \ldots \ldots \ldots \ldots \ldots \ldots \ldots \ldots \ldots \ldots . \ldots \ldots$ Strongly Agree

21. Troy's performance has a lot to do with working hard.

Strongly Disagree 1

7 Strongly Agree 
22. Troy's performance has a lot to do with competence.

Strongly Disagree $1 \quad \ldots \ldots \ldots \ldots \ldots \ldots \ldots \ldots \ldots \ldots \ldots$ Strongly Agree

23. Troy's performance has a lot to do with how difficult his job is.

Strongly Disagree $1 \quad \ldots \ldots \ldots \ldots \ldots \ldots \ldots \ldots \ldots \ldots . \ldots \ldots$ Strongly Agree

24. Troy's performance has a lot to do with being in the right place at the right time.

Strongly Disagree $1 \quad \ldots \ldots \ldots \ldots \ldots \ldots \ldots \ldots \ldots \ldots . \ldots \ldots$ Strongly Agree

The following items will measure the perceived importance of the Troy's mistake to the rest of the WTM production crew.

25. Overall, how important is Troy's performance to the rest of the WTM production crew.

Not at all Important 1

7 Very Important

26. Troy's performance probably isn't significant to the rest of the WTM production crew.

Strongly Disagree $1 \quad \ldots \ldots \ldots \ldots \ldots \ldots \ldots \ldots \ldots \ldots \ldots$ Strongly Agree

27. In general, Troy's performance is significant to the rest WTM production crew.

Strongly Disagree 1

7 Strongly Agree

The following items will measure the perceived importance of Troy's mistake on the viewing audience.

28. Overall, how important is Troy's performance to the viewers at home watching the broadcast?

Not at all Important 1

7 Very Important

29. Troy's performance probably isn't significant to the viewers at home watching the WTM broadcast.

Strongly Disagree 1

7 Strongly Agree 
30. In general, Troy's performance is significant to the viewers at home watching the WTM broadcast.

Strongly Disagree 1 7 Strongly Agree

The following items will measure the perceived importance of the mistake to Troy, the camera operator.

31. Overall, how important is the performance to Troy, the camera operator?

Not at all Important 1

7 Very Important

32. Troy's performance probably isn't significant to him.

Strongly Disagree 1

7 Strongly Agree

33. In general, Troy's performance is significant to him.

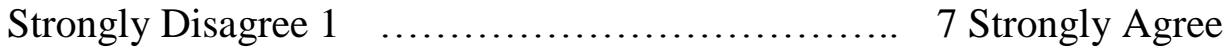

The following items will measure the perceived importance of the mistake to James, the director.

34. Overall, how important is Troy's performance to James, the director?

Not at all Important 1

7 Very Important

35. Troy's performance probably isn't significant to James, the director.

Strongly Disagree 1

7 Strongly Agree

36. In general, Troy's performance is significant to James, the director.

Strongly Disagree 1

7 Strongly Agree

The following items will measure future hiring recommendations.

37. How likely is James, the director, to recommend Troy for work on another show.

Not Likely 1

7 Very Likely

38. How likely would you be to recommend Troy for work on another show?

Not Likely 1

7 Very Likely 
39. How likely are the other WTM camera operators to recommend Troy for work on another show?

Not Likely 1 7 Very Likely

40. How likely are the other WTM production crew members to recommend Troy for work on another show?

Not Likely 1 7 Very Likely

Manipulation checks

41. How fatigued do you think Troy was when this happened?

Not at all Fatigued 1 7 Very Fatigued

42. Overall, how would you rate Troy's relationship with the director?

They have a distant relationship $1 \quad \ldots \ldots \ldots . . . . . . .7$ They have a close relationship

The following items measure the perceived frequency of the specific camera mistake.

43. This type of camera mistake occurs frequently in live sports productions.

Strongly Disagree $1 \quad \ldots \ldots \ldots \ldots \ldots \ldots \ldots \ldots \ldots \ldots \ldots . \ldots \ldots$ Strongly Agree

44. This kind of camera mistake is unusual in live sports productions.

Strongly Disagree $1 \quad \ldots \ldots \ldots \ldots \ldots \ldots \ldots \ldots \ldots \ldots .7$ Strongly Agree

45. I can't recall this type of camera mistake ever happening on a show I've worked.

Strongly Disagree $1 \quad \ldots \ldots \ldots \ldots \ldots \ldots \ldots \ldots \ldots \ldots \ldots . \ldots \ldots$ Strongly Agree

Open ended questions:

46. If you were Troy's director, how would you react if he made a camera mistake like this onthe-air?

47. Why do you think Troy made a camera mistake on-the-air? 
Now we would like to ask you some information about yourself and your experience in the broadcast industry.

Categorical questions:

48. How many years of overall television production experience do you have? (Drop down menu)

49. How many years of experience do you have as a camera operator? (Drop down menu: $0=$ no experience.)

50. How many years of experience do you have as a director? (Drop down menu: $0=$ no experience.)

51. Please select what production format you primarily work in:

Sports News Entertainment Other (with text box)

52. Please select the audience reach of the shows you normally work:

National Regional Local Other (with text box)

53. Please select the sports you typically cover in a year (select all that apply)

Football Basketball Baseball Hockey Soccer

Motorsports Swimming Softball Other (with text box)

54. Please select the category that best describes your current role in a production:

Remote Production Remote Technical Remote Other Non-Remote Other

(with text box) (with text box)

55. What is your gender:

Male Female Transgender Prefer to not answer Other (with text box) 
56. Please select your age: (drop down menu) 